\begin{abstract}
Cleary, Katherine. Effects of Oxygen and Turmeric on the Formation of Oxidative Aldehydes in Fresh-Pack Dill Pickles. (Under the direction of Roger F. McFeeters.)
\end{abstract}

Oxidative off-flavors can develop in pickle products that are exposed to oxygen. Plastic containers, which are becoming more common in the pickle industry, can allow oxygen to migrate into the containers during storage. Pickled cucumber products have been colored for many years using the spice turmeric. The color in turmeric is a result of the presence of the phenolic compound curcumin, which is also a natural antioxidant. Therefore, the objectives of this research were to determine the effect of oxygen concentration on the formation of aldehydes, and to determine if turmeric, at levels suitable for use in pickle products, would be effective in inhibiting the formation of oxidative aldehydes in cucumber pickles. Aldehydes were monitored using purge and trap, and gas chromatography-mass spectrometry (GC-MS). Hexanal, pentanal, 2-hexenal, and heptanal were detected and quantified, and were used as indicators of oxidative off-flavor formation.

Commercial fresh-pack dill pickles from several processors were analyzed for oxidative aldehydes at the beginning and near the end of their expected shelf life. Hexanal, pentanal, and heptanal were identified and quantified in all commercial samples tested. Mean total aldehyde levels declined from 305 to $202 \mathrm{ppb}$ between the short and long term storage samples. In the laboratory, acidified cucumbers were prepared in an anaerobic hood and then injected with increasing amounts of oxygen to determine the effect of oxygen on the formation of oxidative aldehydes. There was a positive linear correlation between the 
amount of oxygen injected and the formation of the aldehydes hexanal, pentanal, and heptanal. In anaerobic treatments with no added oxygen, there was still development of oxidative aldehydes, with particularly high levels ( $\sim 800 \mathrm{ppb})$ of pentanal after 4 days. Regardless of the amount of oxygen that was injected, pentanal declined between 4 and 28 days of storage while hexanal and heptanal concentrations increased in treatments that had oxygen injected. Finally, fresh-pack dill pickles were made and packed in glass containers. Oxygen and different concentrations of turmeric were added to the pickles and the formation of aldehydes was monitored over a 10-week storage period. Turmeric was found to retard formation of hexanal and other aldehydes, specifically pentanal, 2-hexenal, and heptanal, with greater effectiveness as turmeric concentration increased from 16 to $250 \mathrm{ppm}$. Dill spices were also found to reduce formation of aldehydes. Turmeric was determined to be an effective antioxidant at concentrations appropriate for coloring in pickles. With a level of oxygen comparable to that which would enter a plastic container during a one-year storage period, turmeric maintained hexanal levels near concentrations found in commercial freshpack pickles packaged in glass containers. 


\section{Effects of Oxygen and Turmeric on the Formation of Oxidative Aldehydes in Fresh-Pack Dill Pickles}

by

Katherine Cleary

A Thesis submitted to the Graduate Faculty of

North Carolina State University

in partial fulfillment of the

requirements for the Degree of

Master of Science

FOOD SCIENCE

Raleigh

2004

Chair of Advisory Committee 


\section{Dedication}

For my Grandma Kahl, who made the world's best chocolate cookies.

It was from her that I learned my love of cooking and

inherited my sweet tooth. She will always be in my heart. 


\section{Biography}

Katherine Ann Cleary, the first daughter of Karen and Joseph Cleary, was born on March 29, 1978. She grew up in Granby, Connecticut, where her parents still live, and has one younger sister named Stephanie. During her childhood she enjoyed activities such as mountain biking, soccer, piano, and tennis. Katherine also practiced and competed with a club gymnastics team. She attended Granby Memorial High School, where she was involved in several clubs as well as the National Honor Society, and was co-captain of the GMHS gymnastics team for three years.

After graduating, she went to Saint Joseph College in West Hartford, CT. During her time at SJC, Katherine participated in a chemistry internship at the University of Massachusetts, and a summer study abroad program in Dublin, Ireland. Outside of school, she coached gymnastics at Conard High School in West Hartford. In May of 2000 she graduated from college with bachelor's degrees in Chemistry and Philosophy. After graduation, Katherine spent a year in Connecticut where she tutored at SJC and worked at a small eatery, and continued to coach at Conard. Before moving to North Carolina, she spent two months traveling throughout Western Europe, primarily in France, Italy, Germany, and Ireland.

In June of 2001, Katherine moved to Raleigh, NC to begin her Master of Science in the Department of Food Science at North Carolina State University, under the direction of Dr. Roger McFeeters in the USDA/ARS Food Fermentation Lab. During her time at NCSU, she participated in the Kraft Foods internship program in the summer of 2002, was President 
of the NCSU Food Science Club in 2002-2003, and was a member of the NCSU club gymnastics team.

Katherine is partial to chocolate, U2, Paris, red and pink candy, New York City, scrapbooking, Dublin, white wine, cooking, tomatoes, existential philosophy, Carl Sagan's Contact, the Boston Red Sox, swimming in the ocean, and Beverly Hills, 90210 reruns. She has an aversion to meat, port wine (but not port wine cheese), The Simpsons, bad drivers, orange and green candy, Brussels (Belgium, not Sprouts), insects, cold weather, the New York Yankees, and swimming in lakes. 


\section{Acknowledgements}

There are many people who have helped me during my journey, both on my way to NCSU and during my time in Raleigh. I wouldn't be here without the family, friends, and pickle people who have helped me along the way. I would like to extend numerous thanks to:

- My parents, for telling me hundreds of times to "Try hard, be neat, have fun trying hard and being neat." I wouldn't be where I am today without them and their endless guidance. I thank them for everything they have given me, and also for not giving me everything. They are the best parents I could ever have asked for. $\bullet$ Mrs. P., for filling in when my mom and dad couldn't be there, and for being a great second mother. My Uncle Tommy, for all the one-dollar bills he has put inside childish birthday cards, and for always being ready with a heartfelt rendition of "Feelings." $•$ My sister, Stephanie, who helps me remember GCP-62F, Jeter and her headset, and how to count to 10 in Japanese, and who still loves me despite my sisterly abuse when we were young. My almost-sister, Beth, for always listening and also for telling me everything, no matter how mundane; for her thousands of supportive e-mails over the past few years, and also for her singing voicemails. $\bullet$ My aunts, uncles, and cousins in the South; Russ, Betsy, Keith, Mary, Meredith, Kristi, Spencer, Amanda, and Carli, for including me, their Yankee kin, on many family weekends since I've been in Raleigh. My Loriface, for many laughs at SJC and in the years since, for bringing me bagels, and for still putting up with small-town soap operas. $•$ My roommate Melody, for being a great Food Chemistry lab partner and a fantastic roommate, and for being such a good influence on me. 
- Rodney, for sharing many Baja Burritos over the past two years; for being a great friend, for always listening to and laughing with me (or at me if I needed it), and teaching me that too much of anything, even independence, can be a bad thing. My birthday twin, Mary, for understanding and for keeping me sane when I realize over and over again that all people aren't like us. The best office-mate in the world (and also a great partner-in-crime), Julie, who I wish had come earlier, but with whom I have still had many laughs. $\bullet$ Jeff, for putting up with me as a pseudo-roommate, and sharing his Friend Ship with me. Jon, for being a great study partner in too many classes, for allowing me to be his confidant (and vice versa), and for making me smile. My many other friends in the Food Science Department and Food Science Club, for all the fun times we've had together. My undergraduate chemistry advisor, Dr. McKone, for inspiring me to travel, to come to graduate school, and for still giving me encouragement when I need it. Everyone in the pickle lab, especially Sabine, Suzanne, and Roger T., for all their help along the way; whether it was making pickles, closing jars, answering statistics or sensory questions, or helping me with a multitude of other requests that I came up with, they were always there with a helping hand. $\bullet$ Dr. Drake and Dr. Den Troung, for being on my advisory committee. $•$ Youngmo and Jamie, for all their help with the GC. Last but certainly not least, my graduate advisor, Dr. McFeeters, for taking me on as a graduate student, for all the guidance he has given me and patience he has shown me, and for letting me broaden my horizons with a summer in New Jersey.

Sartre had a philosophy that our lives are open books to write as we choose. Thank you all for being part of my book; I would not be where I am today without the support you have given me. 


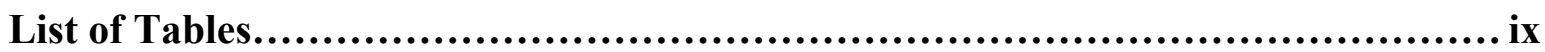

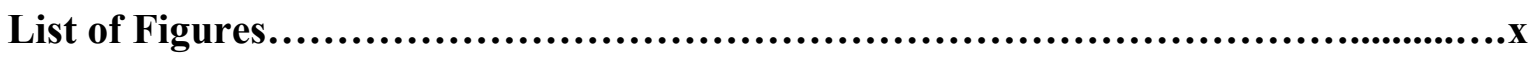

Chapter 1. Literature Review.......................................................... 1

1.1 Lipid Oxidation in Foods.................................................. 2

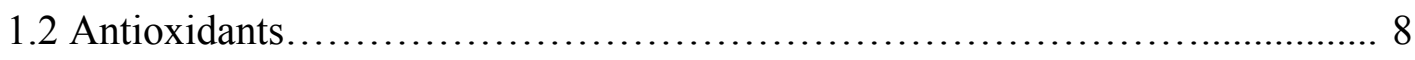

1.3 Turmeric and Curcumin..................................................... 10

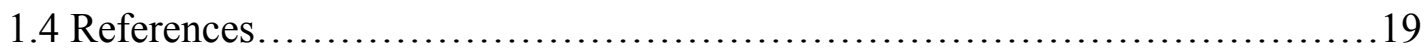

Chapter 2. Oxidative Aldehyde Levels in Commercial Fresh-Pack Dill Pickles........ 31

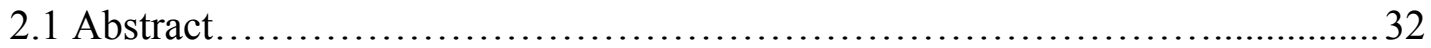

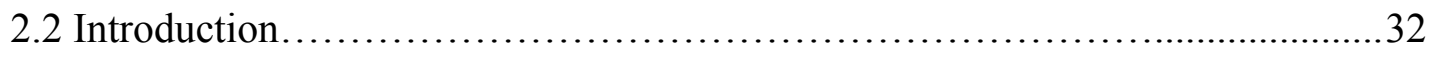

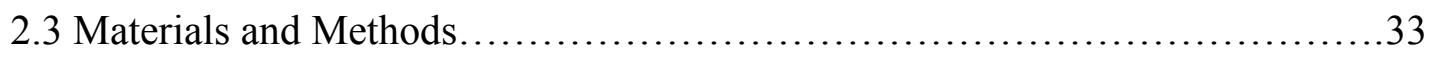

2.4 Results and Discussion..................................................... 36

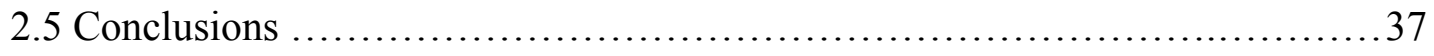

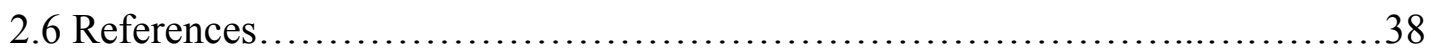

Chapter 3. Formation of Oxidative Aldehydes in Fresh-Pack Dill Pickles............... 46

3.1 Abstract............................................................. 47

3.2 Introduction............................................................... 48

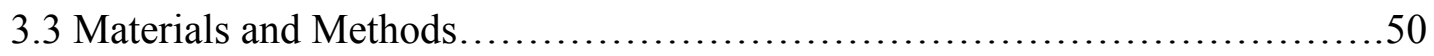

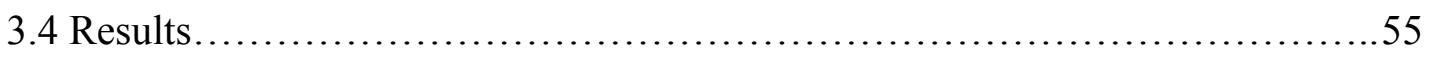

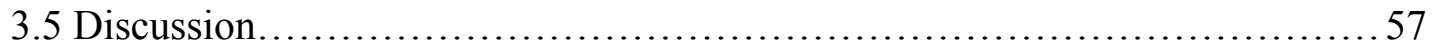

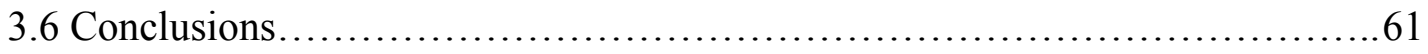

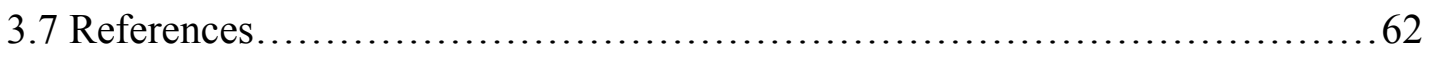


Appendix A. Effect of Rosemarinic Acid on Oxidative Aldehyde Levels in Fresh-Pack

Dill Pickles.......................................................................... 79

A.1 Introduction..................................................... 80

A.2 Materials and Methods........................................................ 80

A.3 Results............................................................. 80

A.4 References...................................................... 82

Appendix B. Effect of Oxygen and an Oxygen Scavenger on Aldehyde Levels in Fresh-

Pack Dill Pickles.........................................................................89

B.1 Introduction........................................................ 90

B.2 Materials and Methods............................................ 90

B.3 Results....................................................... 91

B.4 References...................................................... 92 


\section{List of Tables}

Table 2.1. Time after packing of fresh-pack dill pickles............................ 39

Table 2.2. Mean aldehyde concentrations in commercial fresh-pack dill pickles after short

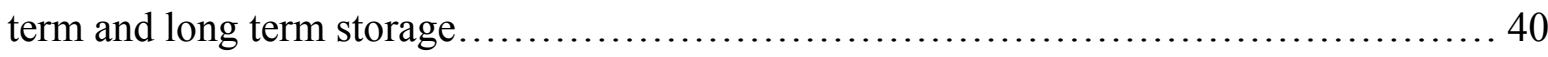

Table 3.1. Observed and predicted aldehyde levels in fresh-pack pickle samples closed in normal atmospheric conditions with no dill spices or turmeric added, and predicted aldehyde values based on regression equations and calculated 0.35 mmole oxygen in the jar upon

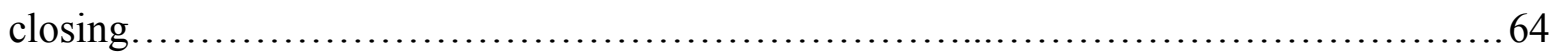

Table A.1. Treatments used to compare the antioxidant activity of rosemary extracts and turmeric oleoresin ...................................................... 83

Table B.1. Treatments used to evaluate the effect of turmeric and a cupric

gluconate/ascorbic acid oxygen scavenging system on fresh-pack pickles. 


\section{List of Figures}

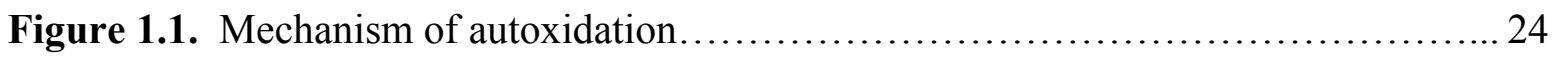

Figure 1.2. Homolytic cleavage of hydroperoxide to form hydrocarbon and oxoacid when cleaved on hydrocarbon side, or aldehyde and acid when cleaved on acid side..... 25

Figure 1.3a. Structures of common antioxidants 26

Figure 1.3b. Resonance structures of BHA

Figure 1.4. Curcumin structures. .28

Figure 1.5. Proposed products of curcumin antioxidant.

Figure 1.6. Tri-cyclic reaction products formed via Diels-Alder reaction between

linoleateperoxyl and curcumin radicals in the antioxidant reaction of curcumin.... 30

Figure 2.1. Total levels of hexanal, heptanal, and pentanal in commercial fresh-pack dill pickles after short and long term storage.

Figure 2.2. Levels of hexanal in commercial fresh-pack dill pickles after short and long term storage.

Figure 2.3. Levels of heptanal in commercial fresh-pack dill pickles after short and long term storage.

Figure 2.4. Levels of pentanal in commercial fresh-pack dill pickles after short and long term storage. .44 
Figure 2.5. Levels of dissolved oxygen in commercial fresh-pack dill pickles after short and long term storage.

Figure 3.1. Effect of added oxygen on hexanal levels in anaerobically-packed fresh-pack pickles 4 and 28 days after packing.

Figure 3.2. Effect of added oxygen on heptanal levels in anaerobically-packed fresh-pack pickles 4 and 28 days after packing. 66

Figure 3.3. Effect of added oxygen on pentanal levels in anaerobically-packed fresh-pack pickles 4 and 28 days after packing. 67

Figure 3.4. Effect of added oxygen on dissolved oxygen levels in anaerobically-packed fresh-pack pickles 4 and 28 days after packing.... 68

Figure 3.5. Effect of turmeric on hexanal levels in fresh-pack dill pickles 2, 6, and 10 weeks after packing.

Figure 3.6. Effect of turmeric on pentanal levels in fresh-pack dill pickles 2, 6, and 10 weeks after packing. .70

Figure 3.7. Effect of turmeric on 2-hexenal levels in fresh-pack dill pickles 2, 6, and 10 weeks after packing..... 71

Figure 3.8. Effect of turmeric on heptanal levels in fresh-pack dill pickles 2, 6, and 10 weeks after packing. .72

Figure 3.9. Effect of turmeric on dissolved oxygen levels in fresh-pack dill pickles 2, 6, and 10 weeks after packing. .73 
Figure 3.10. Effect of turmeric, dill spices, and added oxygen on hexanal levels in freshpack dill pickles

Figure 3.11. Effect of turmeric, dill spices, and added oxygen on pentanal levels in freshpack dill pickles.

Figure 3.12. Effect of turmeric, dill spices, and added oxygen on 2 -hexenal levels in freshpack dill pickles. 76

Figure 3.13. Effect of turmeric, dill spices, and added oxygen on heptanal levels in freshpack dill pickles.

Figure 3.14. Effect of turmeric, dill spices, and added oxygen on dissolved oxygen levels in fresh-pack dill pickles. 78

Figure A.1. Effect of turmeric, dill spices, and rosemary on hexanal levels in fresh-pack dill pickles. 84

Figure A.2. Effect of turmeric, dill spices, and rosemary on pentanal levels in fresh-pack dill pickles.

Figure A.3. Effect of turmeric, dill spices, and rosemary on 2-hexenal levels in fresh-pack dill pickles. .86

Figure A.4. Effect of turmeric, dill spices, and rosemary on heptanal levels in fresh-pack dill pickles.

Figure A.5. Effect of turmeric, dill spices, and rosemary on dissolved oxygen levels in fresh-pack dill pickles. 88 
Figure B.1. Effect of added turmeric, dill spices, cupric gluconate and ascorbic acid on hexanal levels in fresh-pack dill pickles.

Figure B.2. Effect of added turmeric, dill spices, cupric gluconate and ascorbic acid on pentanal levels in fresh-pack dill pickles

Figure B.3. Effect of added turmeric, dill spices, cupric gluconate and ascorbic acid on 2hexenal levels in fresh-pack dill pickles

Figure B.4. Effect of added turmeric, dill spices, cupric gluconate and ascorbic acid on heptanal levels in fresh-pack dill pickles.

Figure B.5. Effect of added turmeric, dill spices, cupric gluconate and ascorbic acid on dissolved oxygen levels in fresh-pack dill pickles. 


\section{Chapter 1}

Literature Review 


\subsection{Lipid Oxidation in Foods}

\subsubsection{Significance of lipid oxidation in the food industry}

A major problem in the food industry continues to be the development of off-flavors and odors in foods. There are several sources of off-flavors, which include contamination of the food, a flavor imbalance within the food, or various chemical reactions (Njissen, 1991; Whitfield, 1986). Food may become contaminated when it absorbs chemicals from the air or packaging, or from impurities in water used during processing. Although it is not common, off-flavors can also result from a severe imbalance in the compounds that comprise the flavor profile of a food. Volatile compounds, whether they are formed in a food or come from outside sources, may cause off-flavors at concentrations of less than one part per billion (Whitfield, 1986). While off-flavors do not often make foods inedible, they do decrease the quality and value of the food product.

One of the most common causes of off-flavors and odors in many foods is lipid oxidation (Eriksson, 1987). Lipid oxidation occurs through either an enzymatic or nonenzymatic mechanism. Both mechanisms yield hydroperoxides, which then break down to form a number of volatile compounds that are responsible for off-flavors and odors. Enzyme-catalyzed oxidation, as the name implies, must be initiated by an enzyme, such as lipoxygenase, acyl hydrolase, or hydroperoxide lyase (Nawar, 1996). Autoxidation, however, does not require enzymatic catalysis. Once the process is initiated, it is "selfcatalyzing" as long as there is molecular oxygen present.

Many foods are now being packed in plastic containers that have significant oxygen permeability. This can lead to an increase in autoxidation as oxygen migrates into the container. Other factors that influence the rate and extent of oxidation include the degree of 
light exposure, storage temperature, natural antioxidants present in the food, or antioxidants that have been added to the food (Nawar, 1996). Some foods are also more prone to autoxidation due to their water activity. Foods with very low or high water activity are more prone to lipid autoxidation than foods with intermediate water activity $\left(\mathrm{a}_{\mathrm{w}} 0.3-0.55\right)$ (Nawar, 1996). In foods with high water activity $\left(a_{w}>0.55\right)$, the increased rate of oxidation is presumably from the greater mobility of oxygen. In addition, foods that have high concentrations of fatty acids, especially polyunsaturated fatty acids, are more susceptible to lipid oxidation.

\subsubsection{Lipid oxidation in cucumber pickles}

Most pickled vegetables are in the $\mathrm{pH}$ range of 3.0 to 4.0. Although there is lipoxygenase in cucumbers and it does show moderate activity at $\mathrm{pH} 3.5$, it is deactivated in less than two minutes at $70^{\circ} \mathrm{C}$ at its optimum $\mathrm{pH}$ of 5.5 (Wardale and Lambert, 1980). These properties suggest that lipoxygenase would not survive the pasteurization process currently used for pickles in glass containers $\left(74^{\circ} \mathrm{C}, 15 \mathrm{~min}\right)$. The majority of pickles sold to consumers are in glass jars and are pasteurized. However, pickles marketed for the food service industry are often packed in plastic buckets, gallon containers, or pouches that cannot withstand pasteurization. Therefore, enzyme catalyzed oxidation may be occurring in these products. Smaller, pasteurizable plastic containers are currently under development for use in the pickled vegetable industry. After pasteurization, any lipid oxidation that occurred would be a result of non-enzymatic oxidation largely due to the oxygen permeability of plastic containers and closures. This autoxidation would be expected to be a factor in reduced shelf life for products preserved in pasteurizable plastic packages. 
Although the total lipid content of cucumbers is only between 0.10 and $0.14 \%$ of the wet weight (Peng, 1992), oxidation can still present a problem. Linoleic acid and linolenic acid constitute $33 \%$ and $16.4 \%$, respectively, of the total fatty acids in cucumbers (Peng and Geisman, 1976). These unsaturated acids can undergo oxidation relatively easily, resulting in the formation of off-flavors and odors.

\subsubsection{Mechanism of lipid autoxidation}

The general mechanism of autoxidation consists of three stages: initiation, propagation, and termination (Fig. 1.1). During initiation, hydrogen is abstracted from the fatty acid to yield a fatty acid free radical and a hydrogen radical. This reaction must be catalyzed by hydroperoxide decomposition, light, or metal. The next stage, propagation, occurs when these radicals react with other species, namely molecular oxygen or other fatty acid molecules, to yield additional fatty acid or peroxy radicals. Propagation is essentially an extended chain reaction with the same two reactions happening over and over again to produce increasing amounts of oxidized lipids. The process may be repeated thousands of times before termination occurs. During the termination stage, free radicals react with each other to form non-radical products.

Generally, the more unsaturated the fatty acid, the higher the rate of oxidation. Oxidation in saturated fatty acids is basically nonexistent, except at very high temperatures. Cis-fatty acids, which are the predominant naturally occurring isomers, oxidize faster than trans isomers. Thus, linoleic and linolenic acids, two of the major fatty acids in cucumbers, are more susceptible to oxidation than many other fatty acids. The rate of oxidation also depends on the concentration of oxygen (Crapiste et al., 1999; Koelsch et al., 1991). When there is excess oxygen present, the rate of oxidation is independent of oxygen concentration, 
while at lower oxygen concentrations the rate of oxidation is approximately proportional to the oxygen concentration. Under conditions of abundant oxygen, it has been found that the oxidation rate depends largely on the surface to volume ratio, or the relation between sample volume and the lipid surface area that is exposed to the air (Crapiste et al., 1999).

The hydroperoxides produced in the propagation step of autoxidation begin to break down as soon as they are formed. They decompose into molecules, such as aldehydes and ketones, which can cause off-flavors and odors in the food product. In the beginning phase of autoxidation, hydroperoxides are formed faster than they break down, but in later stages the rate of decomposition exceeds the rate of formation. Hydroperoxides can break down in a multitude of ways, yielding a variety of products. The first step in their decomposition is homolytic cleavage of the oxygen-oxygen bond. This is followed by carbon-carbon bond cleavage that can occur on either side of the radical alkoxy group. When the carbon-carbon cleavage occurs on the hydrocarbon side of the fatty acid molecule, a hydrocarbon and an oxoacid are produced. If cleavage occurs on the acid side of the molecule, the products are an aldehyde and an acid (Fig. 1.2) (Nawar, 1996). If aldehydes are produced, they are not necessarily the final products of the autoxidation process. Saturated aldehydes, such as hexanal, can be oxidized into acids or can undergo dimerization or condensation reactions. Unsaturated aldehydes, such as 2-hexenal, can also degrade through oxidation into other aldehydes or short-chain hydrocarbons.

In general, the types of aldehydes that are formed depend on the fatty acid that was degraded. A single fatty acid can produce up to 100 different degradation products during and after autoxidation (Njissen, 1991). Linoleate hydroperoxides can break down to form several different aldehydes, including hexanal, 2-heptenal, and 2,4-decadienal. Under certain 
conditions involving a Lewis acid, linoleate hydroperoxides will form higher-than-normal percentages of hexanal (Gardner and Plattner, 1984). Linolenate hydroperoxides can break down to form aldehydes such as propanal, 2-pentenal, and 2-hexenal. Linolenate hydroperoxides decompose more quickly than some other hydroperoxides due to their high reactivity, caused by the presence of an active methylene group (DeMan, 1999).

\subsubsection{Methods for measuring oxidation}

There are many ways to measure the extent of lipid oxidation in a food system. More than one method is often used, because of the complex nature of autoxidation. Since multiple compounds are simultaneously being formed and degraded during oxidation, there is no one variable or compound to measure that will give the "right" answer as to the degree of lipid oxidation. Analytical methods must be selected in relation to the specified questions being asked. Some of the methods employed include peroxide value, thiobarbituric acid test, total and volatile carbonyl compounds, chromatographic methods, and sensory evaluation (Nawar, 1996).

Peroxide value is often used as a measurement of the degree of oxidation, since hydroperoxides are the main initial products of autoxidation. This method takes advantage of the reaction between peroxides and potassium iodide, which produces iodine. By measuring the amount of iodine produced, the peroxide value can then be determined. Alternatively, the reaction between peroxides and ferrous ions can be utilized. This reaction produces ferric ions that can then be measured by assessment of thiocyanate levels. Peroxide value is usually expressed as milliequivalents of oxygen per kilogram of fat (Gray, 1978). Problems with this test are that the results depend on the temperature at which the test is performed, and the specific procedure used. Furthermore, peroxide values reach a peak during oxidation 
and then decline, so use of the peroxide value as a measurement of oxidation is limited to the initial stages of oxidation.

The thiobarbituric acid (TBA) test is another widely used approach for measuring lipid oxidation. The oxidation products in a food produce a color change upon reaction with TBA. This is believed to result from the reaction of two molecules of TBA with one molecule of malonyl dialdehyde (malonaldehyde), which is a common product of lipid oxidation (Nawar, 1996). A problem with the TBA method is that malonaldehyde is not formed in all oxidized systems. Furthermore, other food components such as sucrose and wood smoke compounds can react with TBA and produce the typical color change. When this occurs the results must be corrected for the interference of these compounds. Additionally, malonaldehyde can react with proteins in the food system. Removal of the malonaldehyde by this route results in low TBA values. This method is best used to monitor a single type of food at different stages of oxidation (Nawar, 1996).

Oxidation products, such as aldehydes, can be used to measure oxidation in several ways. One of these, which measures the total carbonyl compounds, is based on the reaction of aldehydes or ketones with 2,4-dinitrophenylhydrazine to form hydrazones (Nawar, 1996). Individual carbonyl compounds can also be measured by headspace analysis, or by various chromatography techniques including liquid, thin-layer, high-performance liquid, or gas chromatography (Vercellotti et al., 1992). These can be used to give a quantitative determination of compounds that are produced during autoxidation. Gas chromatographymass spectrometry has been used to quantify aldehydes including hexanal, 2-heptenal, 2octenal, and 2-pentenal, formed when fermented cucumber slurries are exposed to oxygen (Zhou et al., 2000a; 2000b). Gas chromatography can also be used to analyze volatiles via 
gas chromatography-olfactometry $(\mathrm{GC} / \mathrm{O})$ by the aroma extract dilution analysis (AEDA)

method (Grosch et al., 1992). Using this method, the odor-activity of a sample is determined using serial dilution of the sample extract. This can be expressed as a flavor-dilution factor. The higher the flavor dilution factor, the greater the odor intensity a compound contributes to the sample.

Oxidation can also be measured by sensory evaluation. Descriptors such as painty and cardboard are often used to describe oxidative off-flavors or odors. Zhou et al. (2000a) demonstrated a correlation between off-odor intensity and concentration of aldehydes in oxidized pickles. Sensory work has also been done with products such as oxidized peanuts and potato chips (Bett and Boylston, 1992; Jeon and Bassette, 1984). In peanuts, the "painty" off-flavor descriptor is often associated specifically with hexanal and pentanal (Min, 1998).

\subsection{Antioxidants}

In order to maintain freshness in foods and lengthen their shelf-life, antioxidants are often employed to prevent or delay lipid oxidation. There are two primary mechanisms by which antioxidants can reduce autoxidation. One mechanism is to hinder the development of free radicals at the initiation step, while the other is to stop propagation by quenching free radicals. In most food products, the latter method is used, with the antioxidant acting either as a hydrogen donor or free radical acceptor (Nawar, 1996). There are many synthetic and natural antioxidants used in foods, most of which are phenolic compounds that can easily donate an $\mathrm{H}$. to quench the lipid radical. Natural antioxidants currently used include ascorbic acid, citric acid, and $\alpha$-tocopherol. Some synthetic antioxidants that are commonly used are 
butylated hydroxyanisole (BHA), butylated hydroxytoluene (BHT), tertiary

butylhydroquinone (TBHQ), and propyl gallate (PG) (Nawar, 1996) (Fig. 1.3a).

As seen in Fig. 1.1, the propagation step of autoxidation is a cyclic reaction that continues until radicals start combining to form non-radical, stable products. However, if there is an antioxidant present $(\mathrm{AH})$, the reaction is not allowed to continue, and propagation is disrupted:

$$
\mathrm{ROO} \cdot+\mathrm{AH} \rightarrow \mathrm{ROOH}+\mathrm{A} .
$$

The antioxidant radical is more stable than the peroxy radical, so the propagation is interrupted. Phenolic compounds in particular make good antioxidants because they can undergo resonance stabilization in their radical form to become fairly stable (Fig. 1.3b). In many cases, the antioxidant radical will have several isomers. An isomer may react with other antioxidant radical molecules to either regenerate itself, in which case it can donate an $\mathrm{H} \cdot$ again, or it can become a stable, non-radical molecule. For example, after $\alpha$-tocopherol $\left(\mathrm{TH}_{2}\right)$ reacts with a peroxy radical, it becomes a radical $\alpha$-tocopherol molecule (TH·). Two of these $\alpha$-tocopherol radicals can then react to form a regenerated molecule of $\alpha$-tocopherol $\left(\mathrm{TH}_{2}\right)$ and a methyl tocopherylquinone (T) molecule (Nawar, 1996).

There are several points to consider when choosing an antioxidant for a specific food. These include the characteristics of the food, including the processing and handling conditions, $\mathrm{pH}$, and types of oils or fats present, and characteristics of the antioxidant, such as availability, cost, ease of incorporation into the food, and its hydro- or lipophilicity. For example, when dealing with bulk oils, antioxidants like PG or TBHQ which are relatively hydrophilic work best, since in bulk volumes the oil has a small surface-volume ratio. On the other hand, for a food such as salad dressing, which is an oil-in-water emulsion with a large 
surface-volume ratio for the lipid phase, lipophilic antioxidants such as BHA, BHT, or $\alpha-$ tocopherols work best (Nawar, 1996).

\subsection{Turmeric and Curcumin}

\subsubsection{Background information about turmeric}

Turmeric comes from the rhizomes of the Curcuma domestica plant (previously called Curcuma longa), a member of the ginger (Zingiberaceae) family. Rhizomes are rootlike projections off the main bulb of the plant. They are not the actual roots of the plant, but a separate structure that allows the plant to reproduce asexually and survive underground during unfavorable weather. Turmeric has been used for hundreds of years in many cultures, and was brought to the West after being 'discovered' by Marco Polo in 1280 in China (Tainter and Grenis, 2001). The United States uses 5.8 million pounds of turmeric per year, or approximately $\$ 3.6$ million worth. Of this amount, $97 \%$ is imported from India. Between four and eight percent of turmeric on a dry weight basis is comprised of curcumin (Fig. 1.4), which is the primary antioxidant component (Larson, 1987; Ruby et al., 1995).

Although turmeric does possess a musty or bitter flavor and can be used as a spice, in the United States it is used primarily for its yellow color, which comes from curcumin and two curcumin derivatives (Fig. 1.4) (Price and Buescher, 1996; Tainter and Grenis, 2001). Ground turmeric is used as a natural coloring agent in mustard, chicken bouillon, sauces, and gravies. There is also an oleoresin form that is used in foods such as processed cheeses, soups, beverages, candy, and cucumber pickles. The oleoresin form has two disadvantages. It fades in light due to its unstable keto-enol structure (Purseglove et al., 1981) and it is more expensive than FD\&C yellow \#5. As a result, most cucumber pickle products are now colored with yellow \#5, or a combination of yellow \#5 and turmeric. 
As stated above, there is an oleoresin form of turmeric available in addition to the ground turmeric that most consumers are familiar with. Turmeric oleoresins are standardized to have between 5 and $10 \%$ curcumin. In addition to the pigment, oleoresins contain the bitter flavor and the volatile and fatty oils from the turmeric rhizomes, as a result of an extraction procedure that uses one or a combination of organic solvents such as acetone, ethyl alcohol, methyl alcohol, and methylene chloride (Turmeric, 2002). The oleoresin is a very viscous solution with an orange-red color. Because this solution is not readily soluble in aqueous material, it is often mixed with polysorbate 80 or propylene glycol to make it more readily dispersible (Pruthi, 1980).

\subsubsection{Medicinal uses of turmeric}

Throughout history, turmeric has been used as anti-inflammatory agent (Kunchandy and Rao, 1990; Sugiyama et al., 1996; Tainter and Grenis, 2001) as well as for gall and liver disorders (Purseglove et al., 1981). As an ancient medicine, it has been used both externally and internally (Purseglove et al., 1981). More recently, many studies have been undertaken to determine possible health benefits of turmeric and curcumin. Turmeric has been shown to be antitumerogenic in both topical and oral applications (Tainter and Grenis, 2001), with researchers demonstrating that for topical application, the curcuminoid components in particular are the compounds responsible for inhibiting tumor production (Huang et al., 1991). There has also been a great deal of interest in curcumin as an inhibitor of diseases such as heart disease and cancer (Masuda and Jitoe, 1994). Curcumin is thought to possess anticarcinogenic activity that is related to its inhibition of lipid peroxidation (Gorman et al., 1997), which is attributed to curcumin having a combination of amphiphilic character and the ability to "repair" radicals. Turmeric has also been shown to lower blood and liver 
cholesterol levels and increase immune function, with curcumin being suggested as the ingredient in turmeric responsible for these functions (Liu, 1997). More research is needed in this area, though, as there is evidence that curcumin is very poorly absorbed by the gastrointestinal tract (Ammon and Wahl, 1991), and thus significantly higher doses of curcumin are needed if taken orally than if injected. Other experiments show that absorption of curcumin into the blood is unlikely. Additionally, it is unlikely that substantial concentrations of curcumin stay in the body after oral ingestion (Ammon and Wahl, 1991).

\subsubsection{Effectiveness of curcumin as an antioxidant}

In-depth investigations are now being done as to the effectiveness of turmeric as a food antioxidant (Kikuzaki and Nakatani, 1993). When comparing the antioxidative effects of curcumin to other antioxidants, researchers have come to varying conclusions. Using the TBA method, Jitoe et al. (1992) found it to be more effective than $\alpha$-tocopherol on a weight basis in a water/alcohol system. When measuring antioxidant activity based on the air oxidation of linoleic acid, Toda et al. (1985) found curcumin to be less effective than $\alpha$ tocopherol, but more effective than BHA and BHT on a weight basis. Recalculating Toda's data on a molar basis, curcumin was found to be more effective than BHA and BHT, which is not unexpected since curcumin has two phenolic rings per molecule while BHA and BHT only have one. However, since ingredients are purchased on a weight basis the antioxidant effect based on weight is perhaps more applicable than that based on molarity.

Regardless of exactly how effective curcumin is, one advantage it has over BHA and BHT is that it is considered a natural antioxidant. In addition to consumers showing interest in "natural" medicines such as herbs and spices, they are also looking increasingly for natural ingredients in food. Antioxidant ingredients are no exception, and currently many 
researchers are investigating natural antioxidants as possible replacements for synthetic ones like BHA and BHT. As with some other synthetic food additives, BHA and BHT have been criticized. Specifically, it has been shown that they may cause liver damage or negatively influence liver enzymes (Halladay et al., 1980; Martin and Gilbert, 1968), while this does not seem to be the case with natural antioxidants. Regardless of whether or not synthetic antioxidants really are unhealthy, the food industry must deal with their customer's perceptions, and this includes assumptions that natural compounds are safer than synthetic compounds (Jitoe et al., 1992).

\subsubsection{Curcuminoids}

In addition to curcumin, other curcuminoids (curcumin-like structures) have been isolated from turmeric. Curcumins II and III differ from curcumin only in having fewer groups on the phenolic rings (Fig. 1.4). Turmeric contains between four and eight percent curcuminoids on a dry basis, with curcumin (curcumin I) being the most abundant of these. Curcumin II and curcumin III comprise $6 \%$ and $0.3 \%$, respectively, of the curcuminoids (Ruby et al., 1995). Additionally, a more complex curcuminoid, containing three $\mathrm{OCH}_{3}$ groups compared to two on curcumin, has been isolated from turmeric and was found to have more antioxidant activity than curcumin on a weight basis, based on its ability to inhibit the autoxidation of linoleic acid (Masuda et al., 1993).

It has been shown that curcumin III possesses more antioxidant activity than curcumin does (Ruby et al., 1995; Sharma, 1976). Using the TBA method, synthetic curcumin I and III were shown to be as effective on a weight basis as their natural curcumin counterparts (Ruby et al., 1995). Thus, these may prove to be a cost-effective alternative to natural curcumin being used as an antioxidant. Curcuminoids have been isolated from other 
plants, such as tropical gingers, with these extracts showing antioxidant activity as well (Masuda and Jitoe, 1994). Cassumunarin extracts from tropical ginger have a structure similar to that of curcumin, but with an additional phenolic ring, and show even stronger antioxidant activity (Masuda et al., 1995).

\subsubsection{Antioxidant mechanism of curcumin}

There has, over the past decade or so, been a debate as to the exact mechanism by which turmeric functions as an antioxidant. It is agreed that curcumin and the other curcuminoids are the active antioxidant components in turmeric (Leal et al., 2003; Masuda et al., 1992). Researchers agree that curcumin inhibits propagation by "trapping” and stabilizing free radical species, such as lipid peroxyl radicals, and that this is done through donation of a hydrogen atom. However, there is a debate as to where on the curcumin molecule the hydrogen atom is donated from. Curcumin is somewhat unique in that it possesses both a phenolic ring and a $\beta$-diketone moiety on the same molecule, both of which have been shown in other compounds to possess antioxidant activity (Priyadarsini, 1997). Several researchers claim that curcumin donates hydrogen atoms from the phenolic group (Barclay and Vinqvist, 2000; Khopde et al., 1999; Masuda et al., 1999; Sun et al., 2002), while others claim that the hydrogen comes from the central methylene group (Jovanovic et al., 1999). Cuvelier et al. (1992) maintain that the efficacy of curcumin could be explained by metal chelation by the central $\beta$-diketone group, or also by the lability of the hydrogens on the central methylene group in curcumin.

As stated above, some researchers maintain that, although the antioxidant activity of curcumin had previously been attributed to electron donation from the phenolic part of the molecule, the preferred antioxidant mechanism is that of $\mathrm{H}$-atom transfer from the central 
$\mathrm{CH}_{2}$ group, especially at $\mathrm{pH}<7$ (Jovanovic et al., 1999). In acidic solutions, they argue, the keto form of the molecule dominates, and in this form the $\mathrm{C}-\mathrm{H}$ bonds are very weak, so the molecule lends itself to the mechanism of donating the $\mathrm{H}$-atom from the central $\mathrm{CH}_{2}$ group. Likewise, as $\mathrm{pH}$ increases, the rate of the antioxidant reaction decreases because of the decrease in the percentage of curcumin that is in the keto form. It was concluded that Hatom donation from the $\mathrm{OH}$ group on the phenolic ring would likely only account for $15 \%$ of the reaction (Jovanovic et al., 1999). Based on later research, Jovanovic et al. (2001) state that both the $\beta$-diketone moiety and the phenol group are responsible for the exceptional antioxidant properties of curcumin. In separate research, Osawa and Namiki (1985) theorize that long hydrocarbon chains on both sides of the $\beta$-diketone moiety are necessary for antioxidant activity, and found that curcumin had less antioxidant activity than a compound with longer carbon chains on both sides of the $\beta$-diketone group.

Other researchers maintain that the antioxidant capability of curcumin does not come from the central $\mathrm{CH}_{2}$ group, but from the phenolic groups on either side of the molecule. Barclay et al. (2000) determined the antioxidant activity of compounds that have the same basic skeleton as curcumin, but without the phenolic groups. They found that these compounds did not exhibit antioxidant activity. Therefore, it was concluded that the phenolic groups of curcumin, rather than the central $\mathrm{CH}_{2}$ group, were responsible for its antioxidant capacity. Masuda et al. (1993) also believe that it is largely the phenolic groups that contribute to the antioxidant effect of curcumin, with a minimal contribution from the $\beta$ diketone group.

Sun et al. (2002) looked at bond dissociation enthalpies (BDEs) of the $\mathrm{O}-\mathrm{H}$ and $\mathrm{C}-\mathrm{H}$ bonds in curcumin to try to determine the antioxidant mechanism. Like Barclay et al. and 
Masuda et al., they proposed that the H-atom donation occurred primarily from the phenolic group. They held that, due to its having lower energy than the $\beta$-diketone form, the enol form is more stable in solution. The central $\mathrm{CH}_{2}$ group does not exist while curcumin is in this enol form, thus, the H-atom donation would be coming from the phenolic group. Additionally, the $\mathrm{BDE}$ for the $\mathrm{H}$ on the $\mathrm{OH}$ group is much lower than the $\mathrm{BDE}$ for the $\mathrm{H}$ on the $\mathrm{C}-\mathrm{H}$ group, making it more likely that the $\mathrm{H}$-atom would come from the phenolic group (Sun et al., 2002).

In summary, most researchers now seem to agree that although the $\beta$-diketone moiety may contribute a small amount to the antioxidant activity of curcumin, the majority of the molecule's antioxidant activity stems from its ability to donate H-atoms from its two phenolic groups. Many of the most effective antioxidants, both synthetic and natural, consist of phenolic compounds, and it follows that turmeric is likely to act through the same mechanism. Masuda et al. $(1992 ; 1993 ; 2000)$ have investigated the antioxidant mechanism of curcumin extensively, and have not found evidence that the $\beta$-diketone group is contributing largely to the antioxidant mechanism. Futhermore, based on more recent research, some researchers who originally thought that the $\beta$-diketone moiety was responsible for most of the antioxidant activity have now revised their views and believe that the phenolic groups are also responsible for the high antioxidant activity of curcumin (Jovanovic et al., 2001).

\subsubsection{Products of the curcumin antioxidant reaction}

In addition to the debate over the specific antioxidant mechanism of curcumin, there have also been questions concerning the products of the reaction. After curcumin undergoes the antioxidation process, it forms the curcumin radical, which can take one of several 
resonance forms. This antioxidant radical will then go on to produce a stable, non-radical terminal compound. The question arises as to what exactly are the non-radical terminal compounds, and how are they formed. Masuda et al. (1999) reported that when curcumin reacts with radical species, there were four curcumin compounds produced, three of which were identified (Fig. 1.5). Two of these were fragments of curcumin (compounds 4 and 5), and the third was a curcumin dimer. The initial curcumin radical formed (curcumin radical structure I) is formed after the antioxidant reaction and has a radical on the phenolic group. This structure can rearrange to have the radical on the central part of curcumin, forming one of two curcumin radical structures (II or III). Structures II and III can independently react with molecular oxygen to form a peroxyl radical, which then decomposes to one of the curcumin fragments (compounds 4 and 5). Alternatively, curcumin radical structures II and III can couple at their radical sites, then undergo cyclization to form a stable dimer with a dihydro-furan ring (compound 2 in Fig. 1.5). This dimerization after the antioxidant radical is formed has also been seen in $\alpha$-tocopherol and BHT (Masuda et al., 1999). It was also reported that the curcumin dimer is not necessarily the final compound, because the dimer can react to produce higher-molecular weight compounds as the final products (Masuda et al., 1999).

When curcumin is acting as an antioxidant in a food system, there will also be lipid peroxyl radical groups that may react with the curcumin radicals. Masuda's group also investigated the products of the reaction of curcumin with the lipid, ethyl linoleate (Masuda et al., 2000; 2001). They report that there were four types of linoleate peroxyl radicals produced that reacted with curcumin, to give a total of six reaction products (Fig. 1.6). These products had a tricyclic structure that had been formed via a Diels-Alder reaction. 
With the identification of two termination pathways, there is the question of which pathway is the predominant one in the antioxidant reaction of curcumin. It was found that the rate at which ROOA termination products were formed was independent of the concentration of curcumin, while the concentration of dimer products (A-A) increased with increased concentration of the curcumin. It was concluded that the ROOA pathway was the essential pathway, but at higher concentrations of curcumin the dimer pathway is also significant as a termination pathway. The route of dimerization was expected to contribute up to $40 \%$ of the antioxidant mechanism (Masuda et al., 2002). 


\subsection{References}

Ammon, H.P.T.; Wahl, M.A. Pharmacology of Curcuma longa. Planta Med. 1991, 57, 1-7.

Barclay, L.R.C.; Vinqvist, M.R. On the antioxidant mechanism of curcumin: classical methods are needed to determine antioxidant activity. Org. Lett. 2000, 2, 2841-2843.

Bett, K.L.; Boylston, T.D. Effect of Storage on Roasted Peanut Quality: Descriptive Sensory Analysis and Gas Chromatographic Techniques. In Lipid Oxidation in Food; St. Angelo, A.J., Ed.; American Chemical Society: Washington, D.C., 1992; p 322.

Crapiste, G.H.; Brevedan, M.I.V.; Carelli, A.A. Oxidation of sunflower oil during storage. J. Am. Oil. Chem. Soc. 1999, 76, 1437-1443.

Cuvelier, M.; Richard, H.; Berset, C. Comparison of the antioxidative activity of some acidphenols: structure-activity relationship. Biosci. Biotech. Biochem. 1992, 56, 324-325.

DeMan, J.M. Lipids. Principles of Food Chemistry, $3^{\text {rd }}$ ed.; Aspen Publishers, Inc.: Gaithersburg, 1999; pp 54-63.

Eriksson, C.E. Chemistry in Flavor Research: Achievements, Needs and Perspectives. In Flavour Science and Technology; Martens, M., Dalen, G.A., Russwurm, H. Jr., Eds.; John Wiley \& Sons: Chichester, 1987; pp 5-21.

Gardner, H.W.; Plattner, R.D. Linoleate hydroperoxides are cleaved heterolytically into aldehydes by a lewis acid in aprotic solvent. Lipids. 1984, 19, 294-299.

Gorman, A.A.; Hamblett, I.; Hill, T.J.; Jones, H.; Srinivasan, V.S.; Wood, P.D. Curcumin: a Pulse Radiolysis Investigation of the Radical in Micellar Systems. In Spices: Flavor Chemistry and Antioxidant Properties; Risch, S.J., Ho, C.T., Eds.; American Chemical Society Symposium Series 660; American Chemical Society: Washington, D.C., 1997; pp 234-243.

Gray, J.I. Measurement of lipid oxidation: a review. J. Am. Oil Chem. Soc. 1978, 55, 539546.

Grosch, W.; Konopka, U.C.; Guth, H. Characterization of Off-Flavors by Aroma Extract Dilution Analysis. In Lipid Oxidation in Foods; St. Angelo, A.J., Ed.; ACS Symposium Series 500; American Chemical Society: Washington, D.C., 1992; pp 266-278.

Halladay, S.C.; Ryerson, B.A.; Smith, C.R.; Brown, J.P.; Parkinson, T.M. Comparison of effects of dietary administration of butylated hydroxytoluene or a polymeric antioxidant on the hepatic and intestinal cytochrome P-450 mixed-function-oxygenase system of rats. Food Cosmet. Toxicol. 1980, 18, 569-574. 
Huang, M.T.; Lysz, T.; Ferraro, T.; Abidi, T.F.; Laskin, J. D.; Conney, A.H. Inhibitory effects of curcumin on in vitro lipoxygenase and cyclooxygenase activities in mouse epidermis. Cancer Res. 1991, 51, 813-819.

Jeon, I.J.; Bassette, R. Analysis of n-pentanal and hexanal as indices of potato chip shelflife. J. Food Qual. 1984, 7, 97-105.

Jitoe, A.; Masuda, T.; Tengah, I.G.P.; Suprapta, D.N.; Gara, I.W.; Nakatani, N. Antioxidant activity of tropical ginger extracts and analysis of the contained curcuminoids. J. Agric. Food Chem. 1992, 40, 1337-1340.

Jovanovic, S.V.; Steenken, S.; Boone, C.W.; Simi, M.G. H-atom transfer is a preferred antioxidant mechanism of curcumin. J. Am. Chem. Soc. 1999, 121, 9677-9681.

Jovanovic, S.V.; Boone, C. W.; Steenken, S.V.; Trinoga, M.; Kaskey, R.B. How curcumin works preferentially with water soluble antioxidants. J. Am. Chem. Soc. 2001, 123, 30643068 .

Khopde, S.M.; Priyadarsini, K.I.; Venkatesan, P.; Rao, M.N.A. Free radical scavenging ability and antioxidant efficiency of curcumin and its substituted analogue. Biophys. Chem. 1999, 80, 85-91.

Kikuzaki, H.; Nakatani, N. Antioxidant effects of some ginger constituents. J. Food Sci. 1993, 58, 1407-1410.

Koelsch, C.M.; Downes, T.W.; Labuza, T.P. Hexanal formation via lipid oxidation as a function of oxygen concentration: measurement and kinetics. J. Food Sci. 1991, 56, 816820.

Kunchandy, E.; Rao, M.N.A. Oxygen radical scavenging activity of curcumin. Int. J. Pharm. 1990, 58, 237-240.

Larson, R.A. Review article number 30: the antioxidants of higher plants. Phytochem. 1988, 27, 969-978.

Leal, P.F.; Braga, M.E.M.; Sato, D.N.; Carvalho, J.E.; Marques, M.O.M.; Meireles, M.A.A. Functional properties of spice extracts obtained via supercritical fluid extraction. J. Agric. Food Chem. 2003, 51, 2520-2525.

Liu, Y. Curcumin: An Ingredient that Reduces Platelet Aggregation and Hyperlipidemia, and Enhances Antioxidant and Immune Functions. In Spices: Flavor Chemistry and Antioxidant Properties; Risch, S.J., Ho, C.T., Eds.; American Chemical Society Symposium Series 660; American Chemical Society: Washington, D.C., 1997; pp 199-205.

Martin, A.D.; Gilbert, D. Enzyme changes accompanying liver enlargement in rats treated with 3-tertbutyl-4-hydroxyanisole. Biochem. J. 1968, 106, 22-27. 
Masuda, T.; Isobe, J.; Jitoe, A.; Nakatani, N. Antioxidative curcuminoids from rhizomes of Curcuma xanthorrhiza. Phytochem. 1992, 31, 3645-3647.

Masuda, T.; Jitoe, A.; Isobe, J.; Nakatani, N.; Yonemori, S. Anti-oxidative and antiinflammatory curcumin-related phenolics from rhizomes of curcuma domestica. Phytochem. 1993, 32, 1557-1560.

Masuda, T; Jitoe, A. Antioxidative and antiinflammatory compounds from tropical gingers: isolation, structure determination, and activities of cassumunins A, B, and C, new complex curcuminoids from Zingiber cassumunar. J. Agric. Food Chem. 1994, 42, 1850-1856.

Masuda, T.; Jitoe, A.; Mabry, T.J. Isolation and structure determination of cassumunarins A, B, and C: new anti-inflammatory antioxidants from a tropical ginger, Zingiber cassumunar. J. Am. Oil Chem. Soc. 1995, 72, 1053-1057.

Masuda, T.; Hidaka, K,; Shinohara, A.; Maekawa, T.; Takeda, Y.; Yamaguchi, H. Chemical studies on antioxidant mechanism of curcuminoid: analysis of radical reaction products from curcumin. J. Agric. Food Chem. 1999, 47, 71-77.

Masuda, T.; Bando, H.; Maekawa, T.; Takeda, Y.; Yamaguchi, H. A novel radical terminated compound produced in the antioxidation process of curcumin against oxidation of a fatty acid ester. Tetrahedron Lett. 2000, 41, 2157-2160.

Masuda, T.; Maekawa, T.; Hidaka, K.; Bando, H.; Takeda, Y.; Yamaguchi, H. Chemical studies on antioxidant mechanism of curcumin: analysis of oxidative coupling products from curcumin and linoleate. J. Agric. Food Chem. 2001, 49, 2539-2547.

Masuda, T.; Toi, Y.; Bando, H.; Maekawa, T.; Takeda, Y.; Yamaguchi, H. Structural identification of new curcumin dimers and their contribution to the antioxidant mechanism of curcumin. J. Agric. Food Chem. 2002, 50, 2524-2530.

Min, D.B. Lipid Oxidation of Edible Oil. In Food Lipids; Akoh, C.C., Min, D.B., Eds.; Marcel Dekker, Inc.: New York, 1998; pp 283-296.

Nawar, W.F. Lipids. In Food Chemistry, $3^{\text {rd }}$ ed.; Fennema, O.R., Ed.; Marcel Dekker, Inc.: New York, 1996; pp 254-288.

Njissen, B. Off-Flavors. In Volatile Compounds in Foods and Beverages; Maarse, H., Ed.; Marcel Dekker, Inc.: New York, 1991; pp 689-735.

Osawa, T.; Namiki, M. Natural antioxidants isolated from Eucalyptus leaf waxes. J. Agric. Food Chem. 1985, 33, 777-780.

Peng, A.C. Fatty Acids in Vegetables and Vegetable Products. In Fatty Acids in Foods and their Health Implications; Chow, C.K., Ed.; Marcel Dekker, Inc.: New York, 1992; p 202. 
Peng, A.C.; Geisman, J.R. Lipid and fatty acid composition of cucumbers and their changes during storage of fresh-pack pickles. J. Food Sci. 1976, 41, 859-862.

Price, L.C.; Buescher, R.W. Decomposition of turmeric curcuminoids as affected by light, solvent and oxygen. J. Food Biochem. 1996, 20, 125-133.

Priyadarsini, K.I. Free radical reactions of curcumin in membrane models. Free Radical Biol. Med. 1997, 23, 838-843.

Pruthi, J.S. Spice Products Technology. Spices and Condiments: Chemistry, Microbiology, Technology; Harcourt Brace Jovanovich: New York, 1980; pp 228-242.

Purseglove, J.W.; Brown, E.G.; Green, C.L.; Robbins, S.R.J. Turmeric. Spices; Longman Scientific and Technical: Essex, England, 1981; Vol. 2, pp 532-580.

Ruby, A.J.; Kuttan, G.; Babu, K.D.; Rajasekharan, K.N.; Kuttan, R. Anti-tumour and antioxidant activity of natural curcuminoids. Cancer Lett. 1995, 94, 79-83.

Sharma, O.P. Antioxidant activity of curcumin and related compounds. Biochem. Pharmacol. 1976, 25, 1811-1812.

Sugiyama, Y.; Kawahishi, S.; Osawa, T. Involvement of the $\beta$-diketone moiety in the antioxidative mechanism of tetrahydrocurcumin. Biochem. Pharmacol. 1996, 52, 519-525.

Sun, Y.; Zhang, H.; Chen, D.; Liu, C. Theoretical elucidation on the antioxidant mechanism of curcumin: a DFT study. Org. Lett. 2002, 4, 2909-2911.

Tainter, D.R.; Grenis, A.T. The Spices and Recent Spice Research. Spices and Seasonings: A Food Technology Handbook; John Wiley \& Sons, Inc.: New York, 2001; pp 151-159, $166-179$.

Toda, S.; Miyase, T.; Arichi, H.; Tanizawa, H.; Takino, Y. Natural Antioxidants III. Antioxidative components isolated from rhizome of Curcuma longa L. Chem. Pharm. Bull. 1985, 33, 1725-1728.

Turmeric oleoresin. Code of Federal Regulations, 21CFR73.615, 2002.

Vercellotti, J.R.; Mills, O.E.; Bett, K.L.; Sullen, D.L. Gas Chromatographic Analysis of Lipid Oxidation Volatiles in Foods. In Lipid Oxidation in Food; St. Angelo, A.J., Ed.; ACS Symposium Series 500; American Chemical Society: Washington, D.C., 1992; pp 232-265.

Wardale, D.A.; Lambert, E.A. Lipoxygenase from cucumber fruit; location and properties. Phytochem. 1980, 19, 1013-1016.

Whitfield, F.B. Food Off-Flavours: Cause and Effect. In Developments in Food Flavours; Birch, G.G.; Lindley, M.G., Eds.; Elsevier Applied Science: London, 1986; pp 249-273. 
Zhou, A.; McFeeters, R.F.; Fleming, H.P. Development of oxidized odor and volatile aldehydes in fermented cucumber tissue exposed to oxygen. J. Agric. Food Chem. 2000, 48, 193-197.

Zhou, A.; McFeeters, R.F.; Fleming, H.P. Inhibition of formation of oxidative volatile components in fermented cucumbers by ascorbic acid and turmeric. J. Agric. Food Chem. 2000, 48, 4910-4912. 
$\mathrm{RH} \rightarrow \mathrm{ROO} \cdot \mathrm{R} \cdot \mathrm{H} \cdot$
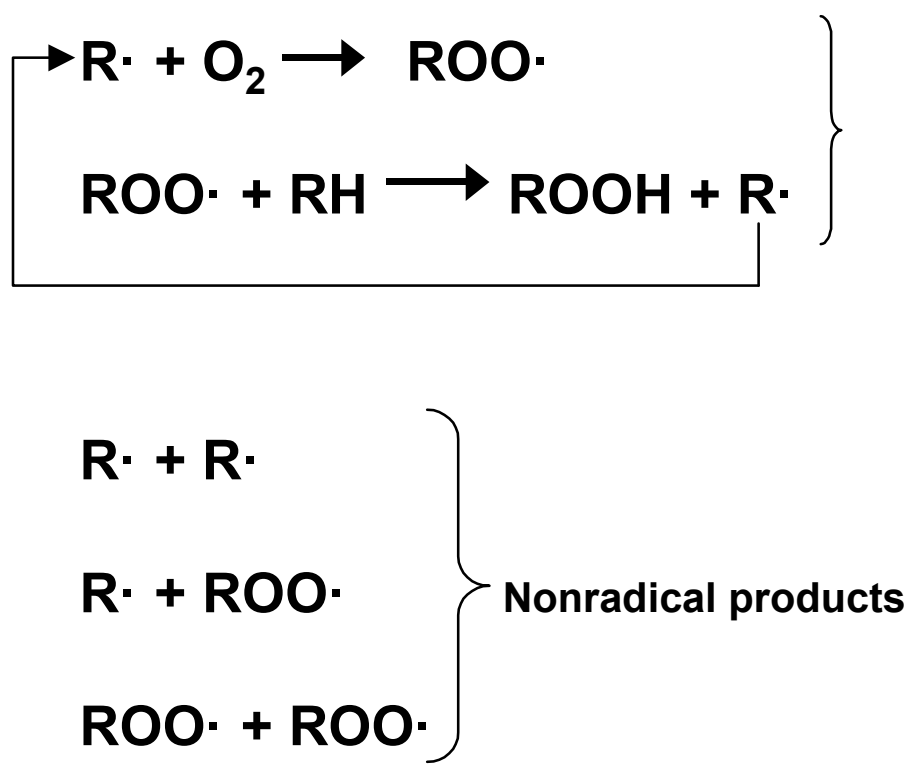

INITIATION

PROPAGATION

\section{TERMINATION}

Figure 1.1. Mechanism of autoxidation. 


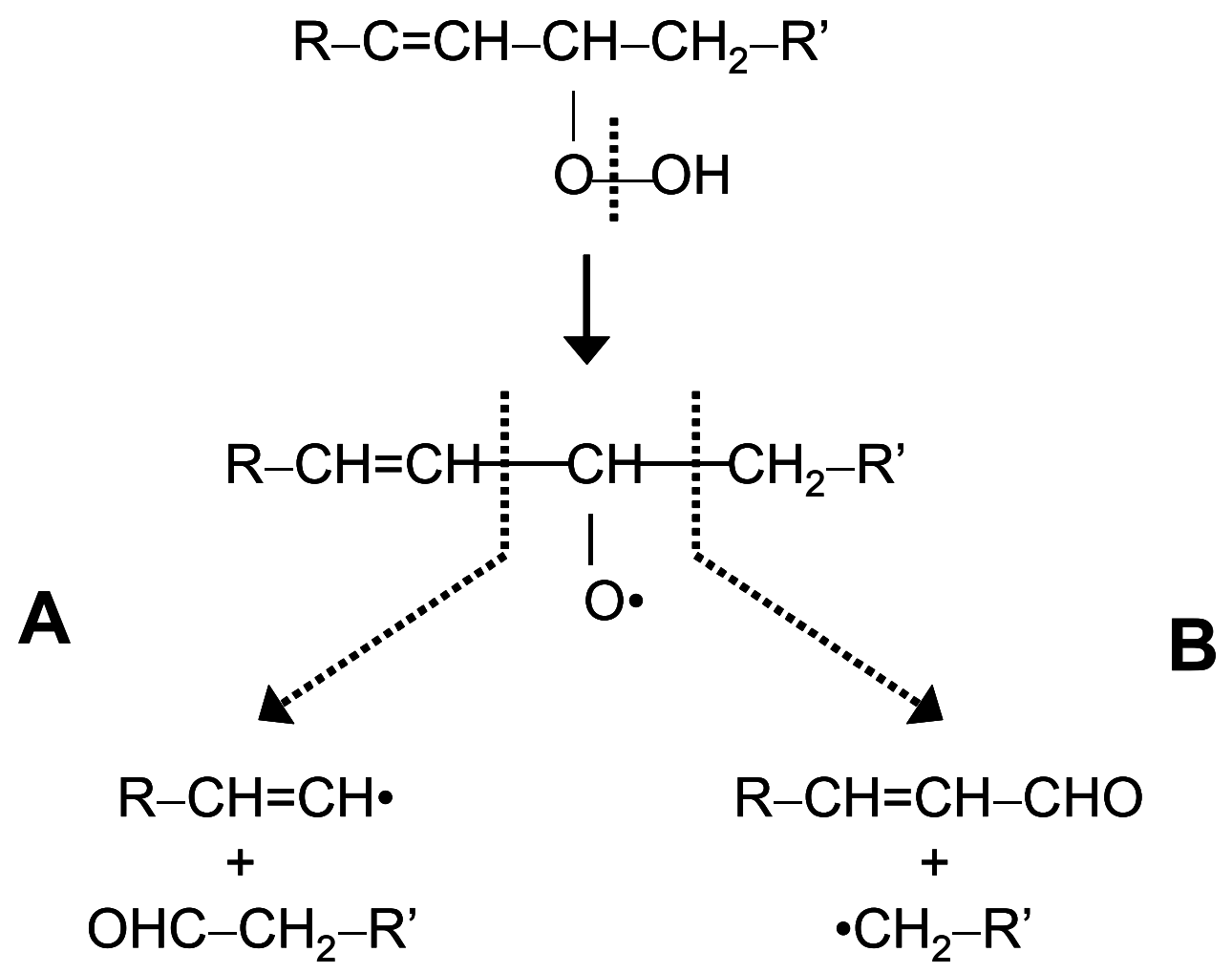

Figure 1.2. Homolytic cleavage of hydroperoxide to form hydrocarbon and oxoacid when cleaved on hydrocarbon side (A), or aldehyde and acid when cleaved on acid side (B) (Nawar, 1996). 
<smiles>COc1ccc(O)c(C(C)(C)C)c1</smiles>

BHA<smiles>CC(C)(C)c1cc(O)ccc1O</smiles>

TBHQ

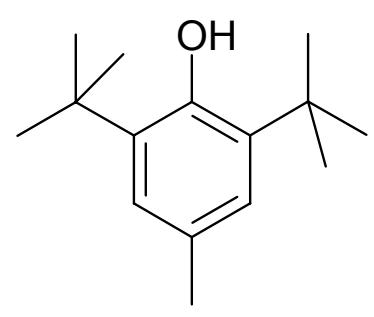

BHT<smiles>CCOC(=O)c1cc(O)c(O)c(O)c1</smiles>

PG<smiles>Cc1c(C)c2c(c(C)c1O)CC(CCCC(C)CCCC(C)CCCC(C)C)C(C)O2</smiles><smiles>O=C1OC(C(O)CO)C(O)=C1O</smiles>

Ascorbic acid
$\mathrm{HOOCH}_{2} \mathrm{C}$<smiles>CCC(O)(CC(=O)O)C(=O)O</smiles>

Figure 1.3a. Structures of common antioxidants.

Citric acid 


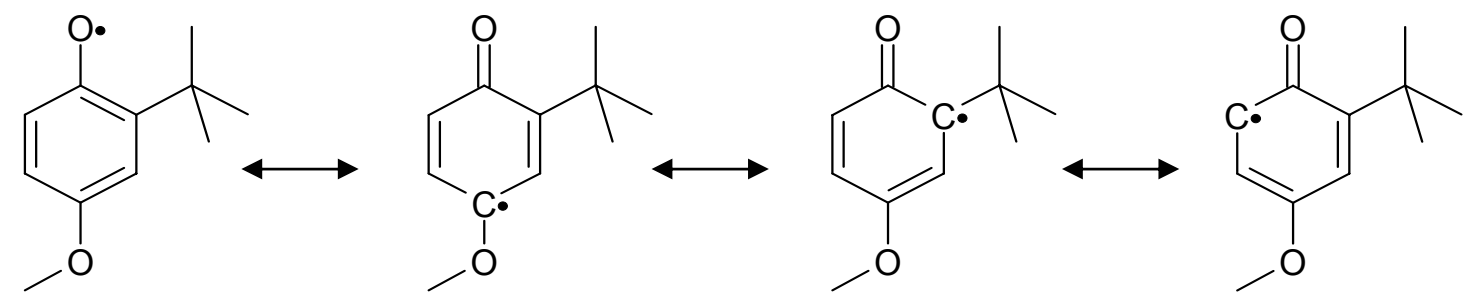

Figure 1.3b. Resonance structures of $\mathrm{BHA}$. 
<smiles>[R1]c1cc(/C=C/C(=O)C(C)C(=O)/C=C/c2ccc(O)c([R2])c2)ccc1O</smiles>

Curcumin: $\quad \mathrm{R}_{1}=\mathrm{OCH}_{3}, \mathrm{R}_{2}=\mathrm{OCH}_{3}$

Curcumin II: $\mathrm{R}_{1}=\mathrm{OCH}_{3}, \mathrm{R}_{2}=\mathrm{H}$

Curcumin III: $\mathrm{R}_{1}=\mathrm{H}, \mathrm{R}_{2}=\mathrm{H}$

Figure 1.4. Curcumin structures. 


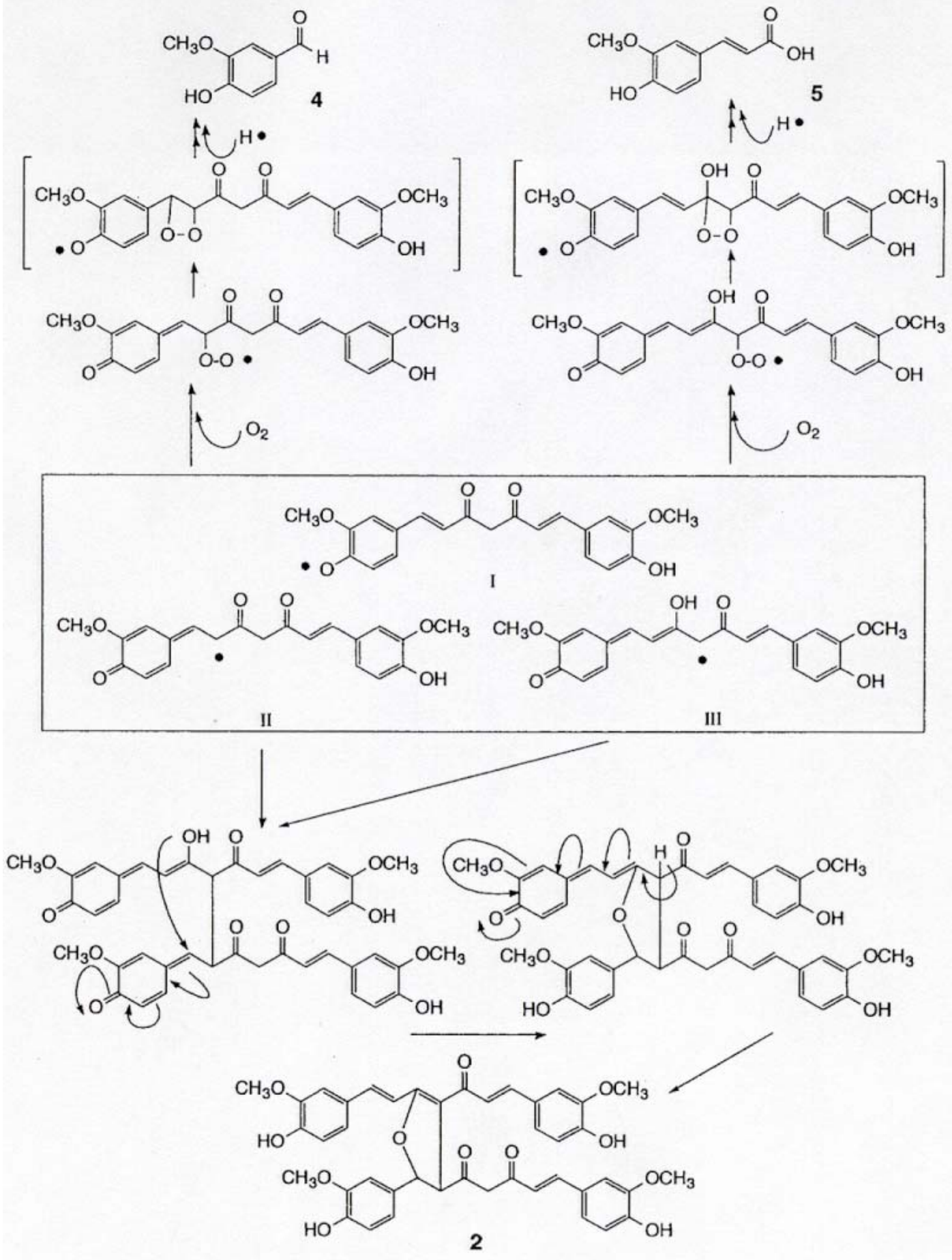

Figure 1.5. Proposed products of curcumin antioxidant reaction (Masuda, 1999). The initial curcumin radical formed (I) rearranges into curcumin radical II or III. Structures II and III can independently react with molecular oxygen and then decompose to compounds 4 or 5 , or couple at their radical sites and undergo cyclization to form a stable dimer (compound 2 ). 


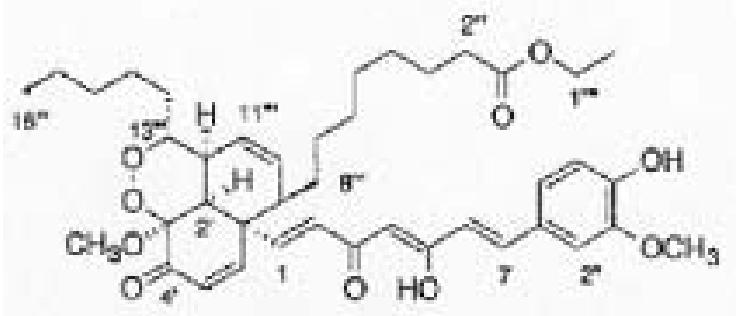

1

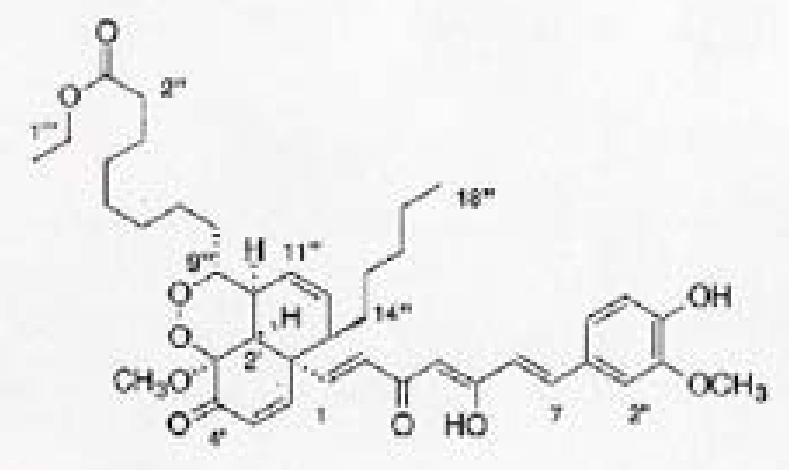

2

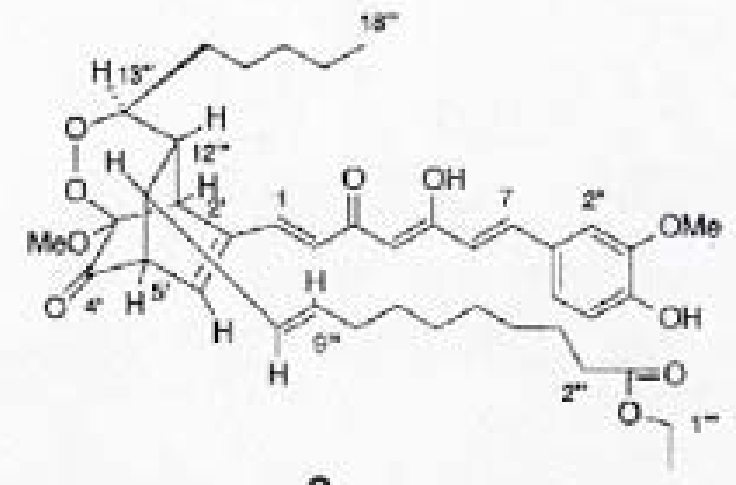

3

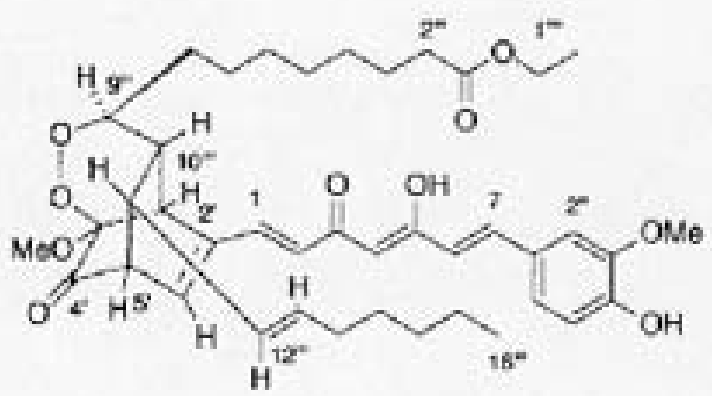

5
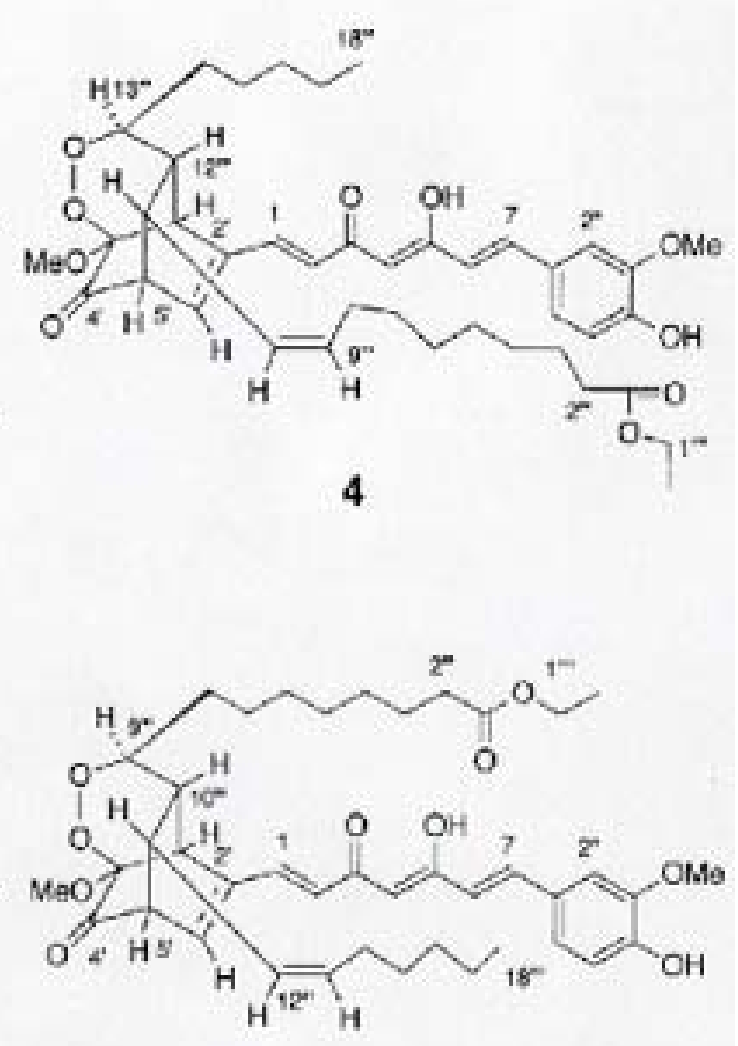

6

Figure 1.6. Tri-cyclic reaction products formed via Diels-Alder reaction between linoleate peroxyl and curcumin radicals in the antioxidant reaction of curcumin (Masuda, 2001). 


\section{Chapter 2}

Oxidative Aldehyde Levels in Commercial Fresh-Pack Dill Pickles 


\subsection{Abstract}

Four brands of commercial fresh-pack dill pickles packed in glass jars were analyzed for volatile aldehydes that are typically associated with lipid oxidation in foods. The pickles were stored approximately one month (short term storage) and one year (long term storage) prior to analysis. Dissolved oxygen was present at very low concentrations in all products ( $0.45 \mathrm{ppm}$ mean oxygen concentration) at both storage periods. Despite the low oxygen levels observed, hexanal, pentanal, and heptanal were identified based upon GC/MS retention times and fragmentation patterns. The short term storage samples had significantly higher mean hexanal, heptanal, and combined aldehyde levels than the long term storage samples. These results show that aldehydes, commonly associated with lipid oxidation, are part of the normal volatile components of commercial fresh-pack dill pickles at an early stage of their shelf life when the products would be considered to be of optimal quality. These aldehydes decreased during storage of the product. The results also indicated that although there may be a decline in product quality during extended storage of fresh-pack pickles packed in glass containers, this decline is not associated with increases in these volatile compounds.

\subsection{Introduction}

Currently, most cucumber pickles marketed directly to consumers are packed and pasteurized in glass jars. However, there is interest in the industry to move from glass containers to plastic containers due to factors such as dealing with broken glass in the plant, reduced weight of plastic containers, and consumer preference. Plastic containers suitable for use with pasteurized pickled vegetables are currently under development. A concern with the use of plastic is that products packed in plastic typically have a shorter shelf life at least 
in part because of the significant oxygen permeability of the containers and closures, which can result in development of off-odors and flavors as a result of lipid oxidation. While the total lipid content of cucumbers is only between 0.10 and $0.14 \%$ on a wet weight basis (Peng, 1992), this is clearly sufficient lipid to impact the flavor if the lipids are oxidized. In fact, the impact compounds primarily responsible for fresh cucumber flavor are the oxidative aldehydes, 2,6-nonadienal and 2-nonenal (Schieberle et al., 1990). These are formed by enzymatic oxidation of linolenic acid and linoleic acid, which are two of the most abundant fatty acids in the lipids of the cucumber (Peng and Geisman, 1976). However, it is not known what aldehydes, if any, might form from the cucumber lipids present in fresh-pack pickles as the pickles are currently produced and stored. Before looking at the potential development of off-flavors via autoxidation when higher levels of oxygen might be present in products, we decided to analyze current commercial pickle products packed in glass jars to determine if aldehydes associated with lipid oxidation developed in these pickles during their normal commercial shelf life. Therefore, the objective of this work was to identify and measure aldehyde levels in commercial fresh-pack dill cucumber pickles at early and late stages of their normal shelf life.

\subsection{Materials and Methods}

Source of Chemicals and Pickle Products. All chemicals were purchased from Aldrich Chemical Co. (Milwaukee, WI). Fresh-pack (non-refrigerated) dill pickles in glass jars were provided by four processors distributed across the United States and Mexico. Each processor provided a case of product approximately 1 month old and a second case of product that had been stored between 11 and 15 months (Table 2.1). These were termed 
"short term storage" and "long term storage" samples, respectively. All samples analyzed were within their normal shelf life. Three jars from each case were analyzed.

Measurement of dissolved oxygen. Dissolved oxygen was measured immediately after opening a jar of stored cucumbers. Dissolved oxygen in the brine was measured using an Oxi330i oxygen meter equipped with a StirrOxG galvanic oxygen probe (Wissenschaftlich-Technische Werkstätten, Weilheim, Germany).

Sampling, identification, and measurement of volatile aldehydes. Measurement of volatile components was carried out by modification of the procedure of Zhou et al. (2000). Samples for volatile component analysis were prepared by transfer of $150 \mathrm{~g}$ of pickles and $150 \mathrm{~g}$ brine into a Waring blender. The cucumber tissue and brine were homogenized for $7 \mathrm{sec}$. Slurry $(10 \mathrm{~g})$ was transferred to a $25 \mathrm{~mL}$ fritless sparger (Angel Inc., Panorama City, CA), then spiked directly with $50 \mu \mathrm{L}$ of $11.4 \mathrm{ppm}$ toluene- $\mathrm{d}_{8}$ as the internal standard. The sparging tube was attached to a CDS 6000 purge and trap sampler (CDS Analytical Inc., Oxford, PA). After $1 \mathrm{~min}$ preheating at $30^{\circ} \mathrm{C}$, volatile components were removed from the sample slurry by bubbling helium gas through the slurry at a flow rate of $40 \mathrm{~mL} \mathrm{~min}^{-1}$ for $30 \mathrm{~min}$. Volatiles were adsorbed on a Tenax trap column (Supelco Inc., Bellefone, $\mathrm{PA}$ ) held at $40^{\circ} \mathrm{C}$ during purging. The Tenax trap was dried for 3 min to remove trapped water, heated at $180^{\circ} \mathrm{C}$ for 6 min with a helium flow rate of $4.0 \mathrm{~mL} \mathrm{~min}^{-1}$ to desorb trapped volatiles, then baked at $250^{\circ} \mathrm{C}$ for 5 min to clean the trap for the next sample.

Desorbed volatile compounds were delivered without splitting to a $30 \mathrm{~m}$ x $0.25 \mathrm{~m}$ i.d., $0.25 \mu \mathrm{m}$ film thickness HP-5MS capillary column (Hewlett-Packard, Palo Alto, CA). The GC/MS system consisted of an HP 5890 II chromatograph with an HP 5972 mass selective detector (MSD) (Hewlett-Packard, Palo Alto, CA). The oven temperature was held at $-20^{\circ} \mathrm{C}$ 
during the $4.5 \mathrm{~min}$ volatile component desorption period with a $4.0 \mathrm{~mL} \mathrm{~min}^{-1}$ helium flow rate. The oven temperature was programmed to increase from $-20^{\circ} \mathrm{C}$ to $140^{\circ} \mathrm{C}$ at $10^{\circ} \mathrm{C} \mathrm{min}^{-1}$ with a 1 min hold at $140^{\circ} \mathrm{C}$. Oven temperature then increased from $140^{\circ} \mathrm{C}$ to $220^{\circ} \mathrm{C}$ at $40^{\circ} \mathrm{C}$ $\min ^{-1}$ with a final hold of $3.5 \mathrm{~min}$. Helium carrier gas was used at a constant flow rate of 1.0 $\mathrm{mL} \min ^{-1}$. MSD settings were as follows: MS interface and ionization source temperature, $280^{\circ} \mathrm{C}$; electronic ionization voltage, $70 \mathrm{eV}$; scanning mass range, $35-350$ daltons. The electron multiplier voltage was set 200 volts above the voltage selected by the "Maximum Autotuning" procedure.

Identification of oxidative aldehydes was based upon preliminary identification using the NIST/EPA/NIH Mass Spectral Library (2002) with HP G1701BA ChemStation software (version B.00.00) (Hewlett-Packard, Palo Alto, CA). Identification was confirmed by matching both retention times and fragmentation patterns with standard aldehydes.

Concentrations of aldehydes were calculated based upon peak areas relative to the peak area of the internal standard. Standard curves were prepared for each aldehyde (hexanal, pentanal, and heptanal) by making known additions of three concentrations of each aldehyde to a baseline cucumber slurry and calculating linear regression equation for each analyte. The three concentrations of each analyte were chosen to encompass the range of aldehyde levels present in all samples.

Statistical Analysis. All statistical analysis was carried out using SAS (Version 8) (SAS Inc., Cary, NC). Significant differences were calculated using Tukey's multiple means comparison. 


\subsection{Results and Discussion}

Three aldehydes, hexanal, heptanal, and pentanal, were detected and quantified in all pickle samples. Total aldehydes (Fig. 2.1) and hexanal (Fig. 2.2), and heptanal (Fig. 2.3) concentrations in the short term storage samples were significantly higher than in the long term storage samples $(\mathrm{p} \leq 0.01)$. However, pentanal levels (Fig. 2.4) were not significantly different between the two storage times. Mean values of aldehydes across brands are shown in Table 2.2. Mean dissolved oxygen levels were very low, at $0.44 \pm 0.9$ and $0.46 \pm 0.9 \mathrm{ppm}$ for short and long term storage samples, respectively. The mean dissolved oxygen levels were not significantly different between storage times.

Because the pickle samples analyzed were in glass jars and had remained closed until analysis, it was assumed that minimal oxygen entered the jars after they were packed and closed. The product had been pasteurized after packing, which would inactivate cucumber lipoxygenase (Wardale and Lambert, 1980), and thus prevent enzymatic oxidation. Although hexanal has been found in fresh cucumber slurry (Zhou et al., 1998), it is assumed that all or at least most of these aldehydes formed in the jar by lipid autoxidation utilizing the initial oxygen present in the fresh cucumbers (Corey et al., 1983), the cover solution, and the headspace of the jars.

The odor detection threshold for hexanal in water is between 4.5 and $30 \mathrm{ppb}$, while the thresholds for heptanal and pentanal are $3 \mathrm{ppb}$ and $12 \mathrm{ppb}$, respectively (Fazzalari, 1978). In the short term storage samples the mean hexanal (146 ppb) and pentanal (149 ppb) concentrations were well above their threshold levels (Table 2). Since the short term storage samples were at the beginning of their shelf life when product quality would be at it highest, and these aldehydes were found in all jars of every brand tested, these aldehydes at the 
concentrations at which they occurred appear to be a part of the normal flavor of commercially produced fresh-pack dill pickles, and therefore cannot be considered off flavor compounds. If they were to increase to substantially higher levels, these aldehydes presumably would be perceived as oxidized off flavor.

The fact that aldehyde concentrations declined moderately during storage (Table 2) suggests that at some point aldehyde formation becomes very slow or stops completely, in addition to the aldehyde molecules breaking down or reacting with other components in the pickles. Therefore, the decline in the quality of fresh-pack pickles that occurs as product is stored for extended periods of time is a separate issue from the formation and degradation of these aldehydes.

\subsection{Conclusions}

Hexanal, pentanal, and heptanal were found to be present in all fresh-pack dill pickles tested, which had been packed in glass jars, pasteurized, and analyzed both at the beginning and end of their shelf life. Hexanal and pentanal were present at concentrations several fold higher than their odor detection thresholds. Thus, the levels of aldehydes present shortly after pickles are manufactured should be considered to be part of the normal flavor volatiles of the pickles and not indicative of off flavor. Hexanal and heptanal levels were found to be significantly lower in long term storage samples than in short term storage samples, while pentanal did not change substantially. Therefore, formation of aldehydes is not a factor in the decline in the quality of fresh-pack pickles when they are stored for extended periods of time. Dissolved oxygen levels were very low in all the pickle products, which were analyzed. 


\subsection{References}

Corey, K.A.; Pharr, D.M.; Fleming, H.P. Pressure changes in oxygen-exchanged, brined cucumbers. J. Amer. Hort. Sci. 1983, 108, 61-65.

Fazzalari, F.A. Table 1: Alphabetical Listing of Chemicals with Data and Bibliography. Compilation of Odor and Taste Threshold Values Data; American Society for Testing and Materials: Philadelphia, PA, 1978; pp 8-166

Peng, A.C. Fatty Acids in Vegetables and Vegetable Products. In Fatty Acids in Foods and their Health Implications; Chow, C.K., Ed.; Marcel Dekker, Inc.: New York, 1992; p 202.

Peng, A.C.; Geisman, J.R. Lipid and fatty acid composition of cucumbers and their changes during storage of fresh-pack pickles. J. Food Sci. 1976, 41, 859-862.

Schieberle, P.; Ofner, S.; Grosch, W. Evaluation of potent odorants in cucumbers and muskmelons by aroma extract dilution analysis. J. Food Sci. 1990, 55, 193-195.

Wardale, D.A.; Lambert, E.A. Lipoxygenase from cucumber fruit; location and properties. Phytochem. 1980, 19, 1013-1016.

Zhou, A.; McFeeters, R.F. Volatile compounds in cucumbers fermented in low-salt conditions. J. Agric. Food Chem. 1998, 46, $2117-2122$.

Zhou, A.; McFeeters, R.F.; Fleming, H.P. Development of oxidized odor and volatile aldehydes in fermented cucumber tissue exposed to oxygen. J. Agric. Food Chem. 2000, 48, 193-197. 
Table 2.1. Age (time after packing) of commercial fresh-pack dill pickles upon analysis by GC/MS.

$\begin{array}{ccc}\text { Brand } & \begin{array}{c}\text { Age of "early storage" } \\ \text { samples (days) }\end{array} & \begin{array}{c}\text { Age of "late storage" } \\ \text { samples (days) }\end{array} \\ \text { A } & 31 & 407 \\ \text { B } & 28 & 448 \\ \text { C } & 41 & 344 \\ \text { D } & 38 & 393\end{array}$


Table 2.2. Mean aldehyde concentrations in commercial fresh-pack dill pickles after short term and long term storage.

Short term St. Dev. Long term St. Dev.

Compound storage (ppb)

Hexanal

Heptanal

Pentanal

Combined aldehydes

146

11

149

305

(ppb) storage (ppb)

37

13

37

74

75

3

125

202 (ppb)

48

69 


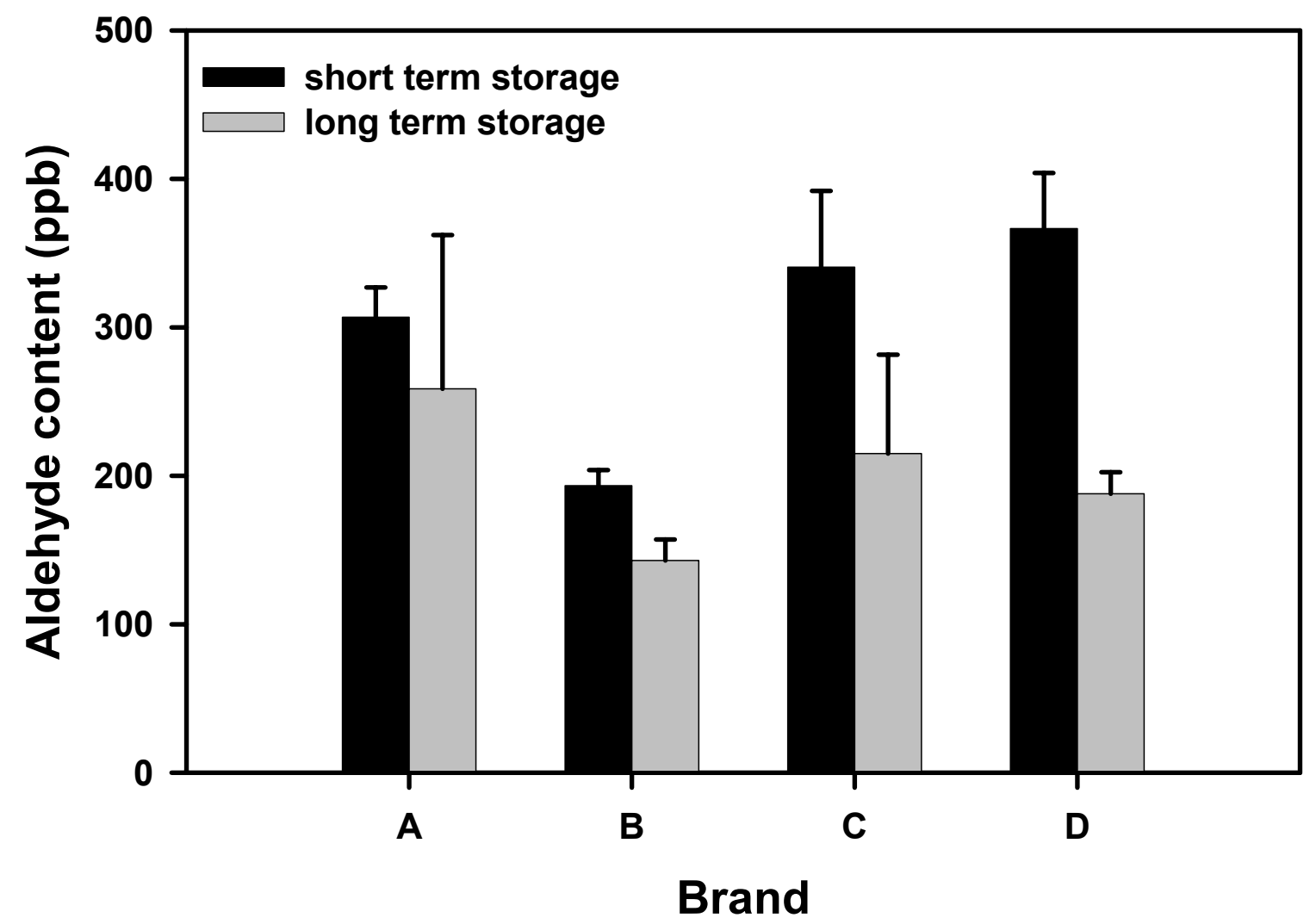

Figure 2.1. Total levels of hexanal, heptanal, and pentanal in commercial fresh-pack dill pickles after short and long term storage, approximately 1 month and 1 year after packing. The bars show the mean of three samples. Error bars show the standard deviation of the aldehyde concentration. 


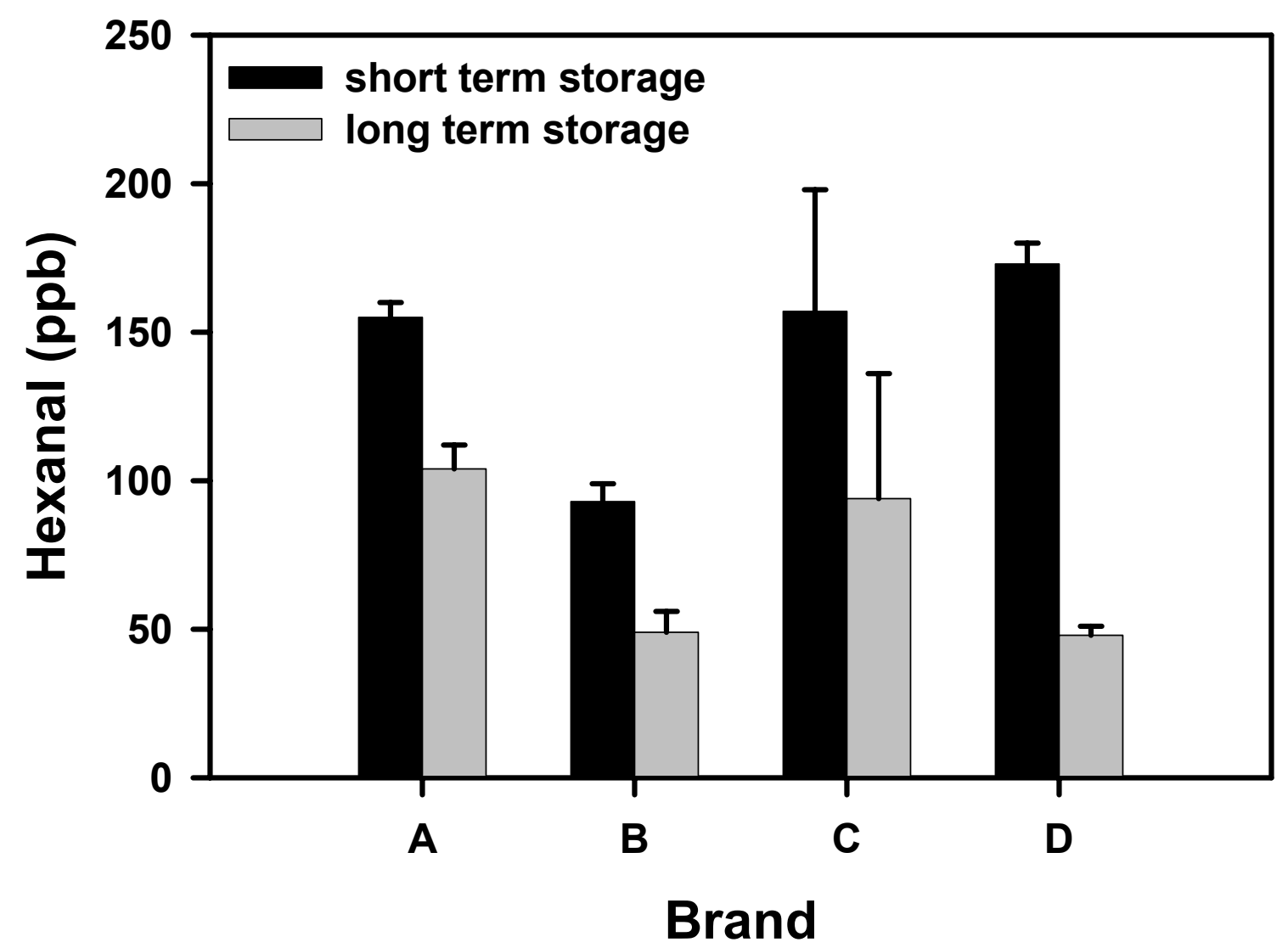

Figure 2.2. Levels of hexanal in commercial fresh-pack dill pickles after short and long term storage, approximately 1 month and 1 year after packing. The bars show the mean of three samples. Error bars show the standard deviation of the hexanal concentration. 


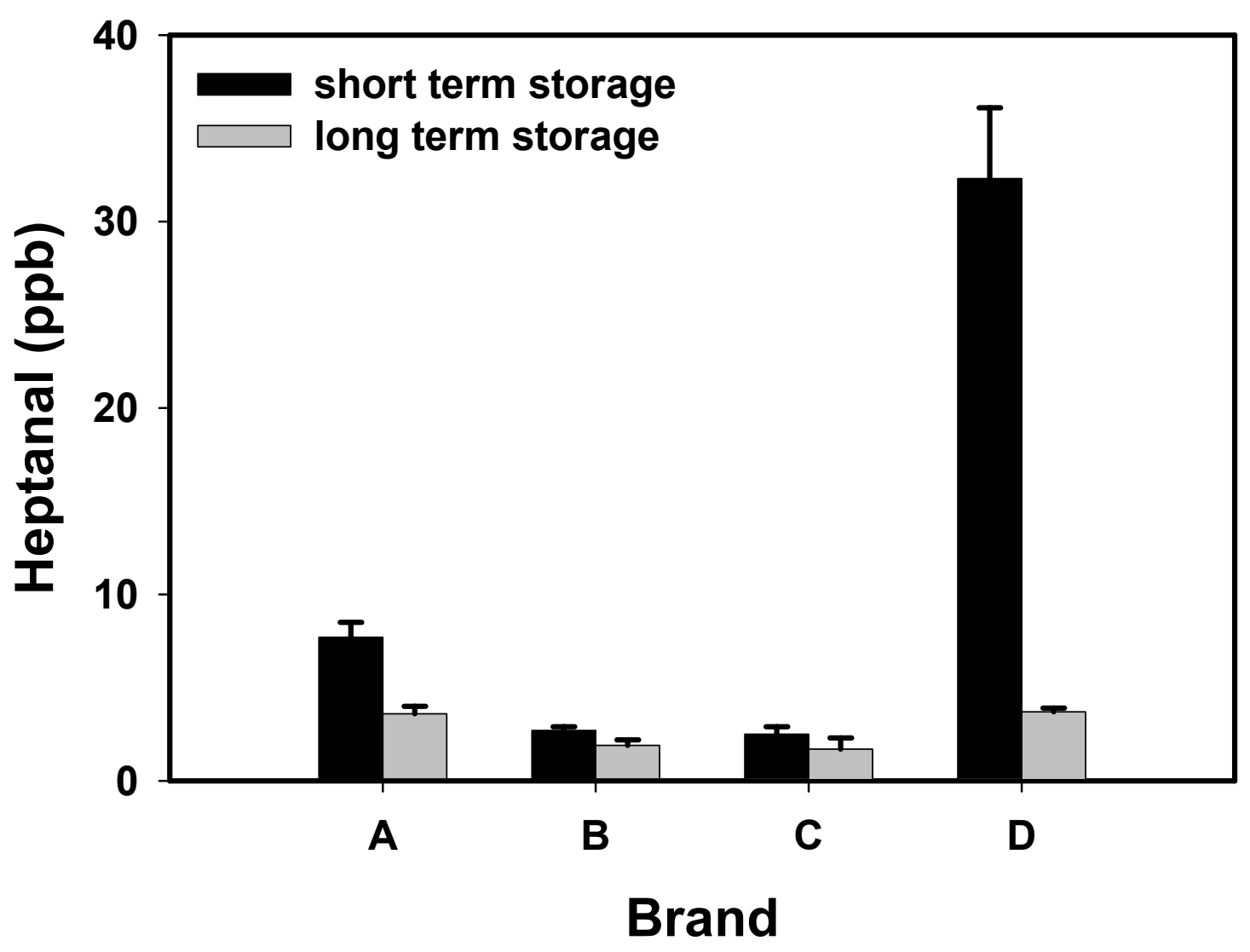

Figure 2.3. Levels of heptanal in commercial fresh-pack dill pickles after short and long term storage, approximately 1 month and 1 year after packing. The bars show the mean of three samples. Error bars show the standard deviation of the heptanal concentration. 


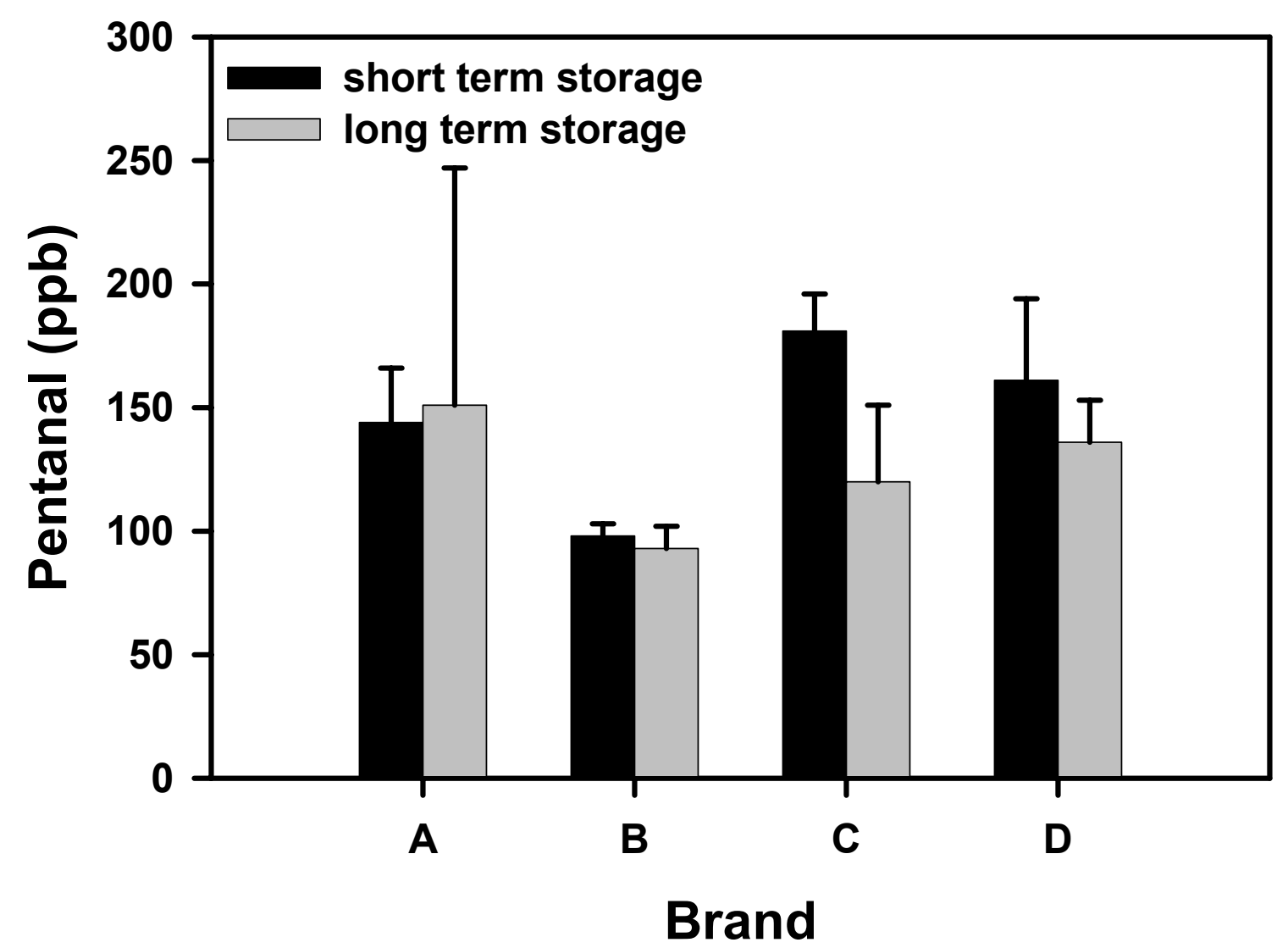

Figure 2.4. Levels of pentanal in commercial fresh-pack dill pickles after short and long term storage, approximately 1 month and 1 year after packing. The bars show the mean of three samples. Error bars show the standard deviation of the pentanal concentration. 


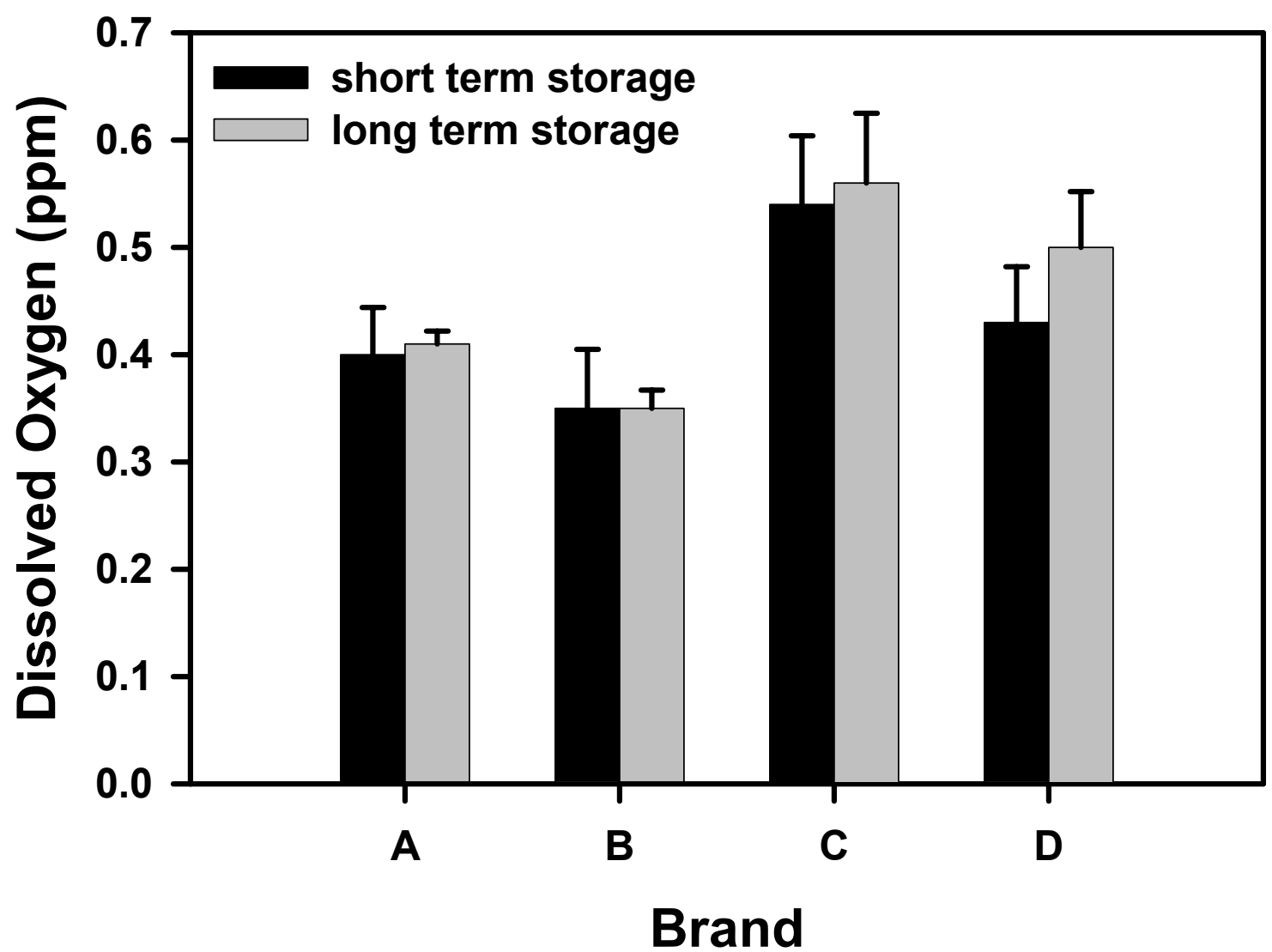

Figure 2.5. Levels of dissolved oxygen in commercial fresh-pack dill pickles after short and long term storage, approximately 1 month and 1 year after packing. The bars show the mean of three samples. Error bars show the standard deviation of the dissolved oxygen concentration. 


\section{Chapter 3}

Formation of Oxidative Aldehydes in Fresh-Pack Dill Pickles 


\subsection{Abstract}

The effect of added oxygen, spices, and turmeric on lipid oxidation in fresh-pack pickles was investigated by monitoring the levels of aldehydes and dissolved oxygen during storage. The oxidative aldehydes hexanal, pentanal, 2-hexenal, and heptanal were detected in all treatments, including containers prepared and stored in strict anaerobic conditions. There was a positive linear correlation between the amount of oxygen injected into jars and the concentrations of hexanal, heptanal, pentanal present after 4 days storage. After 28 days of storage, hexanal and heptanal levels in treatments with injected oxygen had increased, and still showed a positive linear correlation with the amount of oxygen that had initially been injected. There was a negative logarithmic correlation between the amount of turmeric added to pasteurized pickles and the concentrations of hexanal, pentanal, 2-hexenal, and heptanal formed after 2, 6, and 10 weeks of storage. Dissolved oxygen in the cover solution of freshpack dill pickles increased as the concentration of turmeric increased. When turmeric was added at a concentration sufficient for use as a yellow coloring agent $(250 \mathrm{ppm})$, it effectively inhibited aldehyde formation in jars with added oxygen to levels at or near the aldehyde concentrations in jars to which no oxygen was added. When used at or below typical coloring levels, turmeric, a natural yellow colorant traditionally used in pickled cucumbers, appears to be a practical antioxidant to reduce the formation of oxidative offflavors in fresh-pack dill pickles that may result from the oxygen permeability of plastic containers. 


\subsection{Introduction}

Shelf-stable pickles sold directly to consumers are packaged almost exclusively in glass jars up to $3.8 \mathrm{~L}$ (1 gallon) and are pasteurized to assure microbial stability. Currently, plastic containers are under development that can withstand pasteurization processes that assure preservation of fresh-pack pickles. The food service industry presently uses institutional-size plastic pouches, gallon jars, or pails that cannot withstand pasteurization for bulk packaging of non-heated pickled vegetables. These products are preserved only with high acetic acid concentrations, low $\mathrm{pH}(\sim 3.3)$, and the use of preservatives. However, the shelf life of products packed in plastic is shorter than that of products in glass containers. An important factor in reduced shelf life is thought to be migration of oxygen through the plastic containers and closures, which can lead to lipid oxidation. Though by no means the only possible mechanism for product deterioration, formation of off-flavors by lipid oxidation is often a major cause of decline in the quality of the product.

Both enzymatic and non-enzymatic lipid oxidation can form lipid hydroperoxides, which then degrade into various compounds including aldehydes (Nawar, 1996). These aldehydes are normally volatile, and responsible for oxidative off-flavors. As a result, it is common to analyze the aldehydes, particularly hexanal, that are formed to evaluate the progress of oxidation in foods (Christensen and Holmer, 1996; Ekstrand et al., 1993; Min, 1998; Molteberg et al., 1995). Although only about $0.1-0.14 \%$ of the wet weight of cucumbers is comprised of lipids (Peng, 1992), a large fraction of these fatty acids are unsaturated and thus susceptible to lipid oxidation. Zhou et al. (2000a) have shown that several aldehydes, including hexanal, 2-pentenal, 2-hexenal, 2-heptenal, and 2-octenal, formed non-enzymatically when slurries of fermented cucumbers were exposed to oxygen. 
The formation of these aldehydes was shown by sensory analysis to correlate with an increase in oxidized odor.

Extension of shelf life in products packaged in plastic containers would be possible by use of more expensive packaging materials and closures that have very low oxygen permeability. However, use of antioxidants in the products could be a more economical approach if an acceptable, effective antioxidant could be found. Turmeric oleoresin, extracted from the rhizomes of Curcuma domestica, is commonly used as a natural yellow colorant in pickled cucumber products. Curcumin is the major compound responsible for the yellow color of turmeric. In addition to its color, curcumin has also been shown to have high levels of antioxidant activity (Beddows et al., 2000; Lean and Mohamed 1999; Masuda et al., 1992). Zhou et al. (2000b) showed that concentrations of turmeric oleoresin below that used for coloring purposes in cucumber pickle products were effective in inhibiting the formation of oxidative aldehydes in fermented cucumber slurries exposed to oxygen. In contrast, FD\&C yellow \#5, which is also used commercially as a yellow coloring agent for cucumber pickles, did not inhibit oxidation.

The first objective of this research was to identify the aldehydes formed as a result of lipid oxidation in fresh-pack pickles. The second goal was to determine the relationship between the amount of oxygen present in jars of fresh-pack cucumbers and the formation of oxidative aldehydes. The last objective was to determine if turmeric could function effectively as an antioxidant in the presence of an amount of oxygen that might enter a plastic container during a one-year storage period. 


\subsection{Materials and Methods}

Materials. Size 2B cucumbers (35 to $38 \mathrm{~mm}$ diameter), $480 \mathrm{~mL}$ glass jars (16 oz), lids, dill spice oleoresin, turmeric oleoresin, and high fructose corn syrup (Isomerose ${ }^{\mathrm{TM}}$ ) were obtained from a local processor. The turmeric oleoresin used had a curcumin content of $8.5 \%$. The dill spice was used at the recommended concentration of $0.85 \mathrm{~mL}$ spice oil per 1.5 $\mathrm{L}$ of brine solution. Cucumbers were refrigerated until they were cut into $6 \mathrm{~mm}$ thick slices. All chemicals were purchased from Aldrich Chemical Co. (Milwaukee, WI).

Anaerobic filling of jars with cucumbers and cover solution. The following procedure was used to remove the oxygen in jars of cucumbers as they were filled and closed. Oxygen was removed from cover brine solution by deaerating the solution under vacuum in an FS60 sonicator (Fisher Scientific, Pittsburgh, PA) for 1.5 hours. The deaerated solution was distributed into Erlenmeyer flasks (240g/flask) and then transferred into an anaerobic hood along with a separate Erlenmeyer flask that contained a concentrated solution of sodium benzoate. Cucumber slices were packed into $480 \mathrm{~mL}$ jars ( $240 \mathrm{~g}$ cucumber/jar) and also transferred into the hood.

The anaerobic hood (Coy Laboratory Products, Grass Lake, MI) was filled with a $5 \% \mathrm{H}_{2}: 10 \% \mathrm{CO}_{2}: 85 \% \mathrm{~N}_{2}$ anaerobic gas mixture. The oxygen concentration was maintained

at $<1 \mathrm{ppm}$ with a palladium catalyst that catalyzed removal of residual $\mathrm{O}_{2}$ by reaction with $\mathrm{H}_{2}$ to form water. A heater inside the hood was used to maintain the temperature at $30^{\circ} \mathrm{C}$.

Materials were introduced into the hood in an ante chamber where a vacuum was created and then released two times with $\mathrm{N}_{2}$ gas followed by one exchange with the anaerobic gas mixture to remove most of the oxygen before containers were transferred into the hood. The cover brine, sodium benzoate solution and cucumber slices were held inside the hood for 3 
$\mathrm{hr}$, then a flask of brine was poured into each jar along with a few milliliters of sodium benzoate solution. The jars were tightly closed inside the hood using either standard commercial lids or, for those containers that were to be injected with oxygen after filling, lids that had a flanged rubber septum inserted (Fisher Scientific, Pittsburgh, PA).

Addition of oxygen to jars of preserved cucumbers. A known volume of oxygen at $23^{\circ} \mathrm{C}, 1.003 \mathrm{~atm}$ was injected into the jars through a rubber septum fitted into the lids. To be sure pure oxygen was injected the needle of a gas tight syringe with the plunger down was inserted through the wall of Tygon plastic tubing as oxygen was flowing through the tubing. The syringe was filled with oxygen and then locked to prevent gas further gas exchange. The needle was removed from the tubing, inserted into the jar septum, the syringe was unlocked, and the oxygen injected into the jar. The septum was then caulked to minimize further gas transfer.

Measurement of dissolved oxygen. Dissolved oxygen was measured immediately after opening a jar of stored cucumbers. Dissolved oxygen in the brine was measured using an Oxi330i oxygen meter equipped with a StirrOxG galvanic oxygen probe (Wissenschaftlich-Technische Werkstätten, Weilheim, Germany).

Sampling, identification, and measurement of volatile aldehydes. Measurement of volatile components was carried out by modification of the procedure of Zhou et al. (2000a). Samples for volatile component analysis were prepared by transfer of the entire contents of a $480 \mathrm{~mL}$ jar of pickles into a Waring blender. The cucumber tissue and brine were homogenized for $7 \mathrm{sec}$. Slurry $(10 \mathrm{~g})$ was transferred to a $25 \mathrm{~mL}$ fritless sparger (Angel Inc., Panorama City, CA), then spiked directly with $50 \mu \mathrm{L}$ of $11.4 \mathrm{ppm}$ toluene- $\mathrm{d}_{8}$ as the internal standard. The sparging tube was attached to a CDS 6000 purge and trap sampler 
(CDS Analytical Inc., Oxford, PA). After 1 min preheating at $30^{\circ} \mathrm{C}$, volatile components were removed from the sample slurry by bubbling helium gas through the slurry at a flow rate of $40 \mathrm{~mL} \mathrm{~min}^{-1}$ for $30 \mathrm{~min}$. Volatiles were adsorbed on a Tenax trap (Supelco Inc., Bellefone, PA) held at $40^{\circ} \mathrm{C}$ during purging. The Tenax trap was dried for 3 min to remove trapped water, heated at $180^{\circ} \mathrm{C}$ for 6 min with a helium flow rate of $4.0 \mathrm{~mL} \mathrm{~min}{ }^{-1}$ to desorb trapped volatiles, then baked at $250^{\circ} \mathrm{C}$ for 5 min to clean the trap for the next sample.

Desorbed volatile compounds were delivered without splitting to a $30 \mathrm{~m}$ x $0.25 \mathrm{~m}$ i.d., $0.25 \mu \mathrm{m}$ film thickness HP-5MS capillary column (Hewlett-Packard, Palo Alto, CA). The GC/MS system consisted of an HP 5890 II chromatograph with an HP 5972 mass selective detector (MSD) (Hewlett-Packard, Palo Alto, CA). The oven temperature was held at $-20^{\circ} \mathrm{C}$ during the $4.5 \mathrm{~min}$ volatile component desorption period with a $4.0 \mathrm{~mL} \mathrm{~min}^{-1}$ helium flow rate. The oven temperature was programmed to increase from $-20^{\circ} \mathrm{C}$ to $140^{\circ} \mathrm{C}$ at $10^{\circ} \mathrm{C} \min ^{-1}$ with a 1 min hold at $140^{\circ} \mathrm{C}$. Oven temperature then increased from $140^{\circ} \mathrm{C}$ to $220^{\circ} \mathrm{C}$ at $40^{\circ} \mathrm{C}$ $\min ^{-1}$ with a final hold of $3.5 \mathrm{~min}$. Helium carrier gas was used at a constant flow rate of 1.0 $\mathrm{mL} \min ^{-1}$. MSD settings were as follows: MS interface and ionization source temperature, $280^{\circ} \mathrm{C}$; electronic ionization voltage, $70 \mathrm{eV}$; scanning mass range, $35-350$ daltons. The electron multiplier voltage was set 200 volts above the voltage selected by the "Maximum Autotuning" procedure.

Identification of oxidative aldehydes was based upon preliminary identification using the NIST/EPA/NIH Mass Spectral Library (2002) with HP G1701BA ChemStation software (version B.00.00) (Hewlett-Packard, Palo Alto, CA). Identification was confirmed by matching both retention times and fragmentation patterns with standard aldehydes. 
Concentrations of aldehydes were calculated based upon peak areas relative to the peak area of the internal standard. Standard curves were prepared for each aldehyde (hexanal, pentanal, 2-hexenal and heptanal) by making known additions of three concentrations of each aldehyde to a baseline cucumber slurry and calculating the linear regression equation for each analyte. The three concentrations of each analyte were chosen to encompass the range of aldehyde levels present in all samples.

Effect of oxygen addition on aldehyde formation in preserved cucumbers. Jars of acidified cucumbers were prepared anaerobically. Equal weights of cucumber slices and brine were packed so that the equilibrated components contained $0.12 \% \mathrm{CaCl}_{2}, 0.57 \%$ glacial acetic acid, $2 \% \mathrm{NaCl}$, and $1.75 \%$ high fructose corn syrup. Three milliliters of $1.92 \mathrm{M}$ sodium benzoate solution was added to each jar so that the equilibrated concentration was 12 $\mathrm{mM}$. This prevented microbial growth in the containers during the duration of the experiment. A control treatment without added oxygen plus treatments with $2.5 \mathrm{~mL}, 5.0 \mathrm{~mL}$ and $10 \mathrm{~mL}$ added oxygen were prepared. In addition, one set of jars was filled outside the anaerobic hood without any effort to exclude air from the containers. None of the jars were pasteurized. The jars were stored at $30^{\circ} \mathrm{C}$. Three jars of each treatment were analyzed for dissolved oxygen and volatile components at 4 and 28 days after filling the jars.

\section{Effect of turmeric concentration on formation of aldehydes in pasteurized}

cucumbers. Cucumber slices were packed aerobically in $480 \mathrm{~mL}$ jars and covered with a brine solution so that the components equilibrated at $0.12 \% \mathrm{CaCl}_{2}, 0.57 \%$ glacial acetic acid, $2 \% \mathrm{NaCl}$, and $1.75 \%$ high fructose corn syrup, a standard amount of dill spice, and turmeric oleoresin levels to equilibrate at $0,16,40,100$ and $250 \mathrm{ppm}$. These jars were filled with 230 $\mathrm{g}$ cucumber slices and $230 \mathrm{~g}$ cover brine to allow an additional $20 \mathrm{~mL}$ headspace in the jar 
for injection of oxygen. Two additional treatments were prepared with the same headspace in the jars. One treatment had neither dill spice nor turmeric added, and the second had 250 ppm turmeric added, but no dill spice. The jars were closed with lids that had a septum to allow for oxygen injection. Two more treatments were prepared with minimal headspace by filling the jars with $240 \mathrm{~g}$ cucumber slices and $240 \mathrm{~g}$ of cover brine solution. To one of these minimal headspace treatments, neither dill spice nor turmeric was added to the cover solution. The other cover solution contained the standard amount of dill spice and $250 \mathrm{ppm}$ turmeric. No oxygen was added to these two treatments so the jars were closed with lids that did not have a septum. All jars were pasteurized to a center temperature of $74^{\circ} \mathrm{C}$ for 15 minutes. After cooling, $30 \mathrm{~mL} \mathrm{O}_{2}$ gas was injected into all jars with a $20 \mathrm{~mL}$ headspace. This amount of oxygen was selected to be similar to the amount of oxygen estimated to enter a moderately permeable plastic container and closure during a one year storage period (John Tobias, personal communication). All treatments were stored at $30^{\circ} \mathrm{C}$. Triplicate jars of the 9 total treatments were analyzed for dissolved oxygen and volatile aldehydes at each sampling time. Analyses were done at 2, 6, and 10 weeks after packing. The experiment was duplicated with two different lots of cucumbers.

Statistical analysis. All statistical analysis was carried out using SAS (Version 8) (SAS Inc., Cary, NC). The ANOVA procedure in SAS was used to determine differences among treatments. For anaerobic treatments with oxygen added, the general linear model procedure was used with one class variable (time) at two levels, 4 and 28 days, regressed over the continuous variable, oxygen. The interaction term was the test for homogeneity of slopes. 


\subsection{Results}

Hexanal, pentanal, 2-hexenal, and heptanal were identified in all pickle samples, including pasteurized and non-pasteurized samples, treatments with and without dill spice and turmeric oleoresins, and treatments with various levels of oxygen. This includes samples, which were prepared and stored in an anaerobic hood to strictly exclude oxygen.

Figs. 3.1-3.3 show that at 4 days after packing, aldehyde concentrations increased linearly $(\mathrm{p} \leq 0.01)$ as the amount of oxygen in the jars increased. At 28 days after packing and acidification of the cucumbers, treatments with added oxygen had higher hexanal and heptanal concentrations than at 4 days of storage. The concentrations of these aldehydes increased linearly with the amount of oxygen initially added to the jars. In contrast, the pentanal concentration declined several fold between 4 days and 28 days of storage in all treatments (Fig. 3.3). Furthermore, after 28 days the pentanal concentrations were not significantly different among treatments, so there was no correlation with the amount of oxygen that had initially been injected (Fig. 3.3). In these treatments, 2-hexenal was detected but not quantified.

Four days after packing, the dissolved oxygen in the cover solution was positively correlated with the amount of oxygen that had initially been injected (Fig. 3.4). However, oxygen concentrations after 28 days were not significantly different among treatments, regardless of the amount of oxygen initially added. The mean concentration of dissolved oxygen over all treatments after 28 days was $0.63 \pm 0.06 \mathrm{ppm}$.

In addition to the treatments packed in the anaerobic hood, a set of non-pasteurized samples was prepared in air. The oxygen present in these jars was calculated to be 0.35 mmole, based upon the dissolved oxygen measured in the cover solution, plus the oxygen gas 
present in the cucumbers (Corey et al., 1983; Fleming and Pharr, 1980) and in the headspace. These sources of oxygen contributed 15,39 , and $46 \%$, respectively, to the total oxygen content of the jar. The concentrations of aldehydes formed in these samples (Table 3.1) were compared to the concentrations predicted based upon the regression equations for the aldehyde concentrations formed in the treatments injected with increasing amounts of oxygen. After 4 days of storage, hexanal and heptanal levels in the air-packed samples were higher than predicted based on the relationship of aldehyde concentrations to added oxygen. After 28 days of storage, heptanal levels were within the $95 \%$ confidence interval of the predicted levels, while hexanal was just under the lower $95 \%$ confidence interval. Pentanal levels were within the $95 \%$ confidence interval at both time points. Mean dissolved oxygen levels in the jars filled in air were $0.64 \pm 0.07 \mathrm{ppm}$ after 4 days of storage and $0.55 \pm 0.03$ ppm after 28 days of storage. These concentrations were not significantly different.

The effectiveness of turmeric as an antioxidant in fresh-pack dill pickles was evaluated by addition of turmeric, along with a typical commercial dill spice formulation, to pasteurized pickles. Two replications of this experiment were performed using two different lots of cucumbers. There were no significant differences between the two replications. Treatments were prepared with multiple levels of turmeric oleoresin. The pasteurized pickles were put under oxidative stress by injection of oxygen into the containers to simulate the amount of oxygen that might migrate into a plastic jar during one year of storage. Formation of hexanal, pentanal, 2-hexenal and heptanal decreased logarithmically as the turmeric concentration increased (Figs. 3.5-3.8). This relationship between aldehyde concentration and turmeric concentration was maintained during the 10 week storage period. At the highest turmeric concentrations, aldehyde levels remained constant during storage. 
Dissolved oxygen levels showed a trend opposite that of aldehyde concentrations, in that oxygen increased logarithmically as turmeric concentration increased (Fig. 3.9). Dissolved oxygen levels decreased during the storage period.

Comparisons of results from the four additional turmeric treatments along with the 0 ppm and 250 ppm turmeric treatments described above are shown in Figs. 3.10-3.14. Because there were not many significant differences over time within each treatment, the mean aldehyde concentrations of the three time points are shown in these figures. There were no significant differences in hexanal or heptanal levels over time within treatments. All aldehydes displayed the same trend. The treatments which had both oxygen injected and turmeric present had aldehyde levels similar to those treatments which did not have injected oxygen, regardless of whether or not spices were present in the oxygen treatments. Treatments, which had oxygen injected but did not contain turmeric had significantly higher aldehyde levels than treatments that contained turmeric and/or did not receive injected oxygen.

In these six treatments, similar to the treatments with varying turmeric levels, dissolved oxygen levels displayed trends opposite that of the aldehyde levels (Fig. 3.14). Treatments that contained turmeric tended to have higher dissolved oxygen levels. Treatments that did not have oxygen injected had the lowest dissolved oxygen levels, followed by those which had oxygen injected but no turmeric present.

\subsection{Discussion}

In all pickle samples analyzed, hexanal, pentanal, 2-hexenal, and heptanal were found. These were different than the aldehydes that have been found in fermented cucumber 
slurries exposed to high oxygen levels (Zhou et al., 2000a). Pentanal and heptanal, found in the fresh-pack pickles investigated here, were not found in the fermented cucumber slurries. The unsaturated aldehydes 2-pentenal, 2-heptenal, and 2-octenal were found in the oxidized fermented cucumber slurries, but were not found in these fresh-pack pickles.

The four aldehydes quantified in this work, along with other aldehydes, have been identified and used as indicators of lipid oxidation in other foods. Pentanal and hexanal, along with 1-octen-3-ol, nonanal, and octanal, have been used to monitor lipid oxidation and warmed over flavor in pork (O'Sullivan et al., 2003). Pentanal and hexanal have been used to test for lipid oxidation in milk and in peanuts (Jeon and Bassette, 1984; Marsili, 1999). Hexanal, 2-hexenal, and 2-octenal were used to monitor lipid oxidation in dry fermented sausages (Maguerza et al., 2003). Heptanal and hexanal have been used as indicators of lipid oxidation in oil emulsions, salami, and whey protein concentrate (Jo and Ahn, 2000; Lee and Morr, 1995; Meynier, 1999).

Given the association of the aldehydes detected in acidified cucumbers with lipid oxidation, their occurrence in jars of cucumber slices that were filled and stored anaerobically was unexpected. Especially surprising was that over $700 \mathrm{ppb}$ pentanal was formed within 4 days of packing (Fig 3.3). Between 4 and 28 days of anaerobic storage, hexanal and heptanal concentrations did not change, but pentanal declined to less than 200 ppb (Fig 3.1-3.3). Lipid oxidation as a result of residual oxygen in the acidified cucumbers was not considered to be possible because any oxygen that might have remained in the cucumber slices after the three vacuum exchanges with oxygen-free gases before they were transferred into the anaerobic hood would have been utilized by the respiration of the cucumber tissue within minutes (Saltveit and McFeeters, 1980). The present results do not 
exclude the possibility that aldehydes may have been present in the cucumbers prior to removal of oxygen. However, Zhou and McFeeters (1998) found hexanal, but not pentanal, 2-hexenal, or heptanal in fresh cucumber slurries. Formation of "oxidative aldehydes" anaerobically suggests a previously unrecognized mechanism for their synthesis. One possibility might be that lipid hydroperoxides were present in the cucumber tissues and that the hydroperoxides degraded in the acidified cucumbers, forming aldehydes. There have been no published reports of the changes in volatile components of processed products stored in anaerobic conditions. Mattheis et al. (1991) analyzed the volatiles of fresh apples stored in $1.5 \%$ oxygen compared to $0.05 \%$ oxygen. A large amount of acetaldehyde was formed from ethanol that accumulated in the apple tissue. However, production of saturated aldehydes in the apples from hexanal $\left(\mathrm{C}_{6}\right)$ to decanal $\left(\mathrm{C}_{10}\right)$ declined to very low levels in the $0.05 \%$ oxygen atmosphere compared to apples stored in $1.5 \%$ oxygen.

Despite the presence of aldehydes in the anaerobic acidified cucumbers, the addition of oxygen was clearly responsible for a linear increase in aldehyde formation (Figs. 3.1-3.3). Therefore, the increases in the concentrations of these aldehydes during storage can still be considered to be an indicator of lipid oxidation. Increases in aldehyde levels with increasing oxygen present during product storage have been previously reported in stored nuts and cream powder. Maté et al. (1996) found that over an 8-week time period, hexanal levels in roasted peanuts and walnuts stored in high-oxygen atmospheres were higher than in those stored in low-oxygen atmospheres. They concluded that by decreasing the oxygen concentration surrounding roasted peanuts and walnuts, the oxidative rancidity process could be controlled. When working with cream powder, Andersson and Lingnert (1998) found a 
positive relationship between initial oxygen concentration in the headspace of stored cream powder and formation of hexanal.

Due to its known antioxidant properties (Jitoe et al., 1992; Lean et al., 1999; Zhou et al., 2000b), turmeric was evaluated for its ability to inhibit formation of additional oxidative aldehydes in the presence of an amount of oxygen that might be expected to diffuse into plastic containers during a year of storage. With the addition of 1.3 mmole of oxygen into jars of fresh-pack pickles with no added antioxidants, aldehyde concentrations increased several fold compared to samples with no added oxygen. The addition of increasing amounts of turmeric up to a concentration that would be typical of that used for coloring purposes resulted in a logarithmic decrease in the formation of oxidative aldehydes (Fig 3.5-3.8). Addition of $250 \mathrm{ppm}$ turmeric to pickles with 1.3 mmoles of additional oxygen prevented aldehyde formation above that which was formed when no additional oxygen was added (Figs. 3.10-3.13). In the treatment containing $250 \mathrm{ppm}$ turmeric, hexanal concentrations remained unchanged during 10 weeks of storage, and the other aldehydes changed minimally (Figs 3.5-3.8). Addition of dill spice caused some reduction in aldehyde formation in high oxygen samples. However, when turmeric was added, the additional antioxidant effect of the dill spice was negligible (Figs. 3.10-3.13). The fact that dissolved oxygen in the pickle brines increased with the concentration of added turmeric (Fig. 3.9) suggested that it prevented the reaction of oxygen with the cucumber lipids. However, dissolved oxygen did decrease moderately during the 10 week storage period (Fig. 3.9).

These results suggest that turmeric at reasonable use levels would be effective in preventing formation of oxidative aldehydes in plastic containers that have substantial oxygen permeability. Since turmeric is an ingredient with a long history of use as a coloring 
agent in pickled cucumbers, it would be a compatible natural antioxidant for fresh-pack dill pickles.

\subsection{Conclusions}

Increasing amounts of injected oxygen were found to have a positive effect on the formation of the aldehydes hexanal, heptanal, and pentanal in fresh-pack pickles packed under anaerobic conditions. At 4 days after packing, hexanal, heptanal and pentanal levels were positively correlated with the amount of oxygen that had initially been injected. After 28 days hexanal and heptanal had increased and were positively correlated with oxygen, while pentanal decreased and was not different among treatments. These aldehydes were also found in fresh-pack pickles that were packed under anaerobic conditions and had no oxygen injected, thus indicating that they are either present in fresh cucumbers or formed during the acidification of the cucumbers, presumably not by lipid oxidation.

Hexanal, pentanal, 2-hexenal, and heptanal levels were negatively correlated with turmeric in fresh-pack dill pickles with oxygen injected into the jar, indicating that turmeric is an effective antioxidant. Dissolved oxygen levels were positively correlated with turmeric, further indicating the effectiveness of turmeric. At coloring levels (250 ppm), turmeric inhibited aldehyde formation in jars with added oxygen to levels at or near those in jars with no added oxygen and also commercial samples. Turmeric at or below coloring levels appears to be a feasible antioxidant to add to fresh-pack dill pickles to minimize the formation of oxidative off-flavors that may result from the oxygen permeability of plastic containers. 


\subsection{References}

Andersson, K.; Lingnert, H. Influence of oxygen concentration and light on the oxidative stability of cream powder. Lebensm.-Wiss. u.-Technol. 1998, 31, 169-176.

Beddows, C.G.; Jagait, C.; Kelly, M.J. Preservation of $\alpha$-tocopherol in sunflower oil by herbs and spices. Int. J. Food Sci. Nutr. 2000, 51, 327-339.

Christensen, T.C.; Holmer, G. GC/MS analysis of volatile aroma components in butter during storage in different catering packaging. Milchwissenschaft. 1996, 51, 134-139.

Corey, K.A.; Pharr, D.M.; Fleming, H.P. Pressure changes in oxygen-exchanged, brined cucumbers. J. Amer. Hort. Sci. 1983, 108, 61-65.

Ekstrand, B.; Gangby, I.; Akesson, G.; Stollman, U.; Lingnert, H.; Dahl, S. Lipase activity and development of rancidity in oats and oat products related to heat treatment during processing. J. Cereal Sci. 1993, 17, 247-254.

Fleming, H.P.; Pharr, D.M. Mechanism for bloater formation in brined cucumbers. J. Food Sci. 1980, 45, 1595-1600.

Jeon, I.J.; Bassette, R. Analysis of n-pentanal and hexanal as indices of potato chip shelflife. J. Food Qual. 1984, 7, 97-105.

Jitoe, A.; Masuda, T.; Tengah, I.G.P.; Suprapta, D.N.; Gara, I.W.; Nakatani, N. Antioxidant activity of tropical ginger extracts and analysis of the contained curcuminoids. J. Agric. Food Chem. 1992, 40, 1337-1340.

Jo, C.; Ahn, D.U. Production of volatile compounds from irradiated oil emulsion containing amino acids or proteins. J. Food Sci. 2000, 65, 612-616.

Lean, L.P.; Mohamed, S. Antioxidative and antimycotic effects of turmeric, lemon-grass, betel leaves, clove, black pepper leaves and Garcinia atriviridis on butter cakes. J. Sci. Food Agric. 1999, 79, 1817-1822.

Lee, Y.B.; Morr, C.V. Headspace volatile compounds of whey protein concentrate subjected to an accelerated storage condition. Foods and Biotech. 1995, 4, 249-252.

Maguerza, E.; Ansorena, D.; Bloukas, J.G.; Astiasaran, I. Effect of fat level replacement of pork backfat with olive oil on the lipid oxidation and volatile compounds of Greek dry fermented sausages. J. Food Sci. 2003, 68, 1531-1536.

Marsili, R.T. Comparison of solid-phase microextraction and dynamic headspace methods for the chromatographic-mass spectrometric analysis of light-induced lipid oxidation products in milk. J. Chromatogr. Sci. 1999, 37, 17-23. 
Masuda, T.; Isobe, J.; Jitoe, A.; Nakatani, N. Antioxidative curcuminoids from rhizomes of Curcuma xanthorrhiza. Phytochem. 1992, 31, 3645-3647.

Maté, J.I.; Saltveit, M.E.; Krochta, J.M. Peanut and walnut rancidity: effects of oxygen concentration and relative humidity. J. Food Sci. 1996, 61, 465-468.

Mattheis, J.P.; Buchanan, D.A.; Fellman, J.K. Change in apple fruit volatiles after storage in atmospheres inducing anaerobic metabolism. J. Agric. Food Chem. 1991, 39, 1602-1605.

Meynier, A.; Novelli, E.; Chizzolini, R.; Zanardi, E.; Gandemer, G. Volatile compounds in commercial milano salami. Meat Sci. 1999, 51, 175-183.

Min, D.B. Lipid Oxidation of Edible Oil. In Food Lipids; Akoh, C.C., Min, D.B., Eds.; Marcel Dekker, Inc.: New York, 1998; pp 283-296.

Molteberg, E.L.; Vogt, G.; Milsson, A.; Frolich, W. Effects of storage and heat processing on the content and composition of free fatty acids in oats. Cereal Chem. 1995, 72, 88-93.

Nawar, W.F. Lipids. In Food Chemistry, $3^{\text {rd }}$ ed.; Fennema, O.R., Ed.; Marcel Dekker, Inc.: New York, 1996; pp 254-288.

O’Sullivan, M.G.; Byrne, D.V.; Jensen, M.T.; Anderson, H.J.; Vestergaard, J. A comparison of warmed-over flavor in pork by sensory analysis, GC/MS and the electronic nose. Meat Sci. 2003, 65, 1125-1138.

Peng, A.C. Fatty Acids in Vegetables and Vegetable Products. In Fatty Acids in Foods and their Health Implications; Chow, C.K., Ed.; Marcel Dekker, Inc.: New York, 1992; p 202.

Saltveit, M.E.; McFeeters, R.F. Polygalacturonase activity and ethylene synthesis during cucumber fruit development and maturation. Plant Physio. 1980, 66, 1019-1023.

Zhou, A.; McFeeters, R.F. Volatile compounds in cucumbers fermented in low-salt conditions. J. Agric. Food Chem. 1998, 46, $2117-2122$.

Zhou, A.; McFeeters, R.F.; Fleming, H.P. Development of oxidized odor and volatile aldehydes in fermented cucumber tissue exposed to oxygen. J. Agric. Food Chem. 2000, 48, 193-197.

Zhou, A.; McFeeters, R.F.; Fleming, H.P. Inhibition of formation of oxidative volatile components in fermented cucumbers by ascorbic acid and turmeric. J. Agric. Food Chem. 2000, 48, 4910-4912. 
Table 3.1. Observed and predicted aldehyde levels in fresh-pack pickle samples closed in normal atmospheric conditions with no dill spices or turmeric added, and predicted aldehyde values based on regression equations and calculated $0.35 \mathrm{mmole}$ oxygen in the jar upon closing. An * indicates that the actual level fell within the $95 \%$ confidence interval for the predicted level of the same aldehyde at the same time point.

\begin{tabular}{|c|c|c|c|c|c|c|}
\hline Compound & $\begin{array}{r}\text { Obs. Conc. } \\
4 \text { days } \\
(p p b)\end{array}$ & $\begin{array}{r}\text { S.D. } \\
4 \text { days } \\
\text { (ppb) }\end{array}$ & $\begin{array}{r}\text { Pred. Conc. } \\
4 \text { days } \\
(p p b)\end{array}$ & $\begin{array}{r}\text { Obs. Conc. } \\
28 \text { days } \\
(p p b)\end{array}$ & $\begin{array}{r}\text { S.D } \\
28 \text { days } \\
(p p b)\end{array}$ & $\begin{array}{r}\text { Pred. Conc. } \\
28 \text { days } \\
(\mathrm{ppb})\end{array}$ \\
\hline Hexanal & 379.4 & 48.7 & 211.9 & 647.8 & 141.3 & 742.8 \\
\hline Heptanal & 5.0 & 0.6 & 2.6 & $4.2^{*}$ & 1.2 & 4.6 \\
\hline Pentanal & $1147.2^{*}$ & 109.8 & 1088.0 & $212.8^{*}$ & 48.5 & 213.7 \\
\hline
\end{tabular}




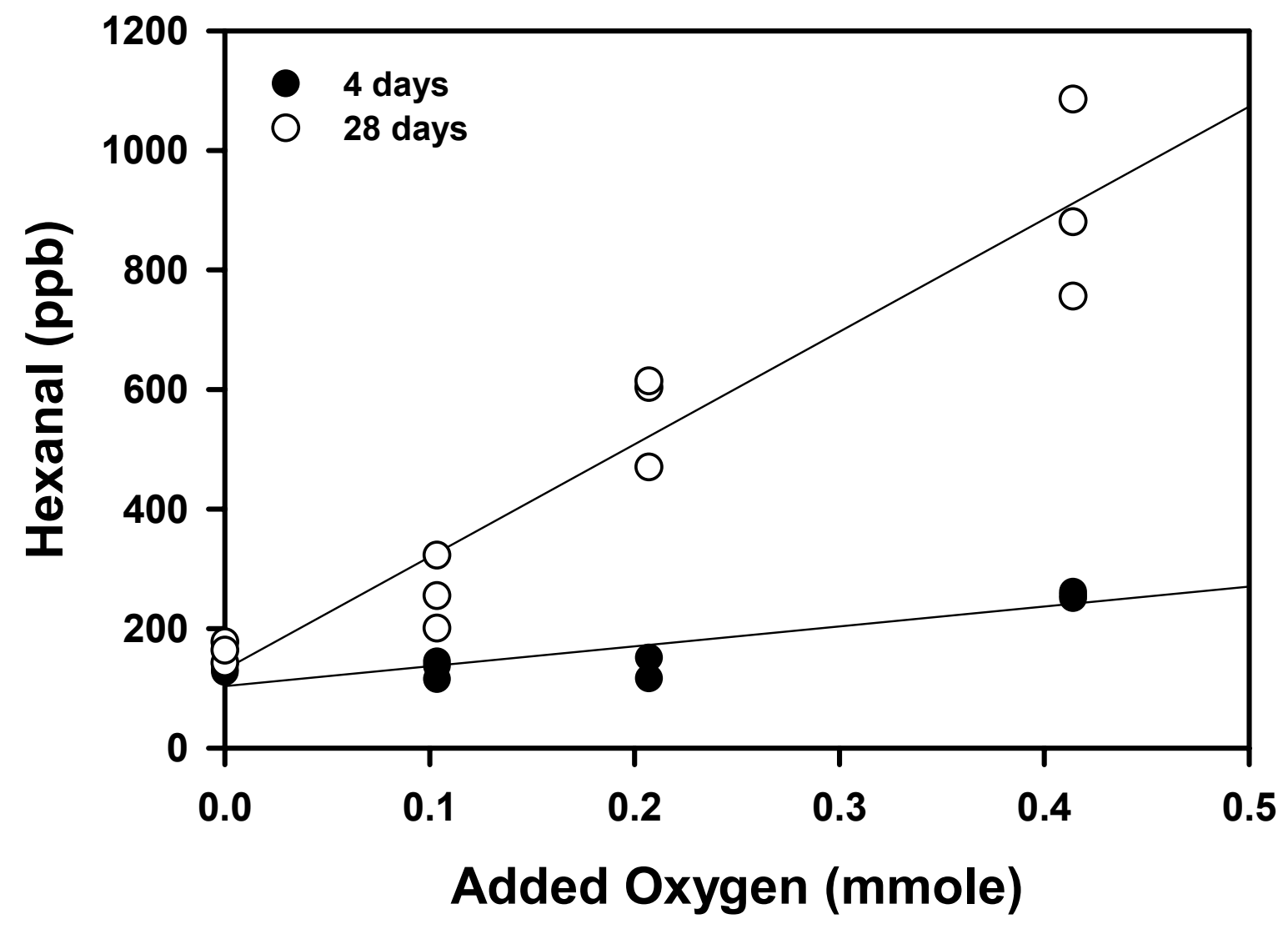

Figure 3.1. Effect of added oxygen on hexanal levels in anaerobically packed fresh-pack pickles 4 and 28 days after packing. 


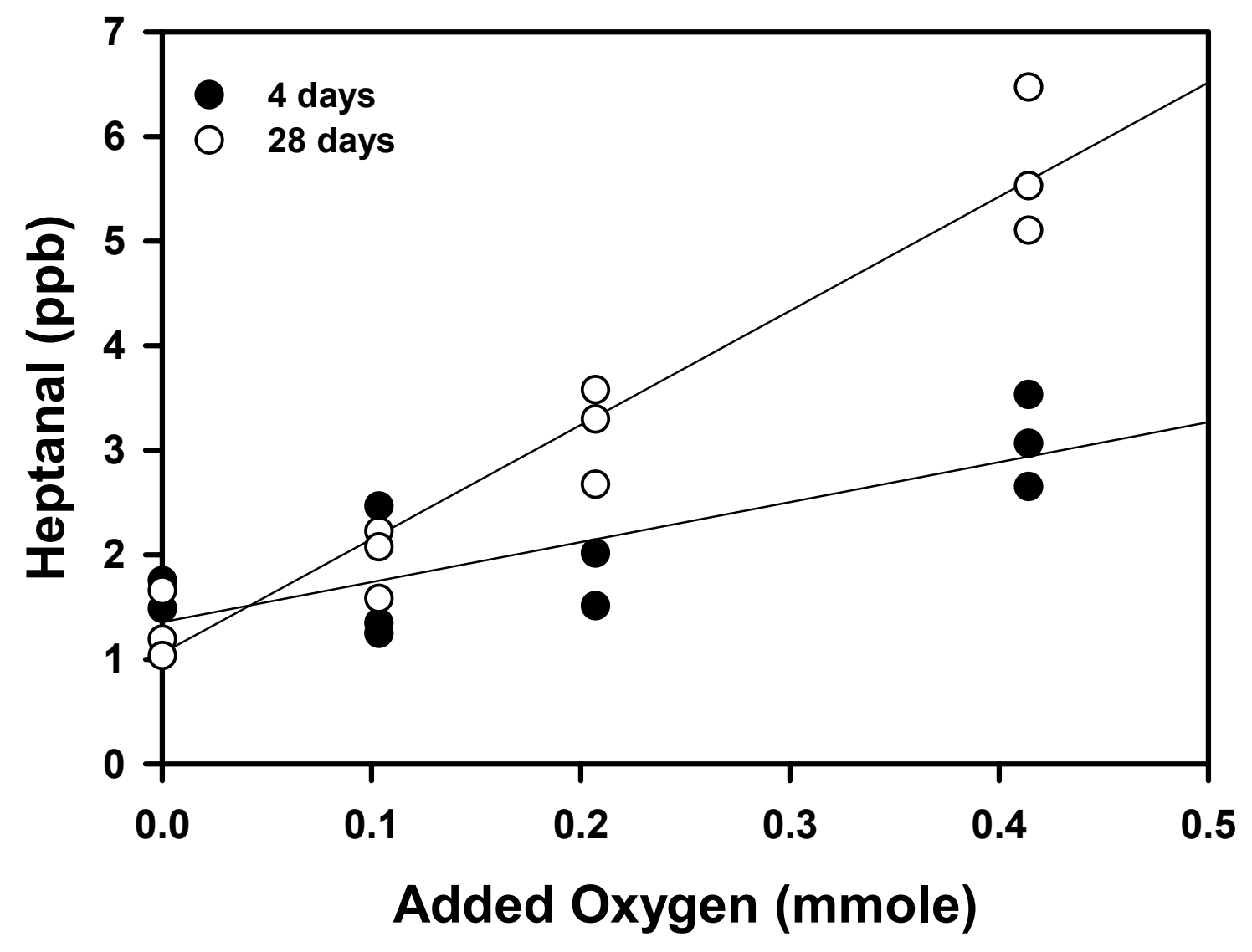

Figure 3.2. Effect of added oxygen on heptanal levels in anaerobically packed fresh-pack pickles 4 and 28 days after packing. 


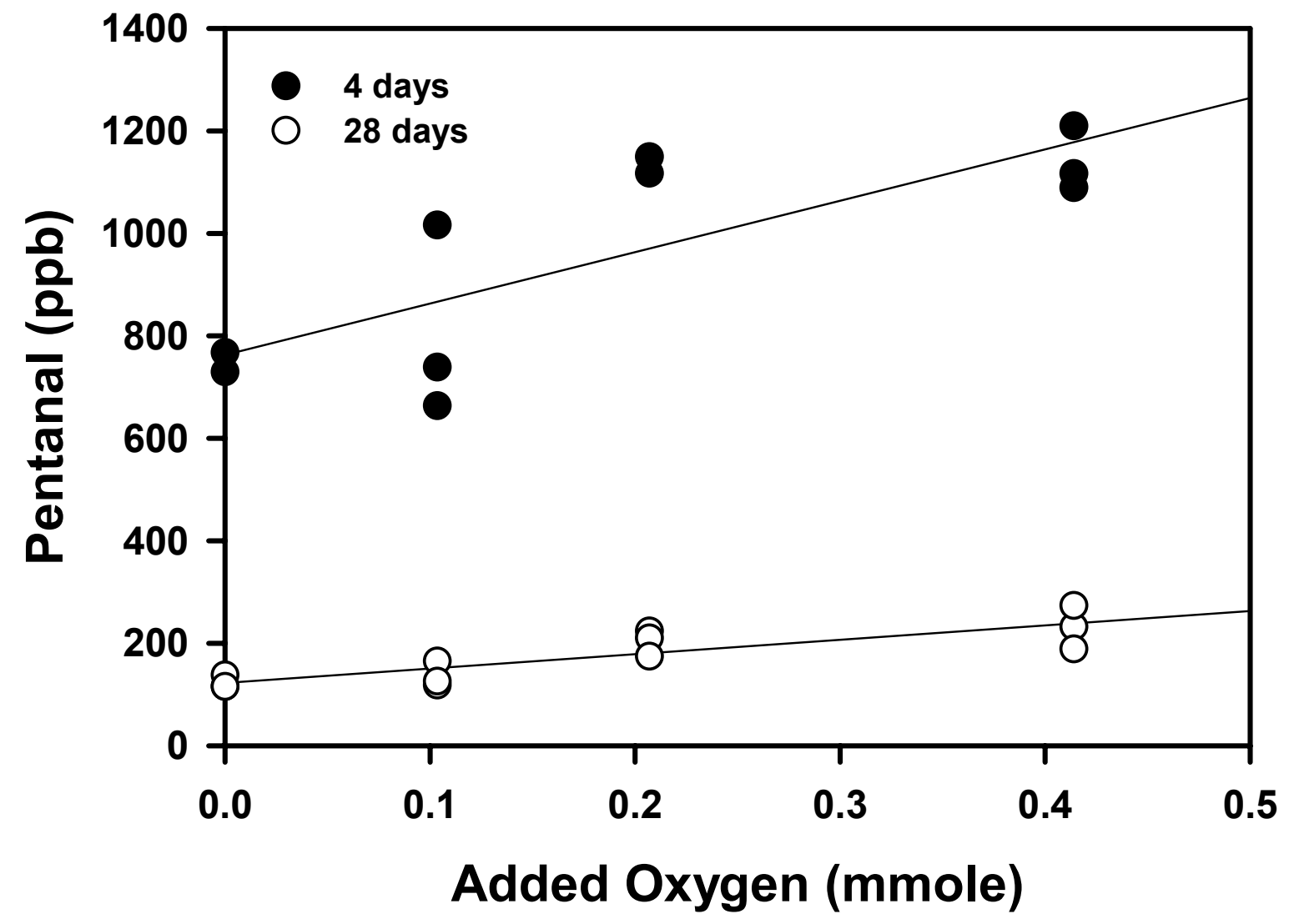

Figure 3.3. Effect of added oxygen on pentanal levels in anaerobically packed fresh-pack pickles 4 and 28 days after packing. 


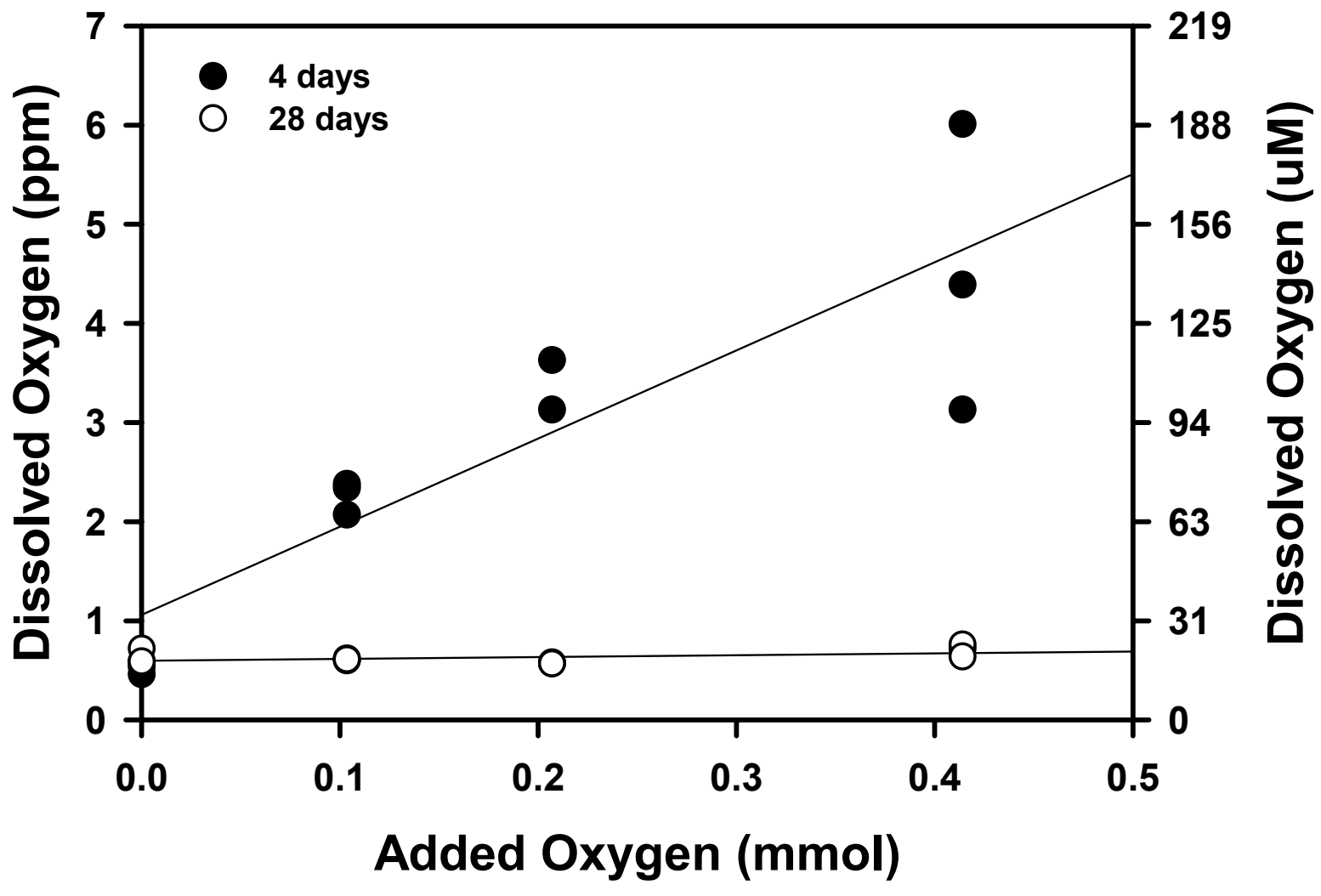

Figure 3.4. Effect of added oxygen on dissolved oxygen levels in anaerobically packed fresh-pack pickles 4 and 28 days after packing. 


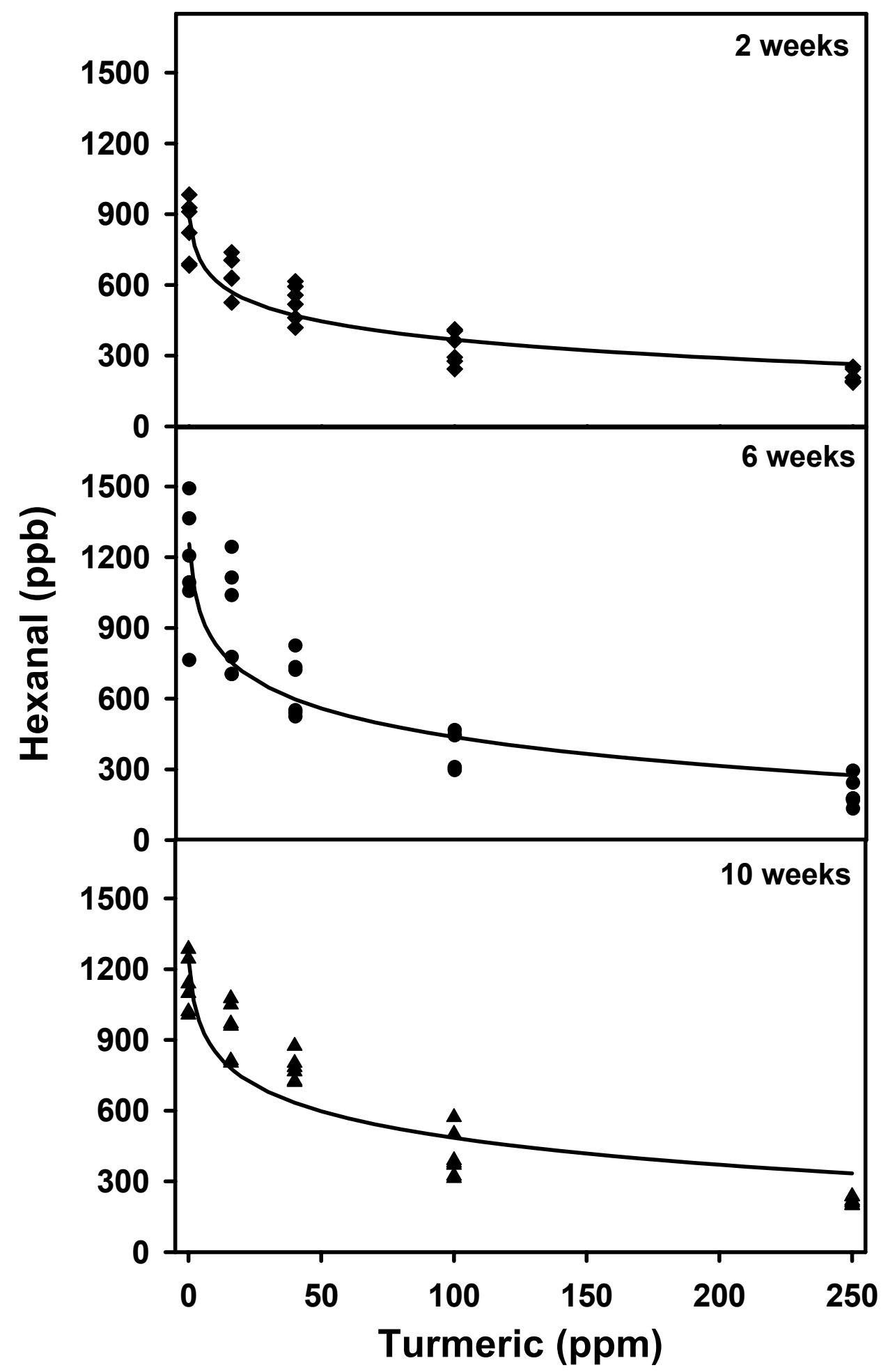

Figure 3.5. Effect of turmeric on hexanal levels in fresh-pack dill pickles 2, 6, and 10 weeks after packing. All samples contain spices and 1.3 mmole injected $\mathrm{O}_{2}$ in a $480-\mathrm{mL}$ jar with a $20 \mathrm{~mL}$ headspace. 


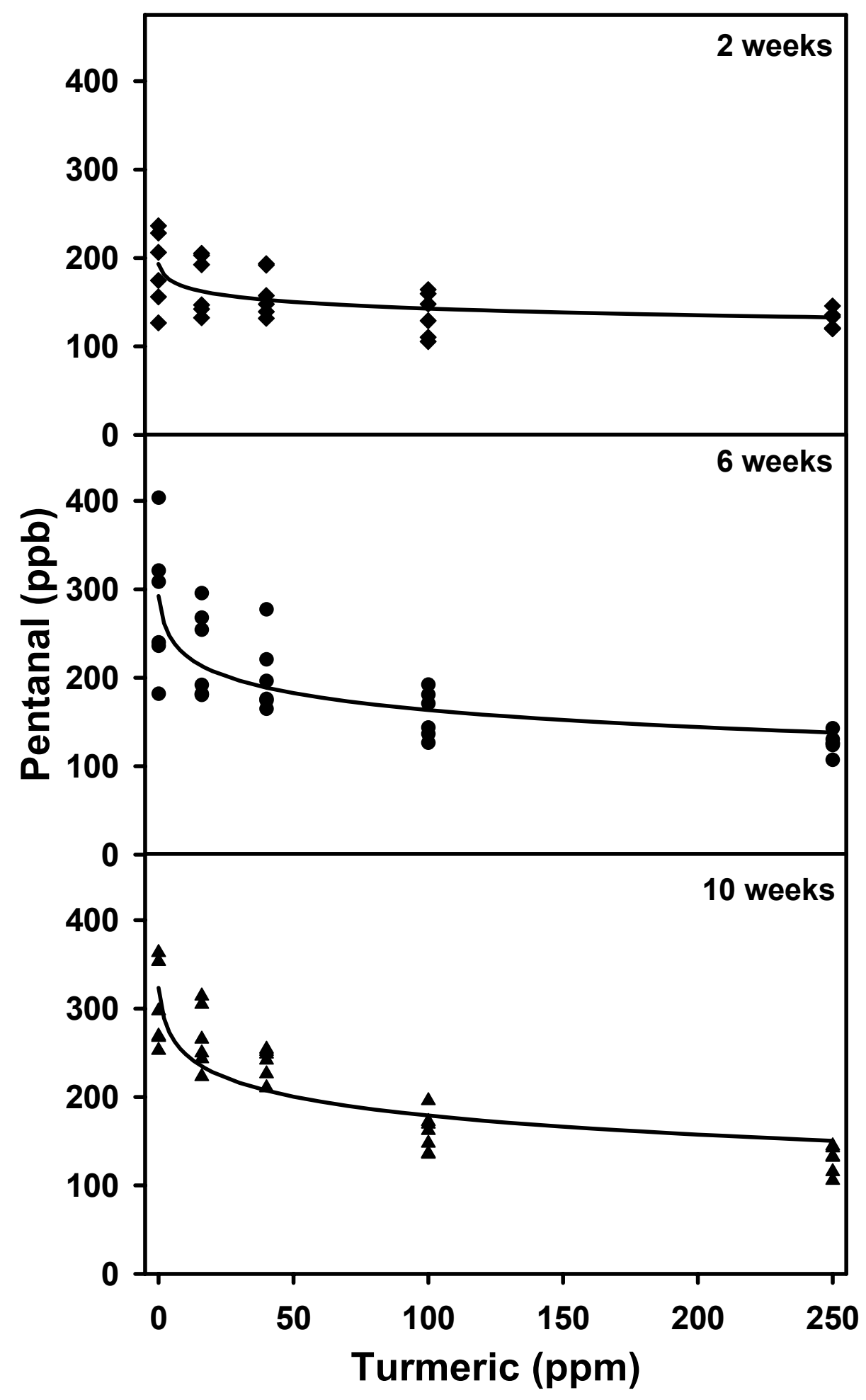

Figure 3.6. Effect of turmeric on pentanal levels in fresh-pack dill pickles 2, 6, and 10 weeks after packing. All samples contain spices and 1.3 mmole injected $\mathrm{O}_{2}$ in a $480-\mathrm{mL}$ jar with a $20 \mathrm{~mL}$ headspace. 


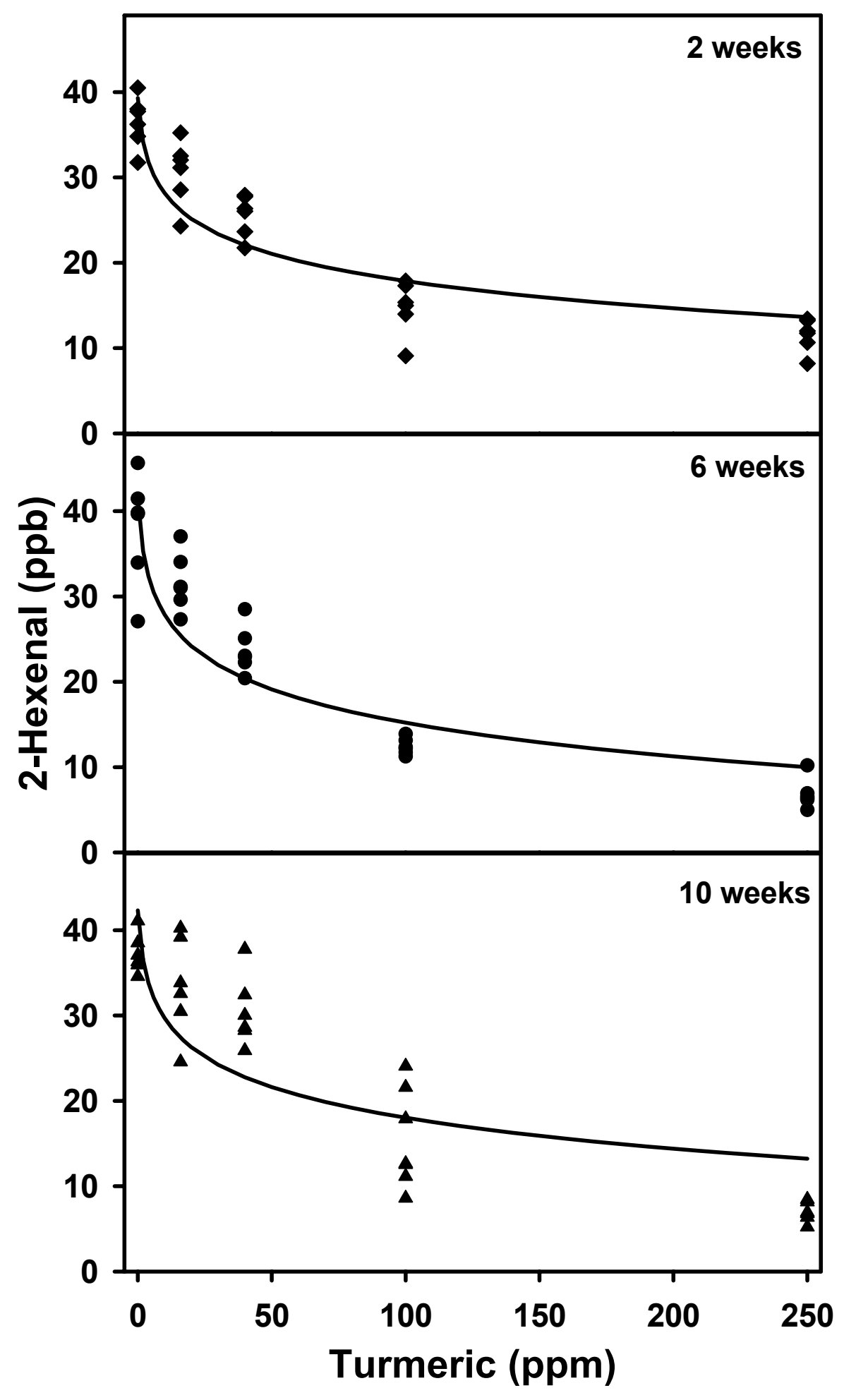

Figure 3.7. Effect of turmeric on 2-hexenal levels in fresh-pack dill pickles 2, 6, and 10 weeks after packing. All samples contain spices and 1.3 mmole injected $\mathrm{O}_{2}$ in a $480-\mathrm{mL}$ jar with a $20 \mathrm{~mL}$ headspace. 


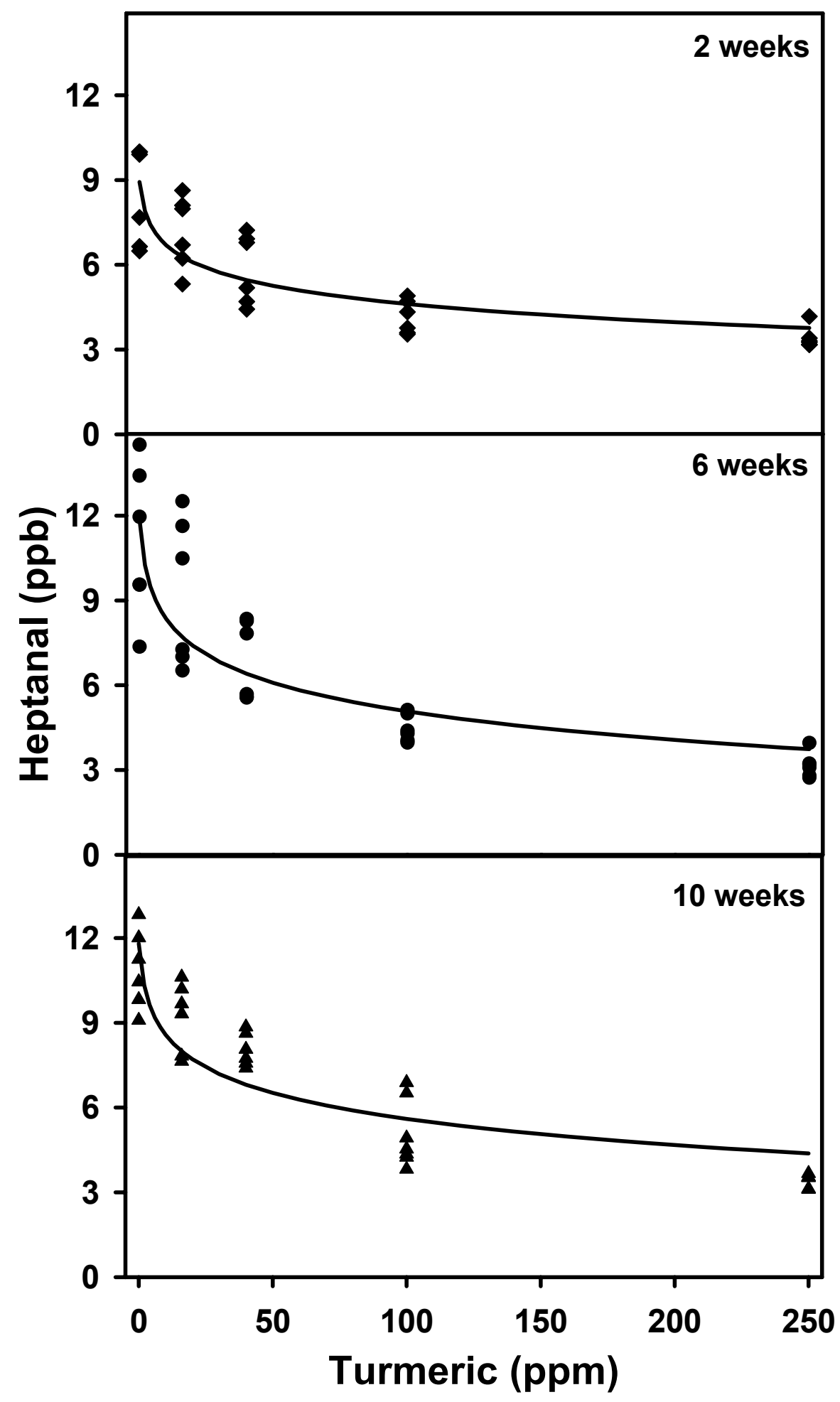

Figure 3.8. Effect of turmeric on heptanal levels in fresh-pack dill pickles 2, 6, and 10 weeks after packing. All samples contain spices and 1.3 mmole injected $\mathrm{O}_{2}$ in a $480-\mathrm{mL}$ jar with a $20 \mathrm{~mL}$ headspace. 


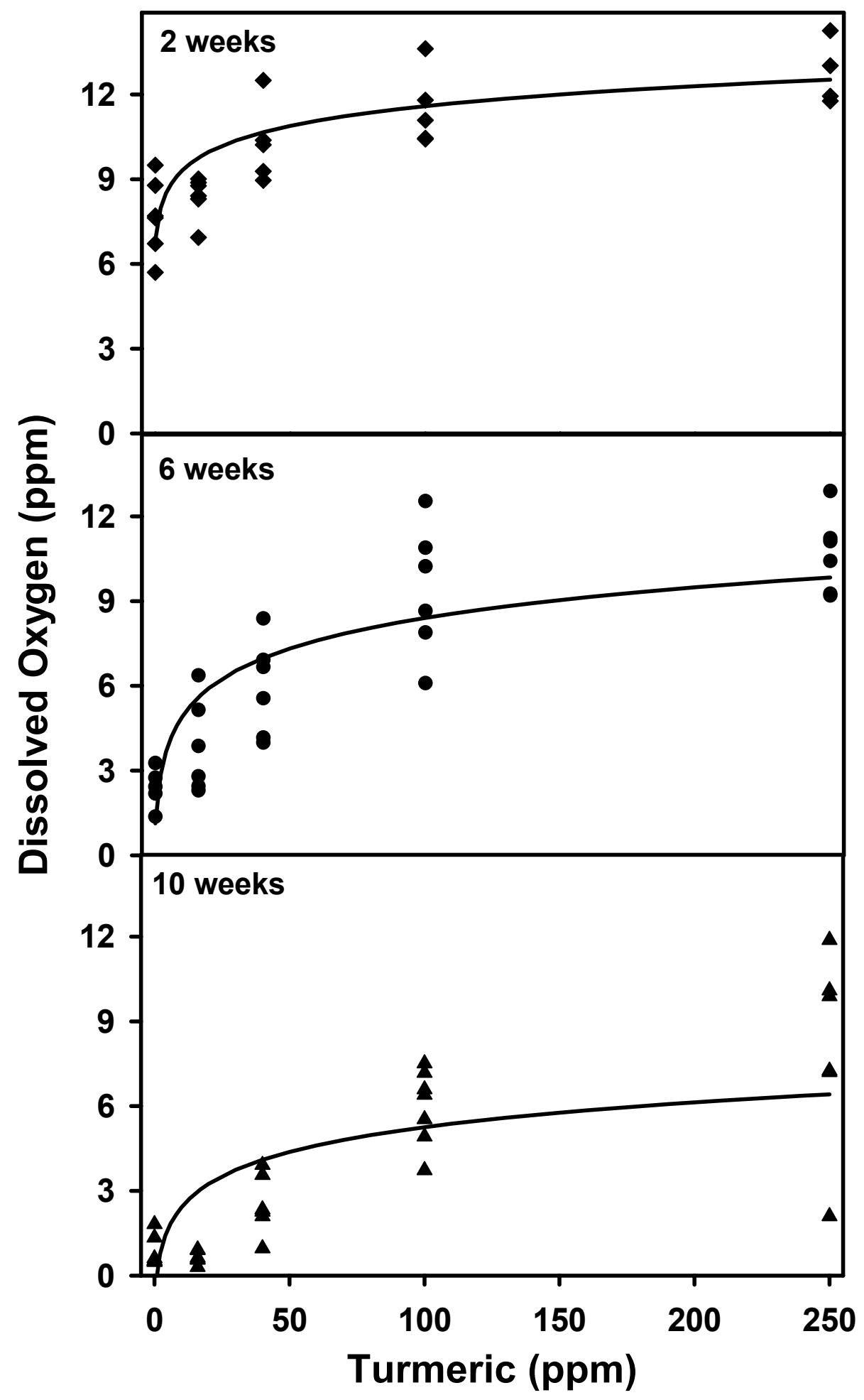

Figure 3.9. Effect of turmeric on dissolved oxygen levels in fresh-pack dill pickles 2,6 , and 10 weeks after packing. All samples contain spices and 1.3 mmole injected $\mathrm{O}_{2}$ in a $480-\mathrm{mL}$ jar with a $20 \mathrm{~mL}$ headspace. 


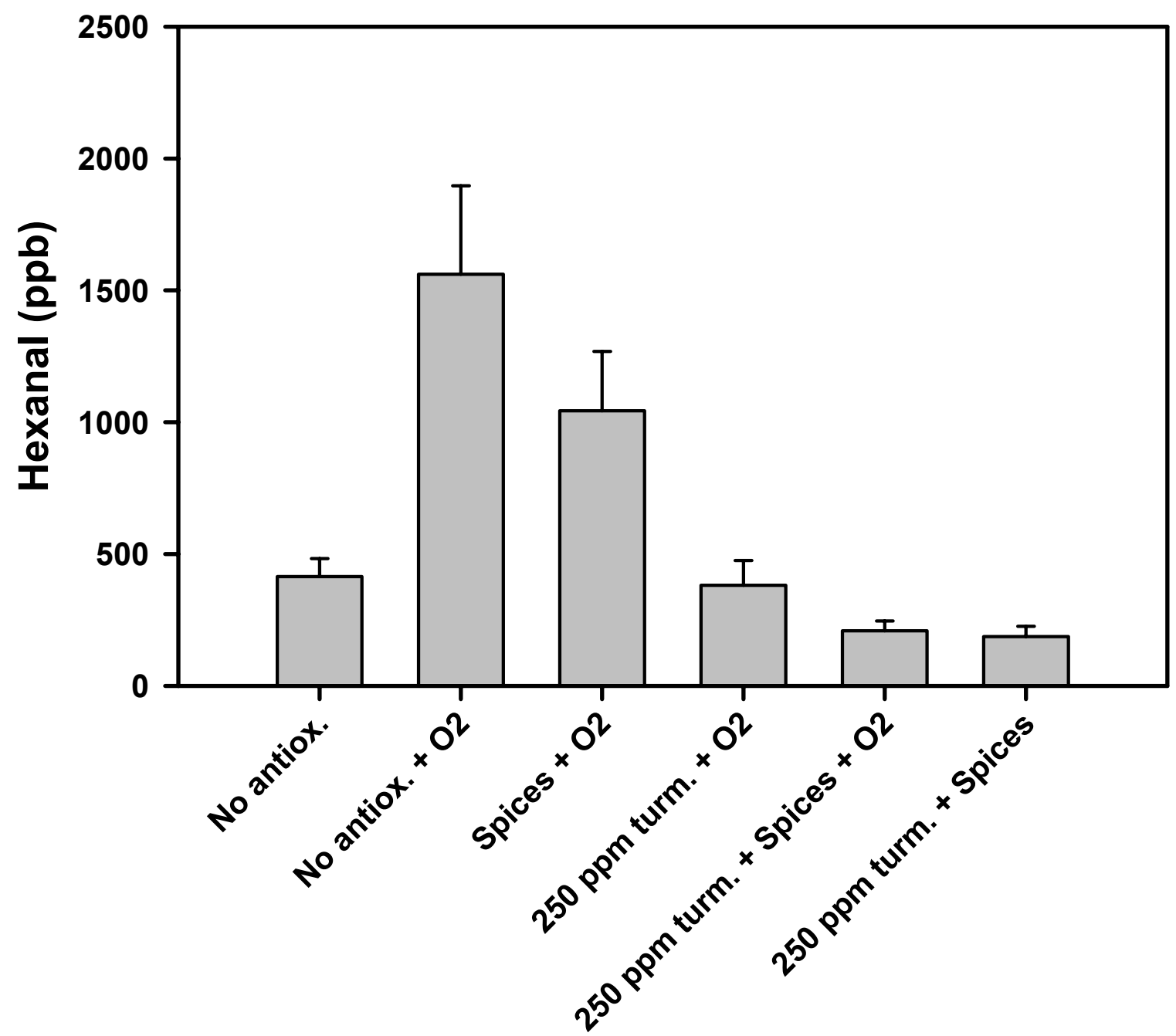

Figure 3.10. Effect of turmeric, dill spices, and added oxygen on hexanal levels in freshpack dill pickles. $\mathrm{O}_{2}$ treatments have 1.3 mmole $\mathrm{O}_{2}$ added to $480 \mathrm{~mL}$ jars with a $20 \mathrm{~mL}$ headspace. The bars show the mean of 3 time points, with 3 samples being tested at each time point. Error bars show the standard deviation of the hexanal concentration. 


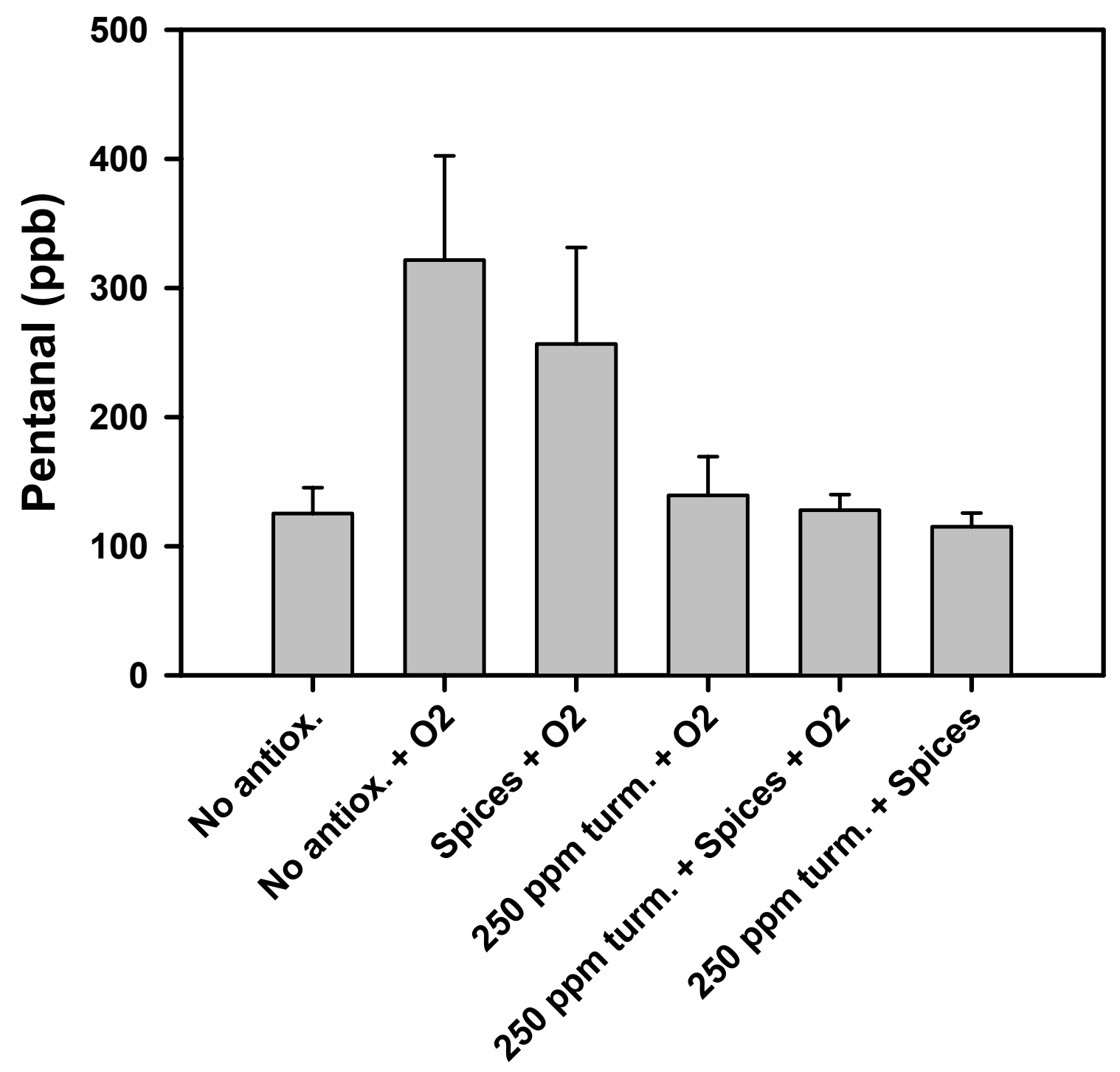

Figure 3.11. Effect of turmeric, dill spices, and added oxygen on pentanal levels in freshpack dill pickles. $\mathrm{O}_{2}$ treatments have 1.3 mmole $\mathrm{O}_{2}$ added to $480 \mathrm{~mL}$ jars with a $20 \mathrm{~mL}$ headspace. The bars show the mean of 3 time points, with 3 samples being tested at each time point. Error bars show the standard deviation of the pentanal concentration. 


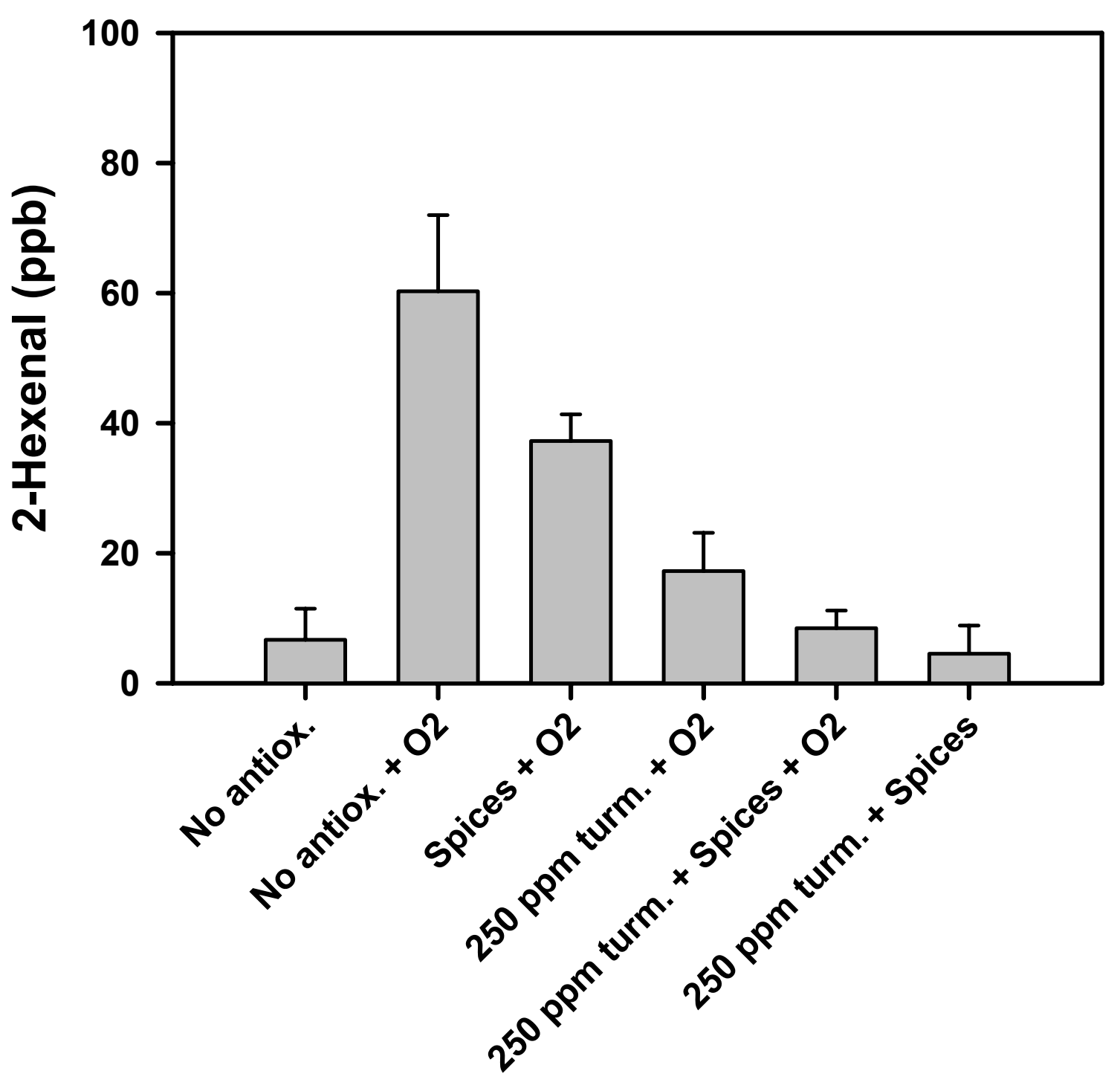

Figure 3.12. Effect of turmeric, dill spices, and added oxygen on 2-hexenal levels in fresh-

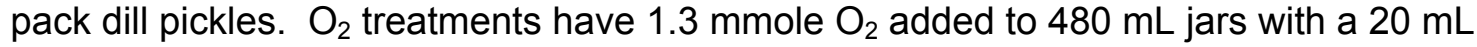
headspace. The bars show the mean of 3 time points, with 3 samples being tested at each time point. Error bars show the standard deviation of the 2-hexenal concentration. 


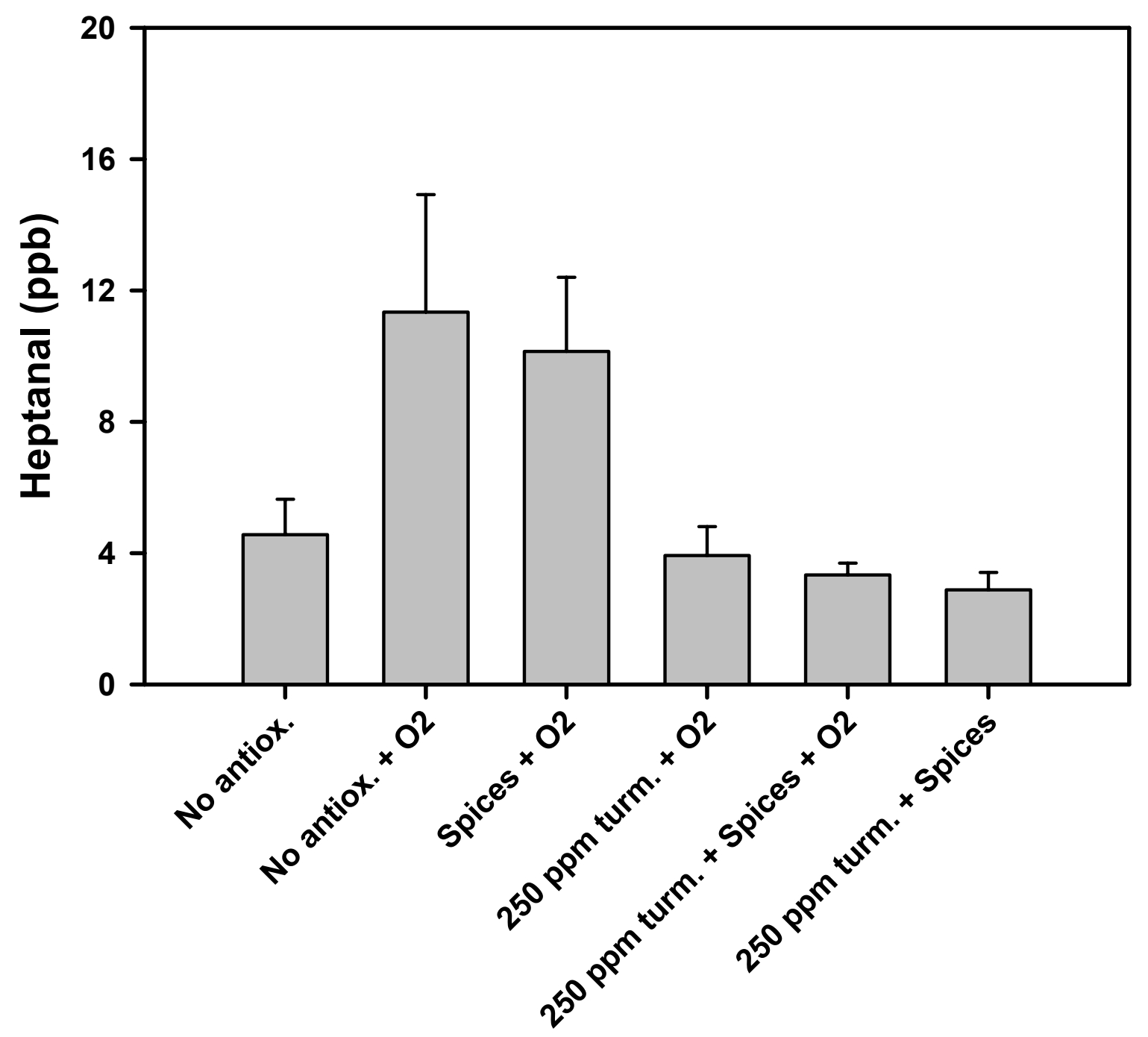

Figure 3.13. Effect of turmeric, dill spices, and added oxygen on heptanal levels in freshpack dill pickles. $\mathrm{O}_{2}$ treatments have 1.3 mmole $\mathrm{O}_{2}$ added to $480 \mathrm{~mL}$ jars with a $20 \mathrm{~mL}$ headspace. The bars show the mean of 3 time points, with 3 samples being tested at each time point. Error bars show the standard deviation of the heptanal concentration. 


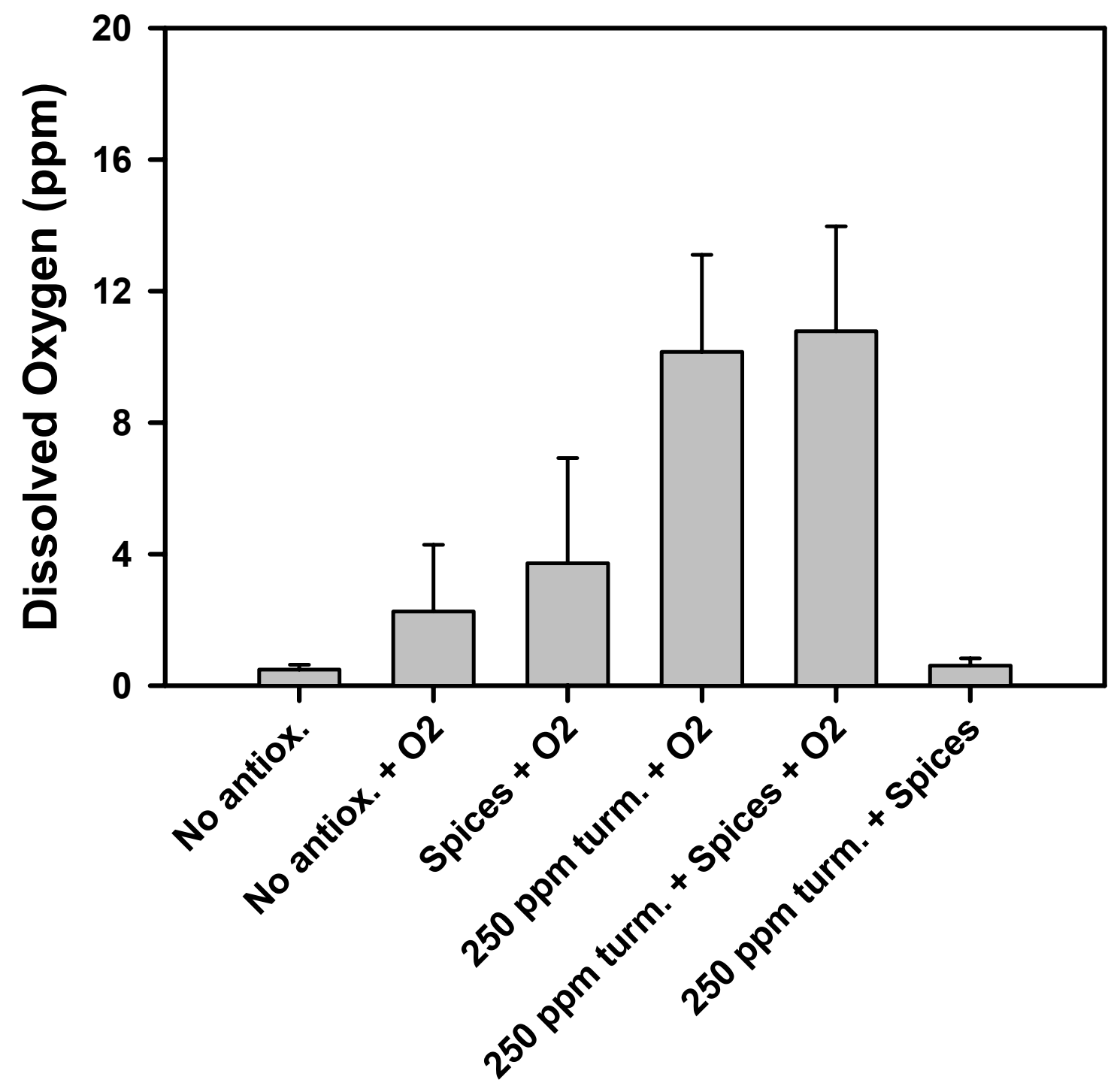

Figure 3.14. Effect of turmeric, dill spices, and added oxygen on dissolved oxygen levels in fresh-pack dill pickles. $\mathrm{O}_{2}$ treatments have 1.3 mmole $\mathrm{O}_{2}$ added to $480 \mathrm{~mL}$ jars with a $20 \mathrm{~mL}$ headspace. The bars show the mean of 3 time points, with 3 samples being tested at each time point. Error bars show the standard deviation of the dissolved oxygen concentration. 
Appendix A

Effect of Rosemarinic Acid on Oxidative Aldehyde Levels in Fresh-Pack Dill Pickles 


\section{A.1 Introduction}

An experiment was designed to evaluate the antioxidant activity of rosemarinic acid. Previous work has shown that rosemary possesses antioxidant activity (Tainter and Grenis, 2001). More specifically, work done at Kalsec, Inc. has shown that rosemarinic acid, a rosemary extract, possesses antioxidant activity in pickles. Thus, the objective of this experiment was to compare the antioxidant effects of turmeric and rosemary oleoresins in fresh-pack pickles exposed to oxygen, by monitoring their effects on the formation of aldehydes.

\section{A.2 Methods}

Ten treatments were packed (Table A.1) in $480 \mathrm{~mL}$ jars with a 50:50 packout ratio using the same brine described in Ch. 3. All treatments were pasteurized. Samples were analyzed in triplicate for dissolved oxygen and aldehydes one month after packing. Procedures to measure dissolved oxygen and aldehydes were the same as in Ch. 3. Rosemary oleoresins were obtained from Kalsec, Inc. (Kalamazoo, MI). The company contact indicated that in their preliminary experiments preparation \#41-19-11 performed slightly better than \#018183 in maintaining the flavor profile of pickles. For that reason it was used in Treatment 10.

\section{A.3. Results}

Results of this experiment indicate that in fresh-pack dill pickles, neither of the rosemary oleoresins exhibited as much antioxidant activity as turmeric, based on the development of oxidative aldehydes. Each of the rosemary oleoresins by themselves 
maintained hexanal levels similar to that of the dill spice treatment. However, the hexanal concentrations in all three of these treatments were almost three times higher than the hexanal concentration in the turmeric treatment (Fig. A.1). Combination of the rosemary extracts with dill spice, as would be done in a commercial product, reduced the hexanal to about the same level as a control with a standard headspace and no added oxygen. However, the hexanal level was higher than that which occurred with a combination of turmeric plus dill spice. Addition of rosemary to the turmeric/dill spice combination (Treatment 10) did not result in any further reduction in the concentration of hexanal. Similar trends were seen in the effects of these antioxidants on the formation of pentanal, 2-hexenal, and heptanal (Figs. A.2-A.4).

As seen in other experiments (Ch. 3), the trend seen with the dissolved oxygen levels was the opposite of that seen with aldehyde levels (Fig. A.5). Treatments which had higher aldehyde levels tended to have lower oxygen levels. The hypothesis, as stated in Ch. 3, is that this is due to the antioxidant mechanism of turmeric, as well as rosemarinic acid in this experiment. Because these antioxidants act by inhibiting propagation, they prevent reaction of the oxygen free radicals so the oxygen tends to build up. Thus, in treatments with no antioxidants, the oxygen is consumed during oxidation so oxygen levels decrease. 


\section{A.4 References}

Tainter, D.R.; Grenis, A.T. The Spices. Spices and Seasonings: A Food Technology Handbook; John Wiley \& Sons, Inc.: New York, 2001; p 133. 
Table A.1. Treatments used to compare the antioxidant activity of rosemary extracts and turmeric oleoresin. All concentrations given are those after equilibration. "Headspace" indicates additional headspace beyond that normally left when jars are closed. An "X" in a row indicates the presence of dill spices, turmeric, or rosemary in the corresponding treatment.

\begin{tabular}{ccccccc} 
Treatment & $\begin{array}{c}\text { Headspace } \\
(\mathbf{m L})\end{array}$ & $\begin{array}{c}\text { Oxygen } \\
\text { injected } \\
(\mathbf{m L})\end{array}$ & $\begin{array}{c}\text { Dill } \\
\text { spices }\end{array}$ & $\begin{array}{c}\text { 250 ppm } \\
\text { turmeric }\end{array}$ & $\begin{array}{c}\text { 250semary } \\
\text { Rosi-19-11 }\end{array}$ & $\begin{array}{r}\text { 250 ppm } \\
\text { Rosemary } \\
\text { \# 018183 }\end{array}$ \\
\hline 1 & 0 & 0 & & & & \\
2 & 30 & 50 & & & & \\
3 & 30 & 50 & & $X$ & & \\
4 & 30 & 50 & $X$ & & $X$ & $X$ \\
5 & 30 & 50 & & & & \\
6 & 30 & 50 & & & & \\
7 & 30 & 50 & $X$ & $X$ & & \\
8 & 30 & 50 & $X$ & & $X$ & \\
9 & 30 & 50 & $X$ & & $X$ & \\
10 & 30 & 50 & $X$ & $X$ & $X$
\end{tabular}




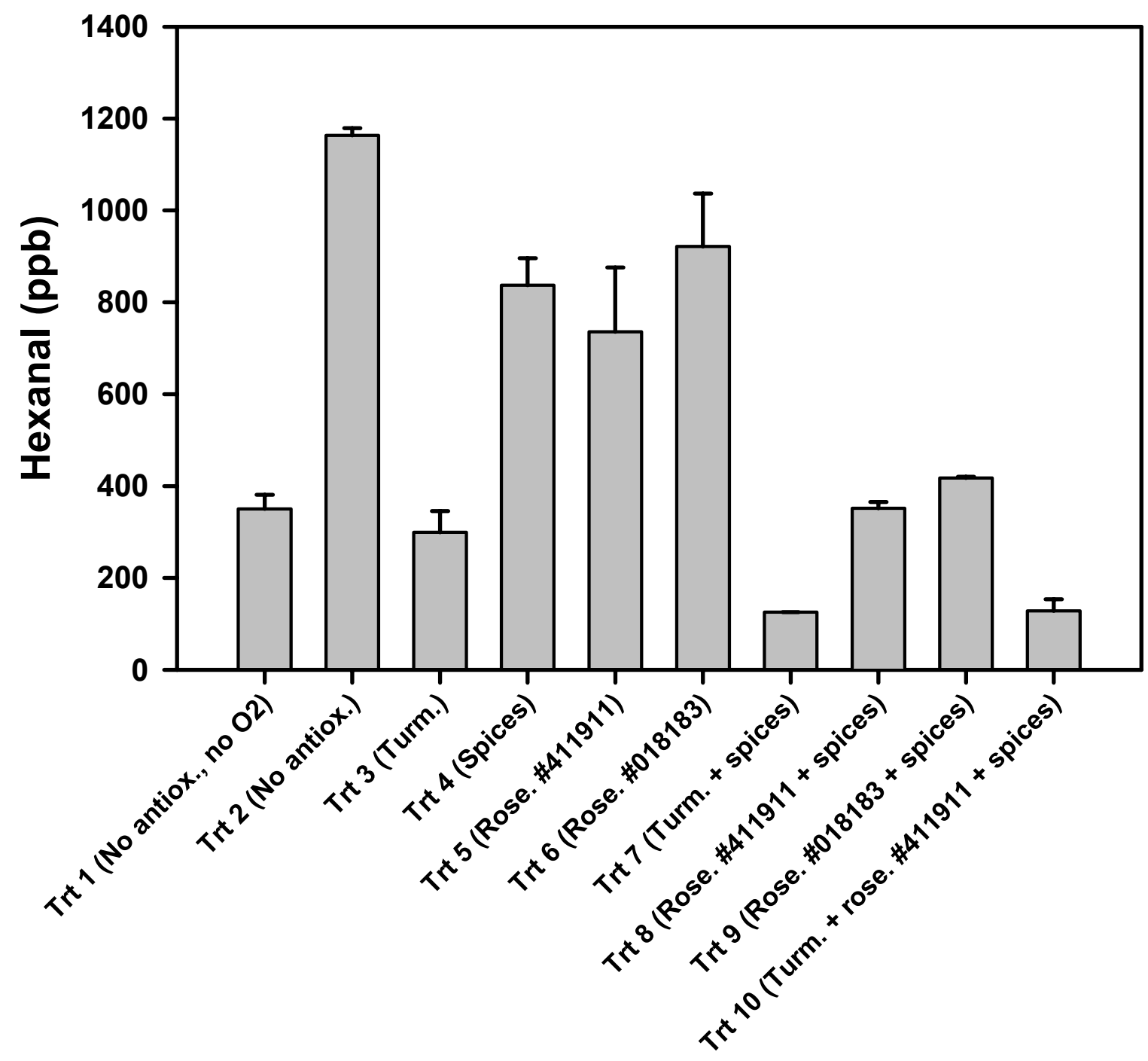

Figure A.1. Effect of turmeric, dill spices, and rosemary on hexanal levels in fresh-pack dill pickles one month after packing. The bars show the mean of three samples. Error bars show the standard deviation of the hexanal concentration. All treatments except Trt. 1 have $50 \mathrm{~mL}$ oxygen injected. 


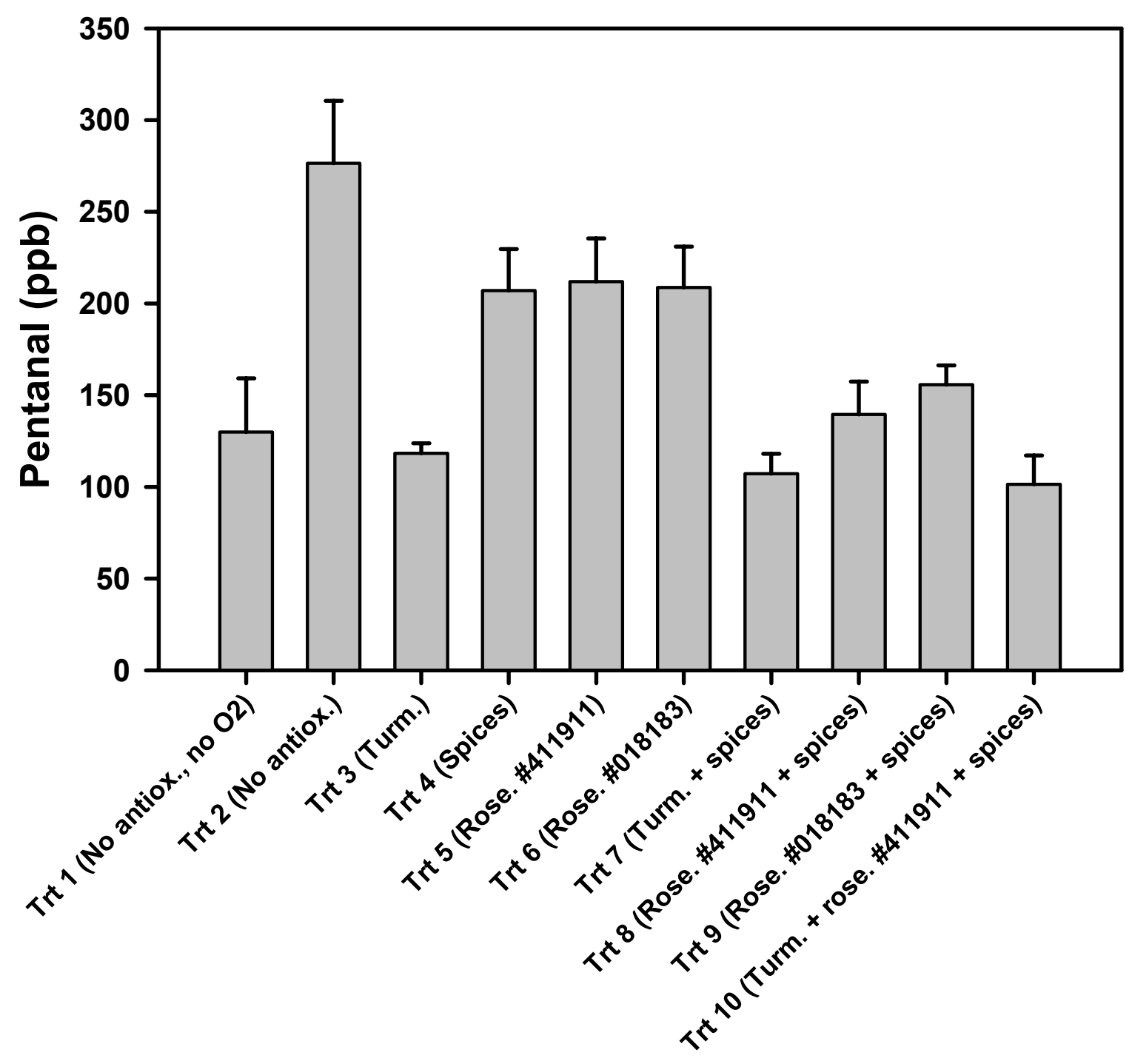

Figure A.2. Effect of turmeric, dill spices, and rosemary on pentanal levels in fresh-pack dill pickles one month after packing. The bars show the mean of three samples. Error bars show the standard deviation of the pentanal concentration. All treatments except Trt. 1 have $50 \mathrm{~mL}$ oxygen injected. 


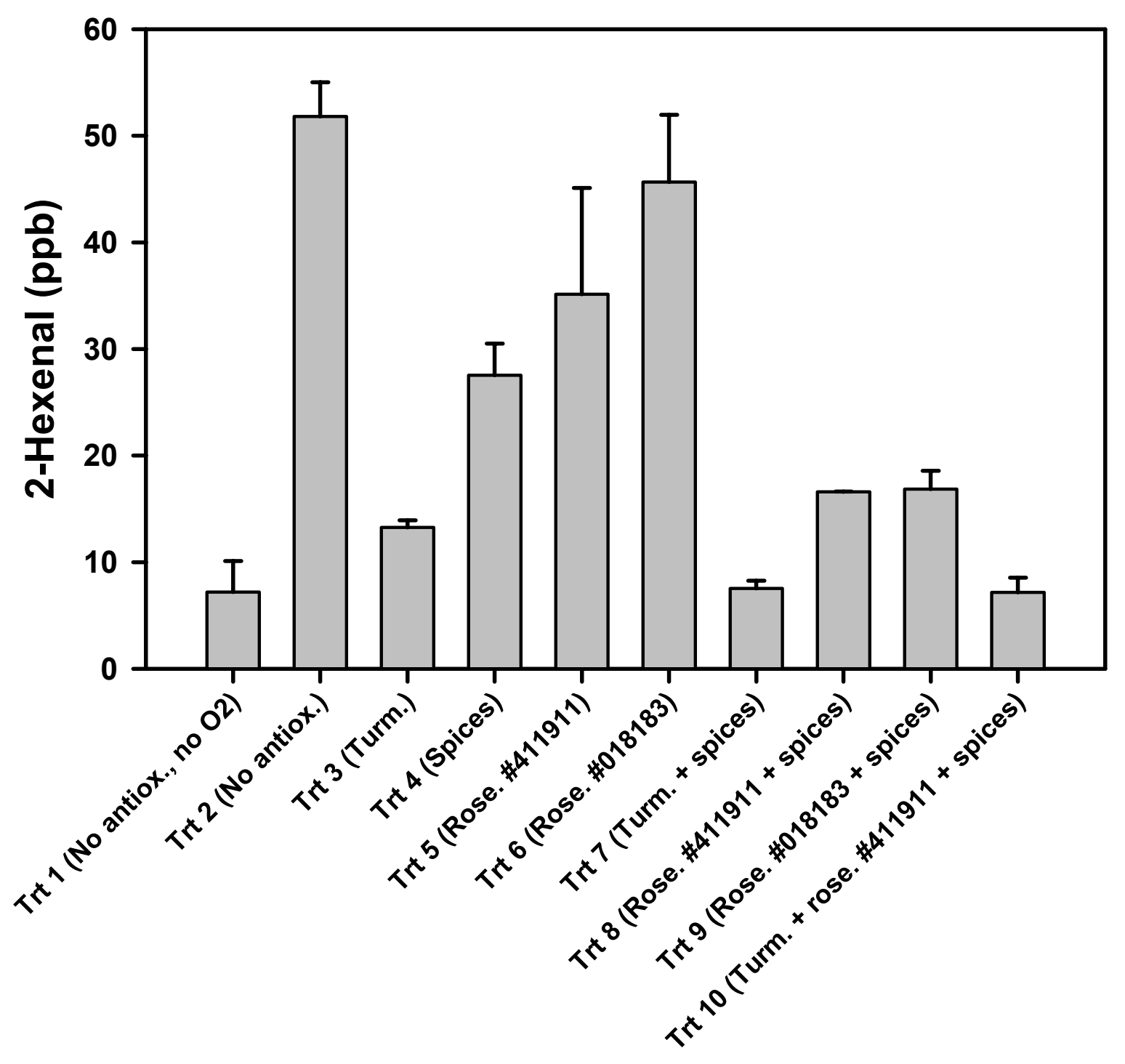

Figure A.3. Effect of turmeric, dill spices, and rosemary on 2-hexenal levels in fresh-pack dill pickles one month after packing. The bars show the mean of three samples. Error bars show the standard deviation of the 2-hexenal concentration. All treatments except Trt. 1 have $50 \mathrm{~mL}$ oxygen injected. 


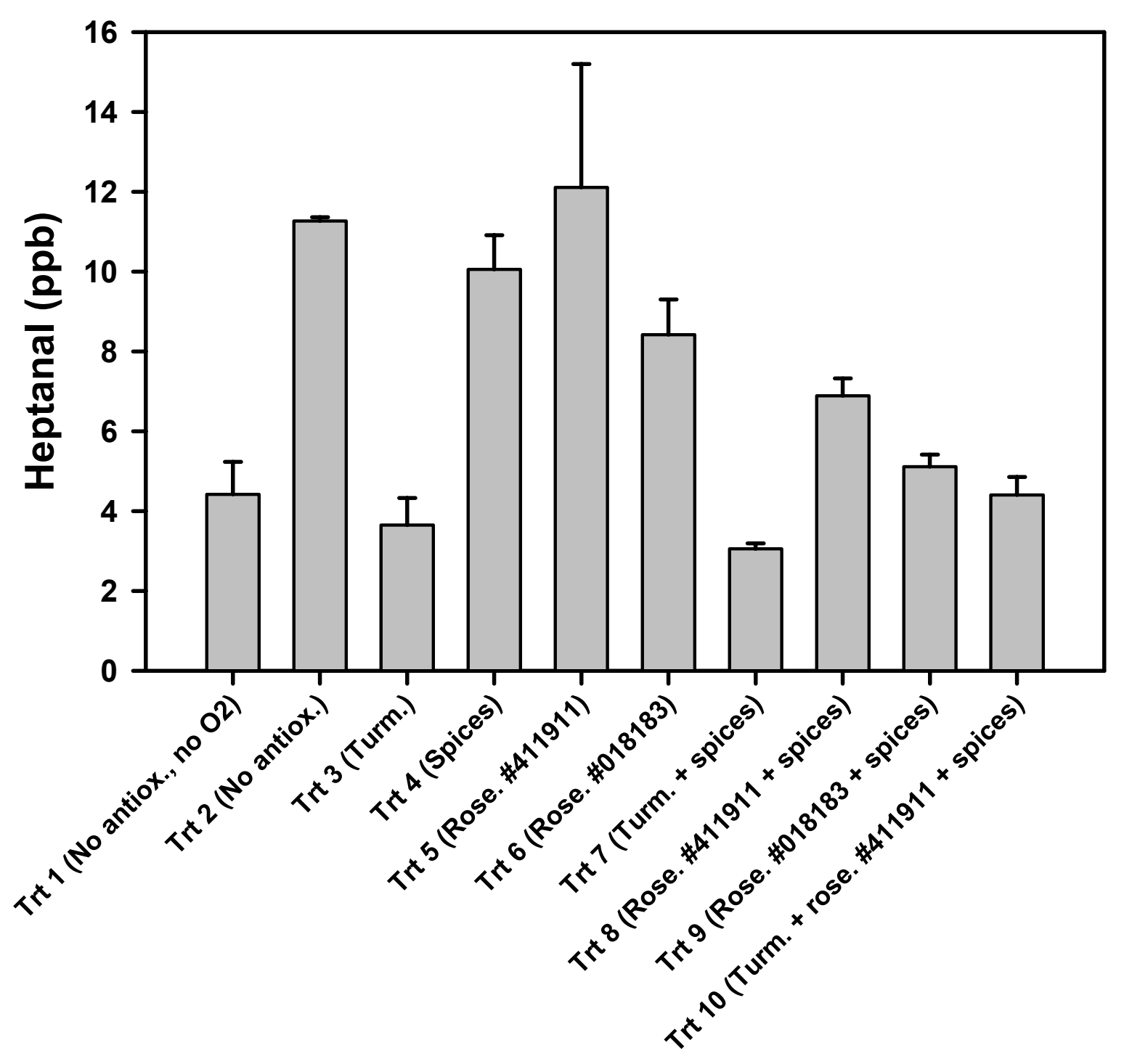

Figure A.4. Effect of turmeric, dill spices, and rosemary on heptanal levels in fresh-pack dill pickles one month after packing. The bars show the mean of three samples. Error bars show the standard deviation of the heptanal concentration. All treatments except Trt. 1 have $50 \mathrm{~mL}$ oxygen injected. 


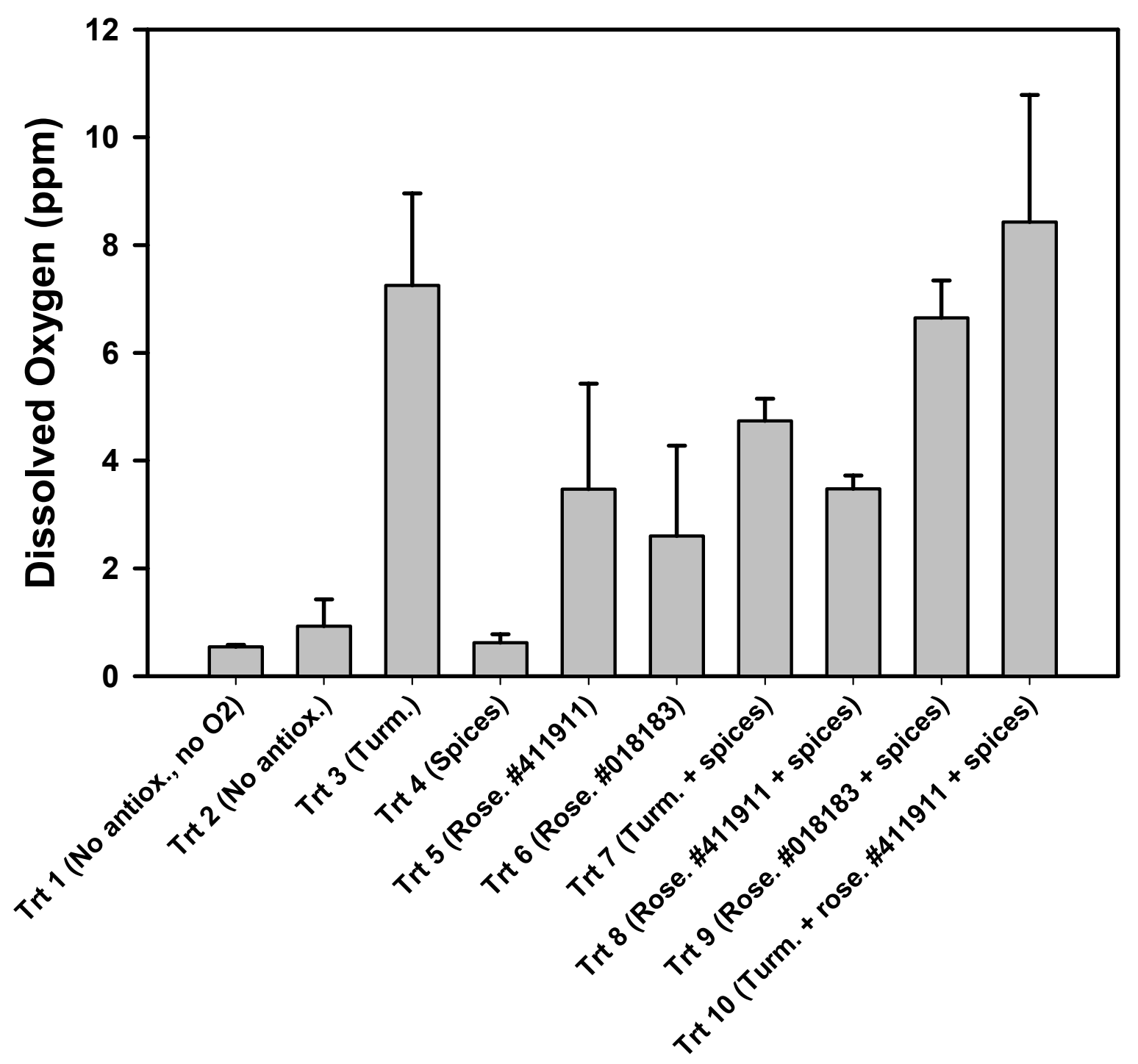

Figure A.5. Effect of turmeric, dill spices, and rosemary on dissolved oxygen levels in freshpack dill pickles one month after packing. The bars show the mean of three samples. Error bars show the standard deviation of the dissolved oxygen concentration. All treatments except Trt. 1 have $50 \mathrm{~mL}$ oxygen injected. 


\section{Appendix B}

Effect of Oxygen and an Oxygen Scavenger on Aldehyde Levels in Fresh-Pack Dill Pickles 


\section{B.1 Introduction}

An experiment was designed to evaluate the effect of copper and ascorbate as oxygen scavengers in jars of fresh-pack dill pickles. Turmeric has been shown to be an effective antioxidant in fresh-pack dill pickles by inhibiting propagation of lipid oxidation. When lipid oxidation was inhibited, however, dissolved oxygen levels in the pickle brine remained high during storage (Ch. 3). Graf (1994) found that catalysis of ascorbic acid oxidation by cupric gluconate could be used as an oxygen scavenging reaction in food systems. Addition of cupric gluconate to red bell peppers, which have a high concentration of ascorbic acid, was found to effectively remove oxygen from acidified peppers (McFeeters et al., unpublished). This experiment was conducted to determine if a combination of turmeric with the cupric gluconate/ascorbic acid oxygen scavenging system would reduce aldehyde formation more than turmeric by itself.

\section{B.2 Methods}

Two treatments were added to the second of the experiments in Chapter 3 that were designed to determine the effect of turmeric in preventing lipid oxidation in fresh-pack cucumbers. One treatment was to add $0.05 \mathrm{mM}$ cupric gluconate and $5.9 \mathrm{mM}$ ascorbic acid to cucumbers with added oxygen, but without addition of turmeric. In the second treatment the same concentrations of these components were added to cucumbers to that also contained added oxygen plus $250 \mathrm{ppm}$ turmeric oleoresin and dill spices. All the treatments relevant to the cupric gluconate/ascorbate experiment are shown in Table B.1. These treatments were packed using the same procedure as in Ch. 3. Samples were analyzed in triplicate for 
dissolved oxygen and aldehydes at 2, 6, and 10 weeks after packing. Procedures to measure dissolved oxygen and aldehydes were the same as in Ch. 3 .

\section{B.3 Results}

The addition of copper and ascorbate to pickles was successful in reducing aldehyde levels (Figs. B.1-B.4). The treatments which had copper and ascorbate added had lower aldehyde levels than all other treatments. The copper and ascorbate were also successful in lowering oxygen levels (Fig. B.5). Pickles with copper, ascorbic acid, and oxygen added had approximately the same dissolved oxygen levels as pickles that were not injected with additional oxygen. Dissolved oxygen remained at high concentrations without the added copper and ascorbate.

Despite the very low aldehyde and dissolved oxygen levels achieved when adding copper gluconate and ascorbate to cover solutions, the addition of these compounds cannot be used to inhibit oxidation in fresh-pack dill pickles. Pickles in both treatments with the added copper and ascorbic acid had a brownish-gray discoloration after two weeks. In addition, the pickles were extremely soft to the point of disintegrating in the jar. This is in marked contrast to the result of the addition of cupric gluconate to red bell peppers, in which softening is inhibited. 


\section{B.4 References}

Graf, E. Copper (II) ascorbate; a novel food preservation system. J. Ag. Food Chem. 1994, 42, 1616-1619. 
Table B.1. Treatments used to evaluate the effect of turmeric and a cupric gluconate/ascorbic acid oxygen scavenging system on fresh-pack pickles. All concentrations given are the concentrations after equilibration. "Headspace" indicates additional headspace beyond that normally left when jars are closed. An "X" in a row indicates the presence of dill spices, turmeric, or copper/ascorbate in the corresponding treatment.

\begin{tabular}{|c|c|c|c|c|c|}
\hline Treatment & $\begin{array}{c}\text { Headspace } \\
\text { (mL) }\end{array}$ & $\begin{array}{l}\text { Oxygen } \\
\text { injected } \\
\text { (mL) }\end{array}$ & $\begin{array}{c}\text { Dill } \\
\text { spices }\end{array}$ & $\begin{array}{l}250 \text { ppm } \\
\text { turmeric }\end{array}$ & $\begin{array}{c}.05 \mathrm{mM} \text { copper } \\
\text { gluconate }+ \\
5.9 \mathrm{mM} \text { ascorbate }\end{array}$ \\
\hline 1 & 0 & 0 & & & \\
\hline 2 & 20 & 30 & & & \\
\hline 3 & 20 & 30 & & & $x$ \\
\hline 4 & 0 & 0 & $X$ & $x$ & \\
\hline 5 & 20 & 30 & $x$ & $x$ & \\
\hline 6 & 20 & 30 & $x$ & $x$ & $X$ \\
\hline
\end{tabular}




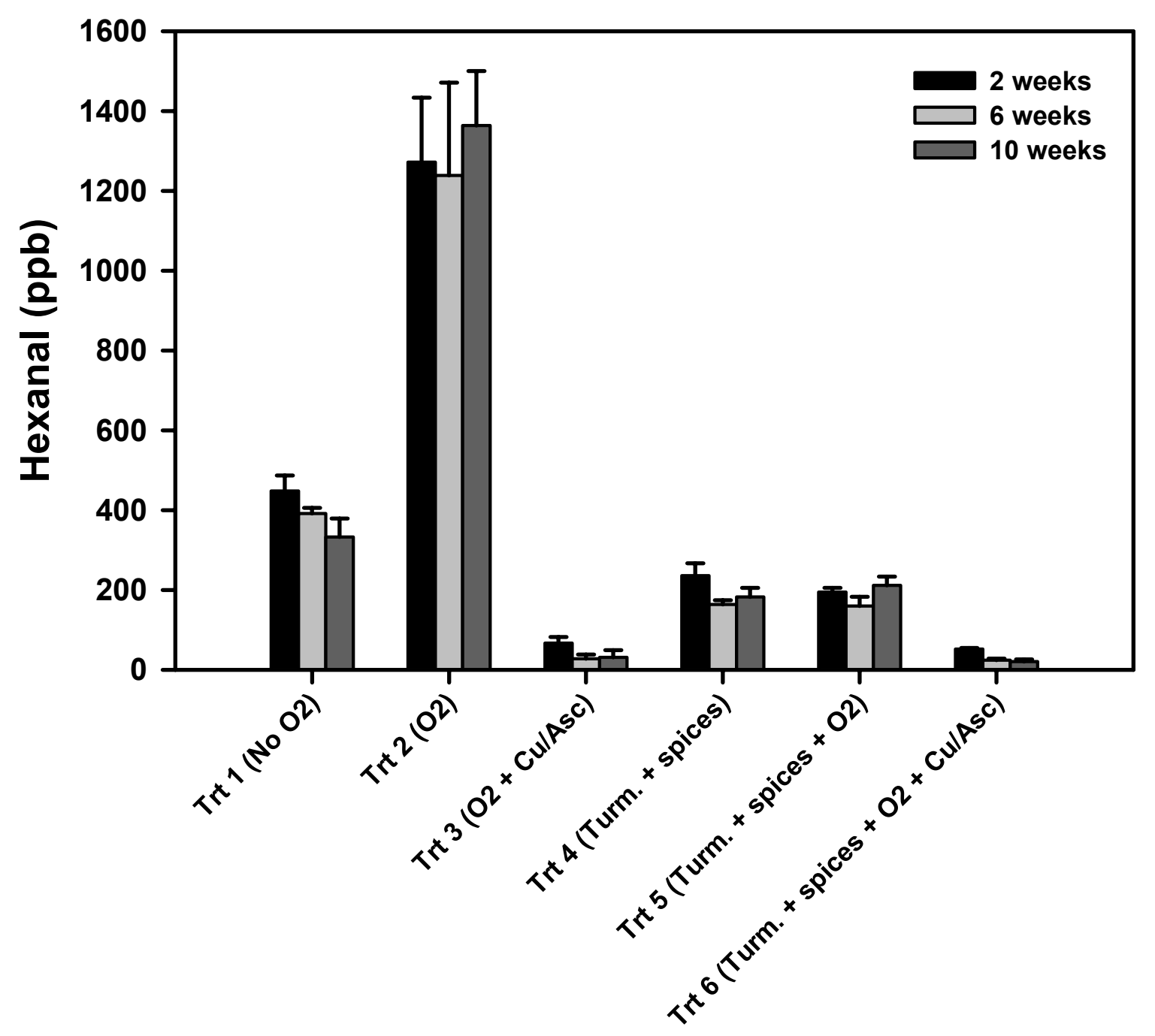

Figure B.1. Effect of added turmeric, dill spices, cupric gluconate and ascorbic acid on hexanal levels in fresh-pack dill pickles 2, 6, and 10 weeks after packing. The bars show the mean of three samples. Error bars show the standard deviation of hexanal concentration. 


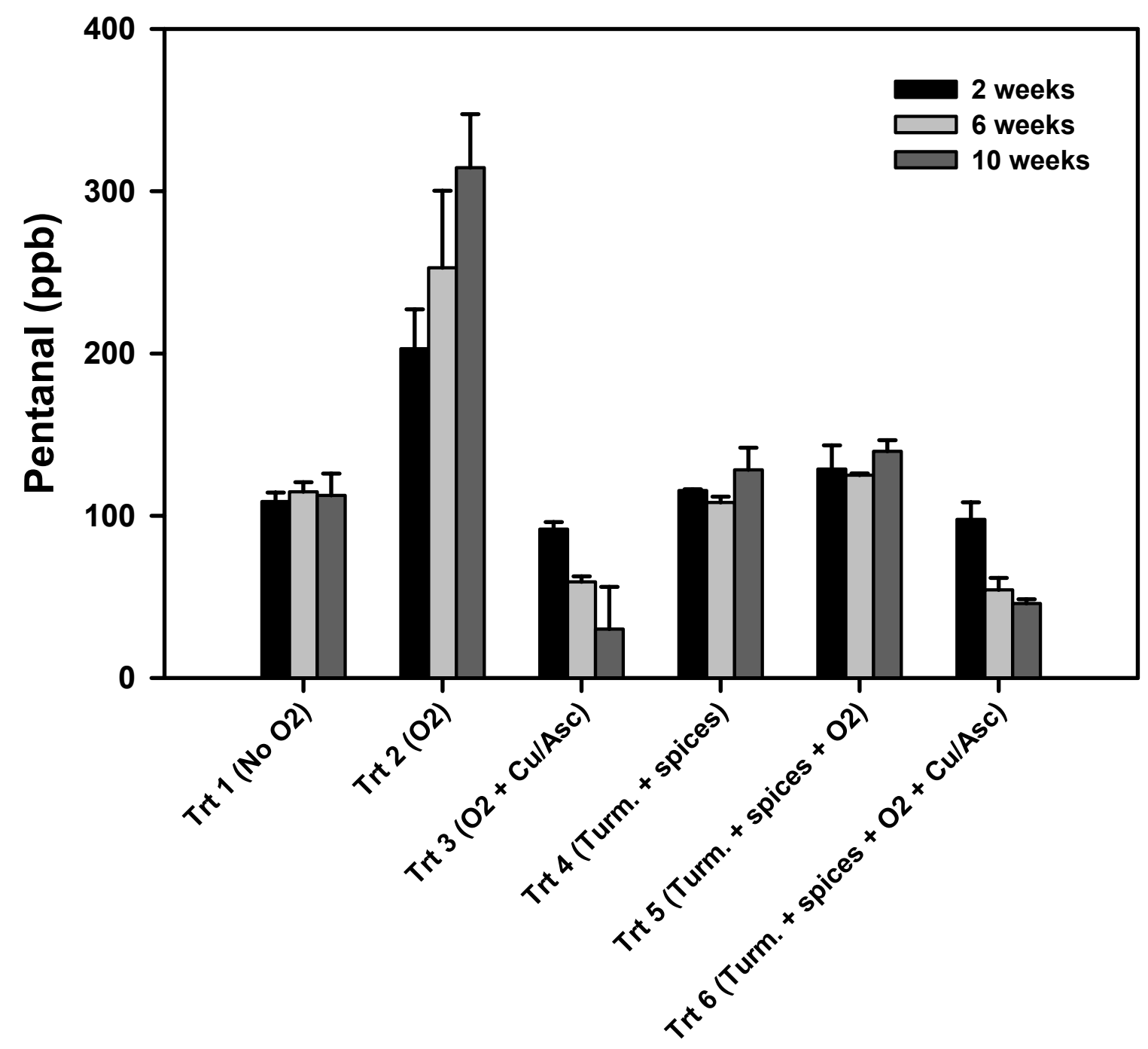

Figure B.2. Effect of added turmeric, dill spices, cupric gluconate and ascorbic acid on pentanal levels in fresh-pack dill pickles 2, 6, and 10 weeks after packing. The bars show the mean of three samples. Error bars show the standard deviation of pentanal concentration. 


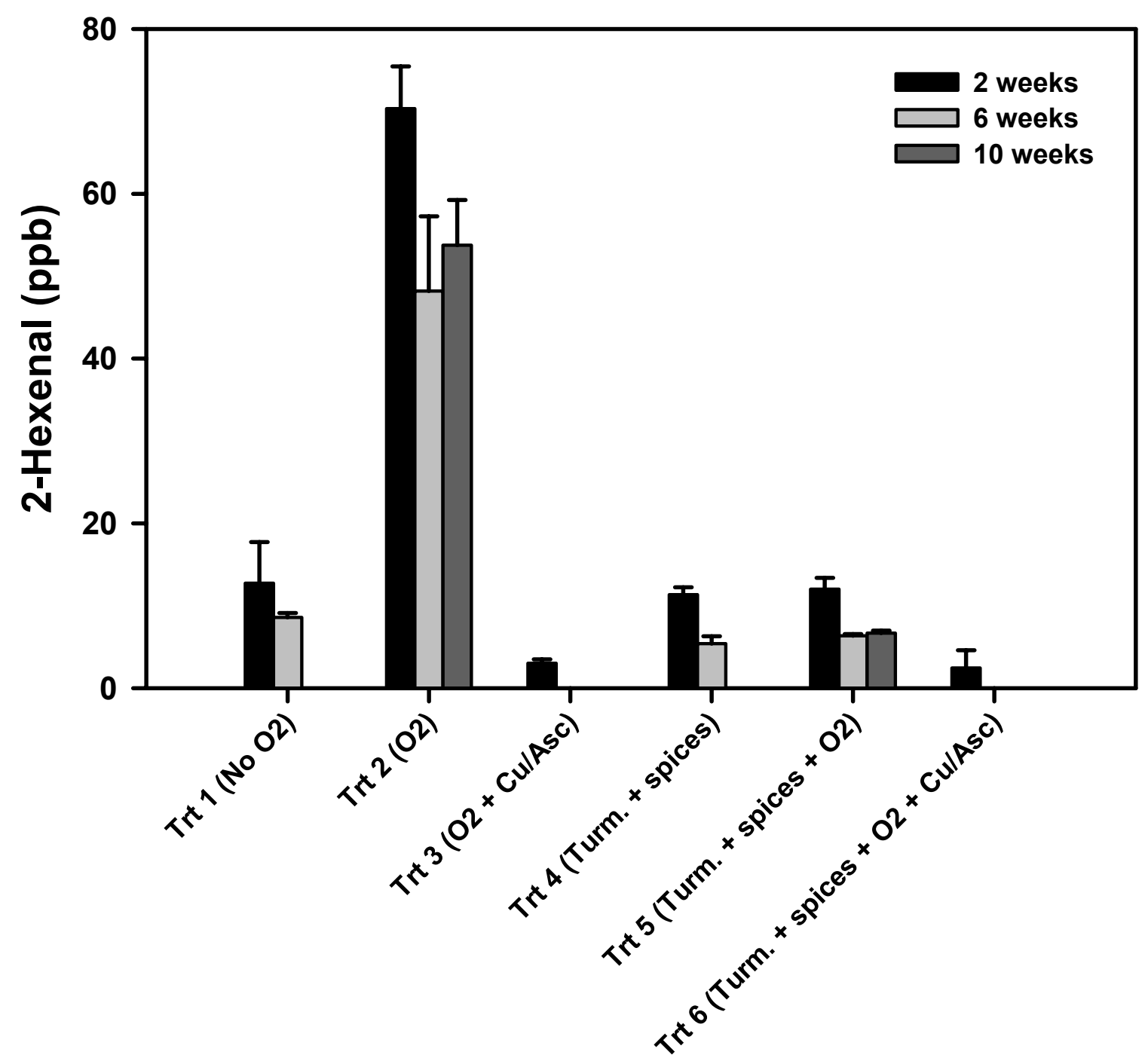

Figure B.3. Effect of added turmeric, dill spices, cupric gluconate and ascorbic acid on 2hexenal levels in fresh-pack dill pickles 2, 6, and 10 weeks after packing. The bars show the mean of three samples. Error bars show the standard deviation of 2-hexenal concentration. 


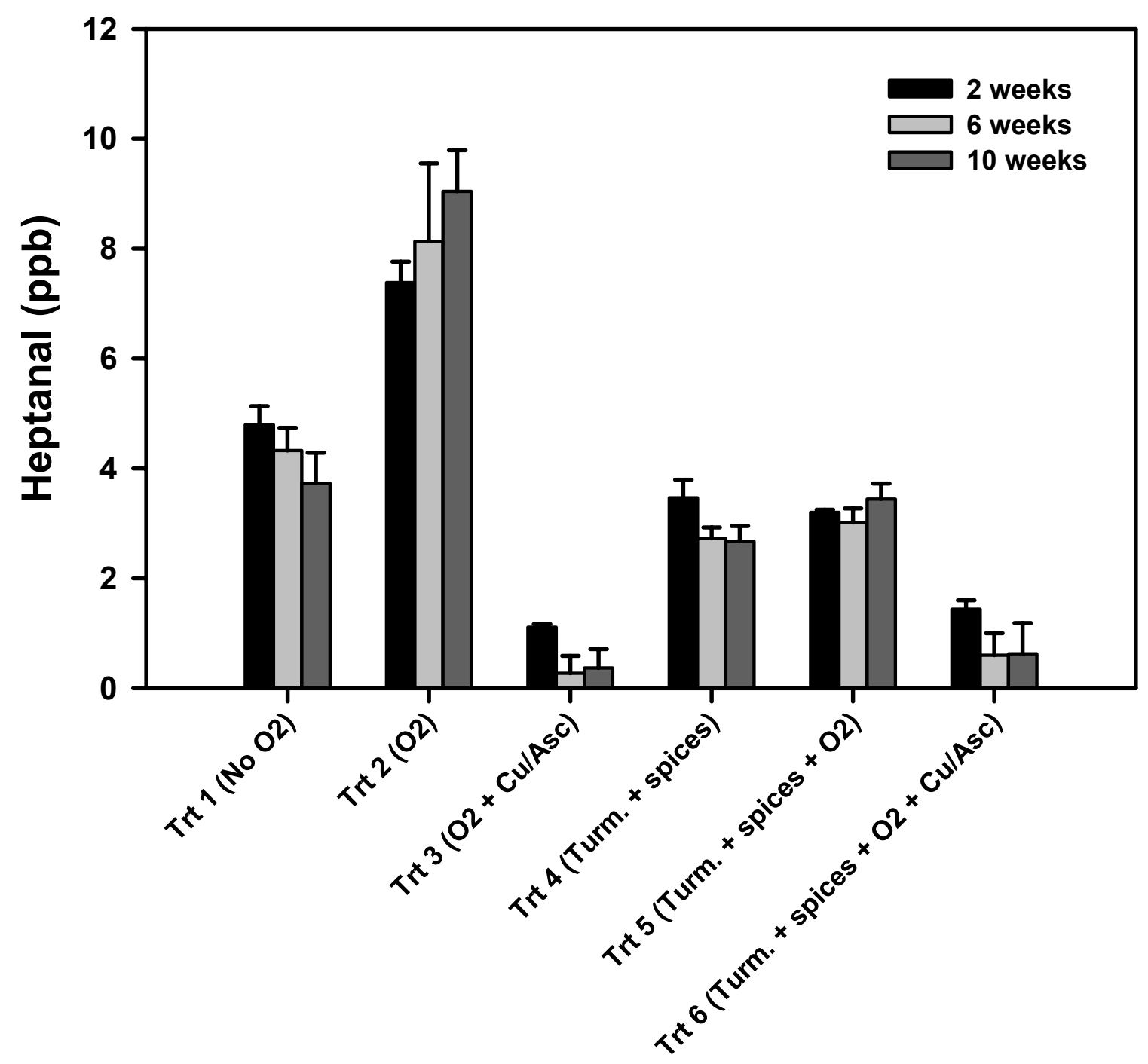

Figure B.4. Effect of added turmeric, dill spices, cupric gluconate and ascorbic acid on heptanal levels in fresh-pack dill pickles 2, 6, and 10 weeks after packing. The bars show the mean of three samples. Error bars show the standard deviation of heptanal concentration. 


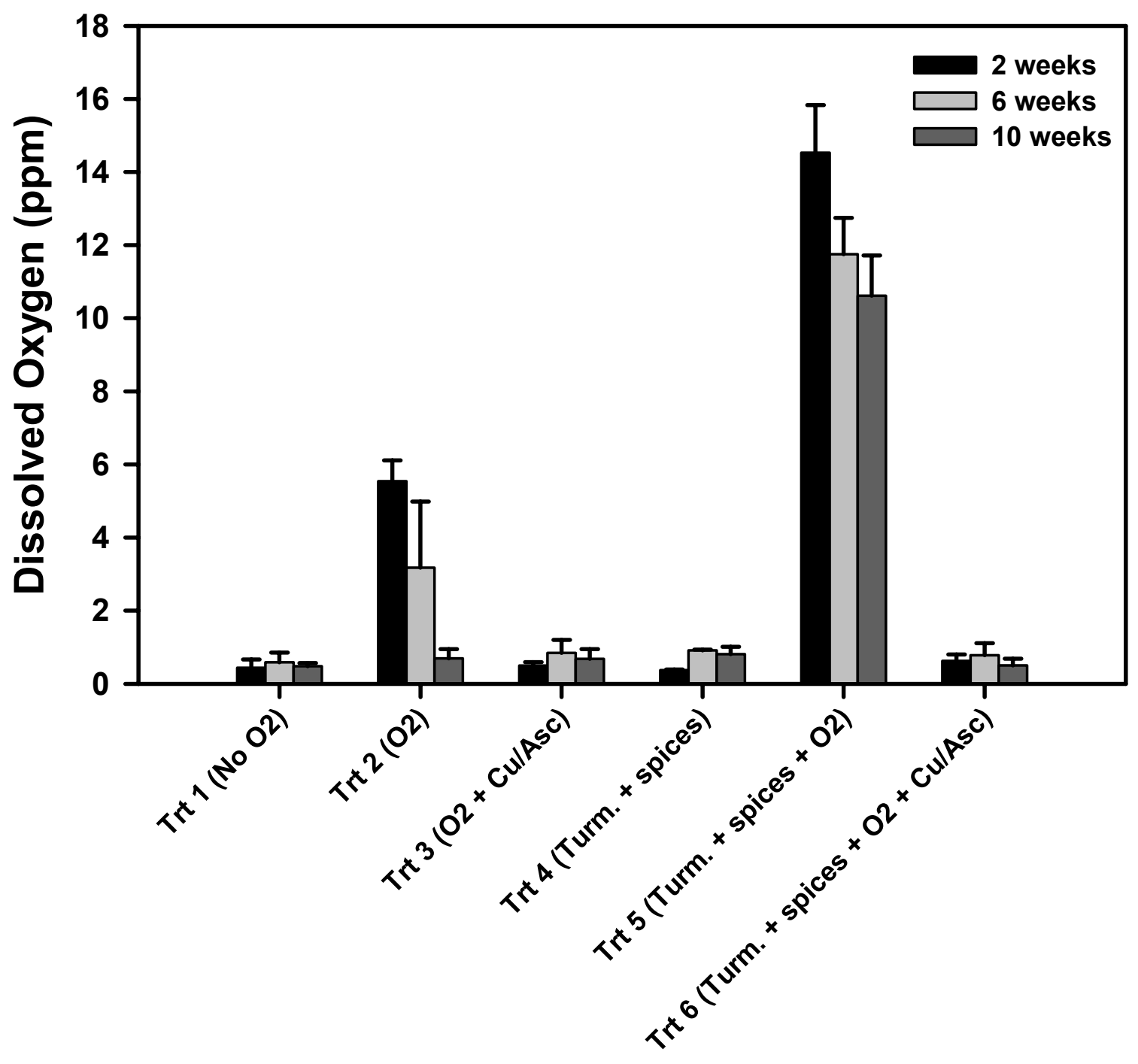

Figure B.5. Effect of added turmeric, dill spices, cupric gluconate and ascorbic acid on dissolved oxygen levels in fresh-pack dill pickles 2, 6, and 10 weeks after packing. The bars show the mean of three samples. Error bars show the standard deviation of dissolved oxygen concentration. 